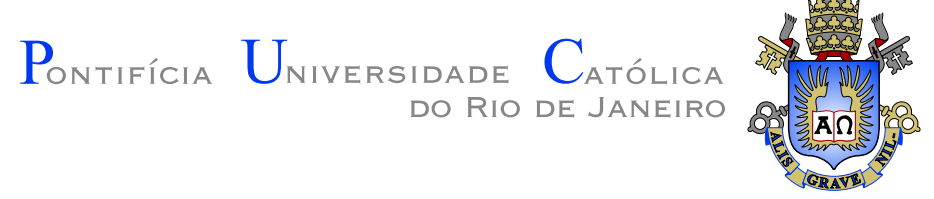

Augusto Cesar Espíndola Baffa

\title{
Storytelling based on audience social interaction
}

Thesis presented to the Programa de Pós-Graduação em Informática of the Departamento de Informática - PUC-Rio as partial fulfillment of the requirements for the degree of Doutor.

Advisor: Prof. Bruno Feijó 


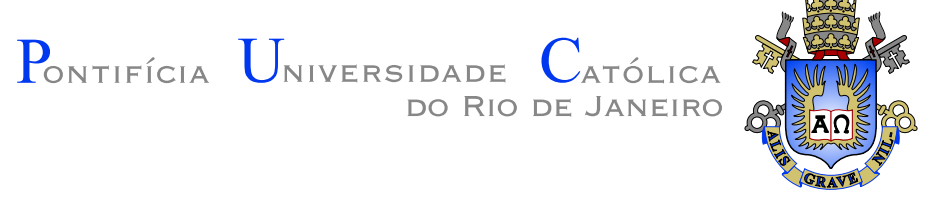

Augusto Cesar Espíndola Baffa

\section{Storytelling based on audience social interaction}

Thesis presented to the Programa de Pós-Graduação em Informática of the Departamento de Informática of Centro Técnico Científico - PUC-Rio as partial fulfillment of the requirements for the degree of Doutor. Approved by the examining committee undersigned:

Prof. Bruno Feijó

Advisor

Departamento de Informática - PUC-Rio

Prof. Simone Diniz Junqueira Barbosa

Departamento de Informática - PUC-Rio

Prof. Marcus Vinícius Soledade Poggi de Aragão Departamento de Informática - PUC-Rio

Prof. Angelo Ernani Maia Ciarlini

Departamento de Informática - Unirio

Prof. Cesar Tadeu Pozzer

Departamento de Computação Aplicada - UFSM

Prof. José Eugenio Leal

Coordinator of the Centro Técnico Científico - PUC-Rio

Rio de Janeiro, July 07th, 2015 
All rights reserved.

\section{Augusto Cesar Espíndola Baffa}

Augusto Baffa obtained a BSc in Computer Science from the Centro Universitário da Cidade (Rio de Janeiro, Brazil) and a MSc in Computer Science from Universidade Federal do Estado do Rio de Janeiro (Unirio, Rio de Janeiro, Brazil). Also obtained a MBA in Marketing from Escola Superior de Propaganda e Marketing (ESPM, Rio de Janeiro, Brazil) and a MBA in Finance from Instituto Brasileiro de Mercados de Capitais (IBMEC, Rio de Janeiro, Brazil). He worked as a web developer in Sevenlab Informatics (2000-2001), systems analyst (2001-2004) and E-Business Product Manager (20042007) at Banco BVA S/A, and Software Enginneer (20072009) in Sakonnet Technology Inc. After this period, he participated in individual initiatives of game development, mobile applications and web systems.

Bibliographic Data

Baffa, Augusto

Storytelling based on audience social interaction / Augusto Cesar Espíndola Baffa; Advisor: Bruno Feijó. 2015.

91 f: il. (color.) ; $30 \mathrm{~cm}$

Tese (Doutorado em Informática) - Pontifícia Universidade Católica do Rio de Janeiro, Departamento de Informática, 2015.

Inclui bibliografia

1. Informática - Teses. 2. Interação social. 3. Tomada de decisão em grupo. 4. Modelo de emoções. 5. Storytelling interativo passivo. 6. Modelo de audiência. 7. Teoria dos jogos. I. Feijó, Bruno. II. Pontifícia Universidade Católica do Rio de Janeiro. Departamento de Informática. III. Título. 


\section{Acknowledgments}

Firstly, I would like to express my sincere gratitude to my advisor Prof. Bruno Feijó for the continuous support, his patience and motivation during all these years of research.

I would especially like to thank those who were my unofficial advisers during this journey. I am grateful to Prof. Angelo Ciarlini for enlightening me the first glance of research and for many other good ideas and advices. I am also grateful to Prof. Marcus Poggi for sharing expertise, the sincere and valuable guidance, and encouragement extended to me.

I would like to thank Prof. Simone Barbosa, Prof. Cesar Pozzer, and Prof. Antonio Furtado, for their insightful comments that greatly improved the manuscript, but also for the hard question which incited me to widen my research from various perspectives.

I am grateful to my partner Aline Donato who supported me patiently through this venture and my parents for the unceasing encouragement, support and attention.

I would like to thank Rafael Martinelli who helped me during some reasonings and suggestions.

I would also like to thank CAPES and $\mathrm{CNPq}$ for the financial support during this research.

Last but not the least, I would like to thank my friends and colleagues from Department of Informatics(PUC-Rio), Galgos and ICAD/VisionLab and express my sense of gratitude to one and all, who directly or indirectly contributed to this work. 


\section{Abstract}

Baffa, Augusto; Feijó, Bruno. Storytelling based on audience social interaction. Rio de Janeiro, 2015. 91p. DSc Thesis Departamento de Informática, Pontifícia Universidade Católica do Rio de Janeiro.

To tell a story, the storyteller uses all his/her skills to entertain an audience. This task not only relies on the act of telling a story, but also on the ability to understand reactions of the audience during the telling of the story. It is not so difficult to adapt a story for a single individual based on his/her preferences and previous choices. However, the task of choosing what is best for a group becomes quite complicated. The selection by majority voting cannot be effective because it can discard alternatives that are secondary for some individuals, but that would work better for the group in question. Thus, the careless selection of events in a story could cause audience splitting, causing some people to give up keep watching because they were not pleased. This thesis proposes a new methodology to create tailored stories for an audience based on personality traits and preferences of each individual. As an audience may be composed of individuals with similar or mixed preferences, it is necessary to consider a middle ground solution based on the individual options. In addition, individuals may have some kind of relationship with others who influence their decisions. The proposed model addresses all steps in the quest to please the audience. It infers what the preferences are, computes the scenes reward for all individuals, estimates their choices independently and in group, and allows Interactive Storytelling systems to find the story that maximizes the expected audience reward. The proposed model can easily be extended to other areas that involve users interacting with digital environments.

\section{Keywords}

Social interaction; Group decision making; Model of emotions; Passive interactive storytelling; Audience modeling; Game theory. 


\section{Resumo}

Baffa, Augusto; Feijó, Bruno. Storytelling baseado na interação social da audiência. Rio de Janeiro, 2015. 91p. Tese de Doutorado - Departamento de Informática, Pontifícia Universidade Católica do Rio de Janeiro.

Ao contar uma história, o narrador usa toda sua habilidade para entreter a audiência. Esta tarefa não define apenas o ato de contar uma história, mas também a capacidade de compreender as reações do público durante a narração da história. Não é muito difícil adaptar uma história para um único indivíduo baseando-se em suas preferências e escolhas anteriores, porém, a tarefa de escolher o que é melhor para um grupo torna-se bastante complicada. A seleção por votação de uma maioria pode não ser eficiente pois descarta alternativas que foram consideradas secundárias por alguns indivíduos, mas que funcionariam melhor para o grupo em questão. Desta forma, a seleção descuidada dos eventos em uma história poderia causar a ruptura do grupo, fazendo com que algumas pessoas desistam de continuar assistindo pois não foram agradadas. Esta tese propõe uma metodologia para criar histórias adaptadas para a audiência com base em traços de personalidade e preferências de cada indivíduo. Como uma audiência pode ser composta de indivíduos com preferências semelhantes ou mistas, é necessário considerar uma solução de meio-termo com base nas opções individuais. Além disso, os indivíduos podem ter algum tipo de relação com os outros que influenciam suas decisões. O modelo proposto aborda todas as etapas da missão de agradar ao público. Deve inferir quais são as preferências, calcular a recompensa das cenas para todos os indivíduos, estimar as escolhas de forma independente e em grupo, e permitir sistemas de Storytelling Interativos encontrar a história que maximiza a recompensa esperada da audiência. O modelo proposto pode ser facilmente estendido a outras áreas que envolvem usuários interagindo com ambientes digitais.

\section{Palavras-chave}

Interação social; Tomada de decisão em grupo; Modelo de emoções; Storytelling interativo passivo; Modelo de audiência; Teoria dos jogos. 


\section{Contents}

I Introduction $\quad 11$

$\begin{array}{lll}\text { I.1 Storytelling } & 12\end{array}$

I.2 Audience 12

I.3 Motivation and Contributions 14

I.4 Thesis Structure 15

II $\quad$ Related Works $\quad 16$

III Interactive Storytelling $\quad 20$

III.1 Story Model 20

III.2 Emotional Notation and Space $\quad 21$

III.3 Writing a Story as a Tree of events 23

IV Game Theory $\quad 25$

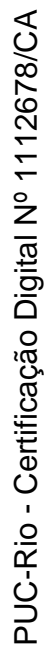

IV.1 Coordination games 25

Example of Coordination games 26

Road Side Game 26

Party x Home Game $\quad 26$

Battle of Sexes $\quad 27$

Stag Hunt Game $\quad 27$

IV.2 Social Contract 28

IV.3 Social Welfare 28

IV.4 Price of Anarchy and Price of Stability 29

IV.5 Cooperative Games 30

Definition $\quad 30$

Types of Valuation Functions $\quad 31$

Solution Concepts $\quad 32$

The Core 33

Non-empty Core $\quad 33$

The Nucleolus $\quad 33$

The Kernel $\quad 34$

The Shapley Value $\quad 35$

Voting Games $\quad 35$

IV.6 Individuals and Empathy 36

IV.7 Emotional Games $\quad 37$

Conscious Empathy $\quad 37$

Prisoners' Dilemma Example $\quad 39$

Chicken Game Example $\quad 40$

Another Examples 41

Unconscious Empathy $\quad 41$

IV.8 Conclusions 42 
V Social Interaction Models $\quad 44$

V.1 Concordance Model 44

V.2 Consensus Decision-making Model 45

Individual Definition $\quad 46$

Openness to Experience $\quad 46$

Conscientiousness (Scrupulosity) 47

Extraversion 47

Agreeableness $\quad 47$

Neuroticism (Emotional Instability) 47

Empathy between Individuals 48

Algorithm Definition $\quad 48$

V.3 Solving the Consensus Decision-making Model 51

Neighborhood Definition $\quad 54$

Simulated Annealing Algorithm $\quad 54$

V.4 Example Applications $\quad 57$

The Office Game $\quad 57$

Bargain Model $\quad 58$

Definition $\quad 58$

Examples $\quad 58$

VI Passive Interactive Storytelling $\quad 60$

VI.1 Audience $\quad 61$

Uncovering Audience Preferences $\quad 62$

VI.2 Problem Definition $\quad 66$

VI.3 Dealing with a Fixed Audience $\quad 67$

VI.4 Dealing with a Dynamic Audience 68

VI.5 Results $\quad 70$

$\begin{array}{ll}\text { Little Red Cap Story } & 70\end{array}$

$\begin{array}{ll}\text { The Princess and the Dragon } & 73\end{array}$

$\begin{array}{lr}\text { VII Closure } & 81\end{array}$

VII.1 Final Considerations $\quad 81$

VII.2 Future Works

$\begin{array}{ll}\text { Bibliography } & 84\end{array}$ 


\section{List of Figures}

III.1 Story as a Decision Tree 21

III.2 Plutchik's wheel of emotions 22

III.3 Simplified 4-axis structure 23

III.4 Example of 8-axis structure to represent genres 23

III.5 Point $s$ represented by its position vector $x_{s} \quad 24$

V.1 Spring-mass example with 2 individuals 49

V.2 Spring-mass example with 4 individuals 50

V.3 Relation between cost and distance given different empathy and openness values - Quadratic x Gaussian formulations: $\mathrm{e}=0.1$ and $\mathrm{o}=0.1$

V.4 Relation between cost and distance given different empathy and openness values - Quadratic x Gaussian formulations: $\mathrm{e}=0.9$ and $\mathrm{o}=0.9$

V.5 Relation between cost and distance given different empathy and openness values - Quadratic x Gaussian formulations: $\mathrm{e}=0.9$ and $\mathrm{o}=0.1$

V.6 Relation between cost and distance given different empathy and openness values - Quadratic x Gaussian formulations: $\mathrm{e}=0.1$ and $\mathrm{o}=0.9$

V.7 Example of the original preferences of an Audience

V.8 Example of an Audience after Social Interaction 56

VI.1 Big-Five Inventory Facebook Application 63

VI.2 Personality Traits collected from Facebook 63

VI.3 Some Movies and TV Shows watched via Netflix - information available from Facebook Profile

VI.4 Some Favorite Bands - information from Facebook Profile 65

VI.5 Example of Friend Matrix Application 66

VI.6 Tree of events of a story currently exhibiting event EV6. Events in bold highlight the sequence of a story to be told. The left image represents the original sequence and the right image the new sequence after an audience change.

VI.7 Little Red-Cap story as a graph of events 72

VI.8 The Princess and Dragon Story as a graph of events $\quad 75$ 


\section{List of Tables}

IV.1 Two Player Coordination Game Example 26

IV.2 Choosing sides game 26

IV.3 Party x Home Game 27

IV.4 Battle of Sexes game 27

$\begin{array}{ll}\text { IV.5 Stag hunt game } & 28\end{array}$

IV.6 Prisoners' Dilemma game 40

IV.7 Prisoners' Dilemma $\beta=0.5, \gamma=0.6 \quad 40$

IV.8 Prisoners' Dilemma $\beta=0.5, \gamma=1 \quad 40$

IV.9 Chicken Game $\quad 40$

IV.10Chicken Game $\beta=0.5, \gamma=0.85$

IV.11Stag Hunt Game $\beta=0.5, \gamma=0.8 \quad 41$

IV.12Battle of Sexes $\beta=0.5, \gamma=0.75$

IV.13Chicken Game $\beta=0.3, \gamma=0.85, b=1.00$

IV.14Battle of Sexes $\beta=0.5, \gamma=0.75, b=1.00$

VI.1 Little Red-Cap story events $\quad 71$

VI.2 Dramatic Curves for Little Red-Cap events 72

VI.3 The Princess and the Dragon story events 74

VI.4 Dramatic Curves for The Princess and the Dragon events $\quad 75$

VI.5 Little Red Cap selected stories using 8 entirely mixed audiences instances with $60 \%$ of individuals supporting a specific emotion

VI.6 Little Red Cap selected stories using 4 mixed audiences with one opinion leader

VI.8 The Princess and the Dragon selected stories using 8 entirely mixed audiences instances with $60 \%$ of individuals supporting a specific emotion

VI.9 The Princess and the Dragon selected stories using 4 mixed audiences with one opinion leader

VI.10The Princess and the Dragon selected stories using 4 random audiences 


\section{Introduction}

This thesis is about situations involving interactive storytelling and game theory - two large research areas that have a multitude of applications, from entertainment to corporate questions. The first area concerns the composition and dramatization of plots with user intervention, what creates new forms of entertainment and educational games. Defensive military operations can also be modeled as interactive storytelling plans. Generally speaking, plot analysis can be used in any situation where narratives or audit logs have a high degree of regularity and a limited set of logical operations, such as business information systems and banking [1] [2]. The second research area above mentioned is concerned with optimal decision making that takes into account not only the benefits of lower costs, but also the interaction between participants. When the present thesis investigates audience interaction, the realm of game theory moves towards a more complex situation: N-person game theory. The reader is referred to [3] for a full account of N-players systems. The challenge is even bigger when the investigation takes emotions and personality into account. This latter challenge is a new area, known as behavioral game theory, which aims to predict how people make optimal choices under conditions of strategic interactions by incorporating psychological, emotional, and cognitive elements into game theory [4] [5].

The main application scenario of this thesis is a story being broadcast to an audience of people who can influence each other (via social nets). In this case, the challenge is to determine the scenes (events) that maximize the audience's preferences taking into account the usual emotional state of the persons and their personality traits. The audience can be static (no one gets in or leaves until the end of the story/game) or dynamic. The present thesis focuses on static audiences (also called fixed audiences), but it sheds light on the dynamic case for future work.

This chapter introduces the basic aspects of interactive storytelling and the main questions about audience. It also presents a summary of the main contributions and the structure of the thesis. 


\section{I.1 Storytelling}

Over the years, stories were told to entertain and teach lessons to many audiences. These stories were responsible for transmitting cultural, moral and ethical teachings through oral tradition since ancient times. Storytellers and theater companies presented variations of stories to keep the audience's attention by observing the individual reactions. Those adaptations were important to make interesting stories for different public and captivate more people. Also, the stories could undergo minor changes using the suggestions from the audiences and thus enriching the story.

After the advent of cinema and television, this feature could not be used anymore because the stories are written and well preserved. As a regular story book, the stories are frozen and cannot be changed. The audience cannot interfere in the continuity of the story and always watches the same sequence of events. In late 1970, was created a new category of entertainment books called Gamebooks. A Gamebook is a work of fiction that allows the reader (or player) to participate in the story by making effective choices. This context gives rise to interactive storytelling as an alternative digital entertainment.

Interactive storytelling systems are used to tell a story that can be created or modified by the direct influence of the audience. The story is created based on a story model written by the author, who provides all the context that must be followed. The system must preserve the logical integrity of the story context and adapt the story events following suggestions made by the audience as defined in [6]. The story can be fully planned before it is exhibited or adapted during exhibition. To make this possible, the storytelling system provides a list of options from actions that must occur to suggestions that may influence the sequences. In the case of stories that are adapted during exhibition, these options are displayed from time to time so that the continuity planning of the story occurs without interruption as shown in [7].

\section{I.2 Audience}

In general, the current applications of interactive storytelling present some approaches to generate a story for a single individual based on his suggestions. The applications are single user only and do not consider an entire audience. Camanho [8] proposed a video stream-based interactive storytelling architecture that presents a solution to capture the choices of an entire audience by using multiple voting strategies. This approach allows an audience to watch the same story and participate in the event selection, but it is not truly engaged with the story. Majority voting implies that a minority is never pleased and 
may give up watching the story. Also, if the audience is very diverse, majority voting is not representative and may not please anyone.

Another problem with interactive storytelling systems is that most of them rely on explicit user interventions, that is, the user should make an explicit action via an interface mechanism (e.g. choosing an action, moving an object, giving a voice command, ...). However, the audience's needs and desires are something that the storyteller senses naturally and continuously. If an interactive storytelling system cannot sense the audience in this subtle way, the application is not able to generate an adequate story for the current audience. Gilroy et al. [9] proposed to name this type of natural and continuous interaction as "passive interaction" in opposition to the delimited intervention called "active interaction" by them. Interactive storytelling systems should have both types of interaction. If there is a story variation that may further please the audience and it is not selected by the users, then it may never occur because the planner may choose another sequence of events.

Motivated by these questions, the present research aims to investigate ways to please the greatest number of individuals in an audience of interactive storytelling applications. We propose that the author should classify each story scene by defining a point in a $2 \mathrm{D}$ space of genres. In this way, we can define a distance between the preferences of a person and the genre of the scene. For instance, if the scene is classified as "dramatic comedy", then a person who likes romantic scenes will be far from the point that represents the emotional content of the scene. We claim that this 2D space should be based on the Plutchik's model [10, 11]. This emotional information is used to select scenes that please the audience most.

Another aspect of the audience that is investigated is the psychological factor in the group decision process. Since each individual in the audience could be identified through an account used to access the storytelling application, it would be possible to store all user information and use it during the event selection. In this case, the interactive storytelling application could adapt the story automatically without the need for explicit audience interactions, because the system can act based on prior knowledge of the individuals that compose the audience. The generated story based on the spectator profile could get better audience results with fewer interferences, and also help the planning of plots if the spectator stays passive. Thus, the storytelling remains interactive, but also passive. This suggests a new kind of storytelling application: Passive Interactive Storytelling. The term "passive interaction" has been proposed in [9] to define the use of biometric monitoring sensors in order to extract the reactions of an individual and redefine the story plots. However, in this thesis, 
we propose a more general concept.

In addition to individual preferences, it is necessary to analyze individual behavior during the selection process. The same individual could choose different options when alone or influenced by friends. This aspect makes the adaptation problem more complex because it is necessary to consider the psychological profile and the relationships between individuals in an audience in order to identify the perceptions of each one.

For example, in some cases a second option ranked by majority voting may be enough to please the greatest number of people in audience while the first ranked option could take the story to an end that upsets most of the individuals. Sometimes divergent individuals could agree to a second option and this decision would please more people in the audience. Always pleasing the majority may cause minority individuals to abandon the story because they would not be watching what they would like. Also, it should be noted that it is possible to find a new majority group for each new event story, which would lead to the fact that the adjustments would not be pleasing anyone.

This analysis leads to the study of game theory problems. In order to adapt the story to please the greatest number of individuals it is necessary to resolve conflicts and find an equilibrium in the audience options. If each individual in the audience interferes with the story and, consequently, with the results of the other individuals, we shall have a situation that can be modeled as a cooperative game. In a cooperative game, all individuals must work together to get the best individual and welfare results as described in $[12]$.

Finally, the identification of each individual in the audience, the knowledge of the individual preferences, the psychological profile used to describe the user behavior, and a game theory model to describe the social behavior are combined to propose a new social interaction model. This new model would identify the middle ground best preference of a group of individuals and then select the plots in a story.

\section{I.3 Motivation and Contributions}

The Passive Interactive Storytelling problem aims to generate the best story given an audience without direct interaction. The story is generated based on the story context written by the author and must maximize the audience by choosing the best options for each individual and for the entire group. As it is necessary to understand how the influence of the group acts in the individual choices, the proposed methodology uses the "Social Interaction Model"' to define the preferred options for the audience. 
This research proposes a model to determine the social influences in the variation of an issue perceived by an individual. The model is called "Social Interaction Model" and aims to describe the group decision process when all individuals reach an agreement or define their final positions. These final positions can be used to define new coalitions, the rupture of the social contract and the terms of compromise in a negotiation.

The "Social Interaction Model" is used in the Interactive Storytelling context to select the best plots of a story given an audience, trying to improve the acceptance of the story and reduce dropouts. It addresses all steps in the quest to please the audience and infers what the preferences are, computes the scenes reward for all individuals, estimates their choices independently and in group, and allows Interactive Storytelling systems to find the story that maximizes the expected audience reward.

The selection of the options available in each story event without the need for immediate action by the audience allows the creation of a new kind of interactive storytelling called Passive Interactive Storytelling.

\section{I.4 Thesis Structure}

This thesis is organized as follows. Chapter II is dedicated to present some related works studied during this research. Chapter III presents the main aspects of interactive storytelling, a simple way to write a story context and emotion modeling of a story event. Chapter IV discusses the related game theory models that influenced the proposed models. Chapter V is dedicated to present the social interaction model. Chapter VI describes how a Passive Interactive Storytelling is solved and present some results. The final analysis, conclusions and future works are presented in the last chapter. 


\section{II \\ Related Works}

During this research, many storytelling papers were consulted to define the state of art of the interactive storytelling applications. The Interactive Storytelling definitions are strongly influenced by the Logtell 3 application researched by Abelha, Gottin et al.[13]. Also the papers presented by [6, 14]. Another major influence is Barbosa, Furtado and Casanova [15], which presents the idea of "Drives" to define stimuli that the characters have to act in the stories. This concept allows modeling the motivations and rules to dynamically define the attitudes of the characters in stories generated by interactive storytelling applications.

In [16], Garber-Barron describes a procedure that allows the recognition of comments in a chat or social network and uses these reviews to select future events and adapt interactive storytelling stories.

In order to understand the emotional notation, some psychological papers were consulted and used to define the aspects initially proposed by Plutchik. He proposed the wheel of emotions model in his works [17, 10, 11], based on psychoevolutionary theories and the idea of complex emotions through a combination of basic emotions. The combination enables the emotions to describe a wider variety of emotional aspects. These ideas are used in several studies in Computer Science to set numerical ranges to represent the relationship between emotions and their intensities.

The descriptions of emotions were adopted through the 4-axis model proposed by Rodrigues [18] and the proposed model was influenced by dramatic curves proposed by Araujo et al. [6]. This latter work also proposes the Little Red Cap story modeling, used during the experiments.

The definition of "empathy" and its relation to stories are proposed by Davis in his research to identify the dimensions that differentiate empathy between individuals [19]. In this work, the author describes his search for a multidimensional model that assists in the classification of differences between the empathy of individuals on literature, music, films and plays. He also proposes that empathy reflects the assessment of the story and produces the identification from viewers/readers with characters of the plot. 
The personality model adopted is based on the Big-Five inventory described by John and Srivastava in [20]. Their work describes the five personality traits and also features a big-five inventory that is used to describe the personalities of real individuals. The John and Srivastava's inventory was used to create individual instances during the experiments. In [21], Kallias debates on the relationship between personality traits and preferences for film genres, arguing that there is a correlation between the personalities and genre biases.

The personality aspects obtained by the big-five inventory can be classified through MBTI and Keirsey temperaments. McCrae and P. Costa present in [22] a way to convert the 5 personality traits and classify them into one of 16 personality types of the Myers-Briggs indicator described in [23, 24, 25]. Personality types are used to trace the personality profile of an individual and tend to group similar individuals in the audience. There is also a user sorting procedure through stereotypes and behaviors proposed by Rich in [26].

In [27], Jones et al. argue that there may be differences in the evaluation of a particular object or action by different individuals. This divergence can be classified as the difference between the expected value and the perceived value by individuals. The relationship between personality traits and emotional factors are described by Tupes et al. in [28].

In another direction, some papers related to recognition and simulation of emotions were consulted. The dynamic models of emotions are presented by $[29,30,31]$. These works propose a dynamic model of emotions based on Plutchik's model and Big-five personality traits to simulate the progression of emotions of an individual or virtual agent after stimuli. In [32], the author presents another dynamic model of emotions to define facial expressions of virtual conversational agents. This technique is used to humanize the agents, producing higher quality communication. Also in [33] similar techniques are used in artificial generation of emotions based on personality, mood and emotions in order to simulate facial expressions in robots.

In $[34,35]$, the state-of-the-art of emotions and personalities simulations are described. The authors propose an approach for the development of virtual agents with emotional memory for objects, people, and certain issues.

The recognition and classification of emotions is covered by [36]. In his work, emotions are analyzed using the text of stories and fairy tales. The author presents an approach to classify the stories in literary genres.

In [37], the author presents a review of the literature regarding the emotional classification based on facial recognition, voice, eyes, gestures, brain waves, heart beats, muscle contractions and other information and achieved 
by sensors. Techniques for the recognition of emotions in continuous time by monitoring individuals are presented by [38].

Finally, Orellana-Rodriguez et al. [39] try to sort the emotions from short YouTube movies by analyzing users' comments.

Some papers related to user recommender systems were studied to verify the possibility of selection or recommendation of plots to the storytelling application users. The paper [40] proposes a model that uses an infrared camera to monitor the reactions of the audience and make inferences through facial recognition. His goal is to predict the rating of films by audience reactions such as smiles, conversation between viewers, mobile usage, eating/drinking, falling asleep and leaving the room.

In [41] presents a Bayesian inference model for recommendations based on information posted on social networks. The idea is try to sort out the psychological profile of individuals and groups based up on reviews ranked in a range of $[1,5]$.

The modeling of behavioral and mutual trust games using the definition of emotions through empathy and actions of the players is proposed by Tortosa et al. [42] and Camerer et al.[43]. Fairchild [44] presents an extensive analysis of the main classic $2 \times 2$ zero-sum games and proposes a new model of equilibrium based on social welfare through the use of empathy between players.

Cooperative games are studied from the Curiel's book [12] Cooperative Game Theory and Applications. Salzman et al. [45] propose a model to simulate rational and emotional investors based on an uncertainty model that seeks survival in the stock market. The proposed model aims to price the market through an index of humor and emotions rather than generating information based purely on historic prices.

The game theory elements of the model proposed by this thesis are aligned with n-person game theory as proposed by researchers on agent systems [3]. The use of personality traits in game theory can be found in works on behavioral game theory [43] [5] [4]. However, as far as we are aware there is no work in the literature combining interactive storytelling with behavioral games, and n-person games.

Emotional contagion models are used in human-machine interfaces to study psychological aspects. These models attempt to simulate or influence emotions through virtual agents. In [46], Tsai et al. propose a model for the spread and contagion of emotions. The proposed model is used by virtual agent simulators to imitate the public dissemination in a crowded environment. In [47], Tsai et al. propose an emotions mirroring model for psychology applications using virtual agents. The objective was to study the spread 
of emotions between two people through the mirroring gestures and body language.

The mechanisms and the influence on the dissemination of information on social networks are studied in [48]. This paper describes how relationship, proximity and common friendships can determine the spread of opinions and the influence of certain individuals in your social network, making them opinion leaders.

In [49], Tsai et al. explore the models of contagion between virtual agents and human users to determine whether the agent can spread emotions. They also use the Stag Hunt game to determine the conditions under which an agent influences the strategy of the users.

In an attempt to define audience profiles, Kamakura et al. [50] aim to discover the preferences of individuals through analysis of the purchased show tickets. During his analysis, he seeks to identify the preferences of the individual and rank preferences for a specific audience.

The influence of human relationships on individual and collective decisions was studied in the works of Jean-Jacques Rousseau, David Hume and Adam Smith. In Social Contract [51], Rousseau proposed that all groups and relationships have an invisible non-written agreement to organize and determine what is expected from this relationship. If a party acts in an unexpected way or a misconduct, it may be breaking the social contract and so the relationship. David Hume wrote about human aspects in A Treatise of Human Nature [52] and defined that sympathy is created by moral sentiments (emotions) in response to moral acts. His work influenced Adam Smith in his book Theory of Moral Sentiments [53]. Smith defined sympathy as the effect that is produced when we imagine that another person's circumstances are our own circumstances, and find their reaction to the circumstances to be reasonable. This concept is used to determine the relationship level and the interest in the welfare of others.

Finally, mass-spring models were studied in order to describe relationships between individuals. In this thesis, we propose the social interactive models based on mass-spring models. The mass-spring models were studied from the book [54] by Nagleet al. 


\section{III \\ Interactive Storytelling}

In recent years, there have been some efforts to build storytelling systems in which authors and audience engage in a collaborative experience of creating the story. Furthermore, the convergence between video games and filmmaking can give freedom to the player's experience and generate tailored stories to a spectator [55].

Interactive Storytelling systems are applications which simulate a digital storyteller. It transforms the narrative from a linear to a dialectical form, creating new stories based on an audience by interactions or suggestions for new events to the story [14].

In order for a storytelling system to be able to generate different stories, the author must write a "story model" that supports different plots. A simple way to create a story model is used by gamebooks. A gamebook is a fictional book that allows the reader to participate in the story by making decisions after some events. The narrative creates some branches after events by offering options that lead to numbered paragraphs or pages [56]. This structure allows to tell different stories and perspectives according to various paths created by the author. Following these ideas, a storytelling system story can be written as an events tree to allow different versions of the same story.

\section{III.1 Story Model}

A story is a single sequence of connected events which represents a narrative, also known as a plot. The narrative context may be organized as a decision tree to define different possibilities of sequences and endings. During the story writing, the author can define different perspectives and endings to each event (or scene). Each ending option forwards to a new event and then to new ending options, until the story ends [16].

For example, Figure III.1 demonstrates a story of three events modeled as a decision tree. Each event has two ending options: A and B. If the storyteller chooses option A twice, the story ends on End1 by the sequence Event1, Event2 
and Event4. In this example, there are 4 different endings. This means that there are 4 different ways to tell the story.

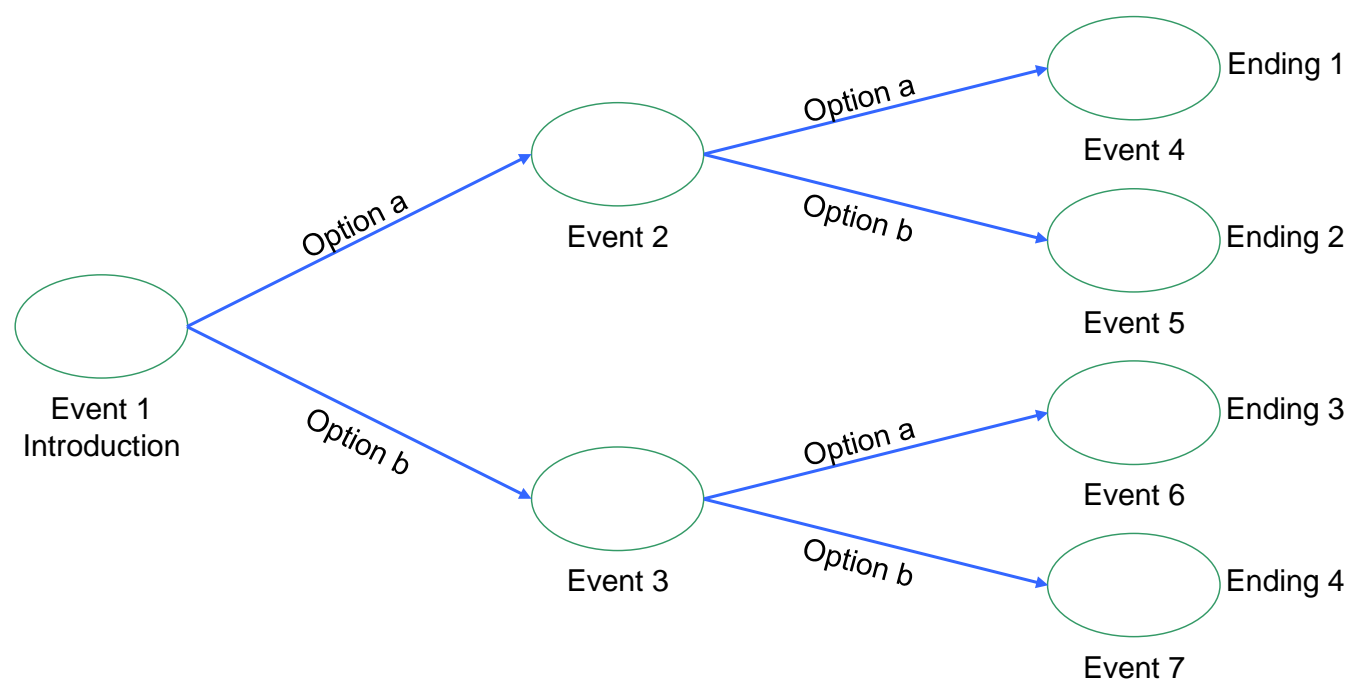

Figure III.1: Story as a Decision Tree

The story event is formalized in section III.3 and must describe what occurs to the characters, to the story, and the emotional information of the scene. The emotional information is called "dramatic curve" and describes how emotions should manifest during the scene. During story writing, an author can define dramatic curves to describe emotions of each event. These dramatic curves define how the event should be played, its screenshot, lighting and soundtrack. After the current event, each new one has a new dramatic curve which adds to the context of the story [6]. The complete sequence of events defines the story narrative, describes a complete emotional curve and "tags" the story with a "genre" classification.

\section{III.2 Emotional Notation and Space}

The emotional notation we adopted is based on the model of "basic emotions" proposed by Robert Plutchik $[10,11]$. It is influenced by the Psychoevolutionary theory and assumes that emotions are biologically primitive, evolved in order to improve animal reproductive capacity. Each of the basic emotions demonstrates a high survival behavior, such as the fear that inspires a fight-or-flight reaction. In Plutchik's approach, the basic emotions are represented by a three-dimensional circumplex model where emotional words are plotted based on similarity (Figure III.2)[17]. Plutchik's model is often used in computer science in different versions, for tasks such as affective humancomputer interaction or sentiment analysis. It is one of the most influential approaches for classifying emotional responses in general [57]. 


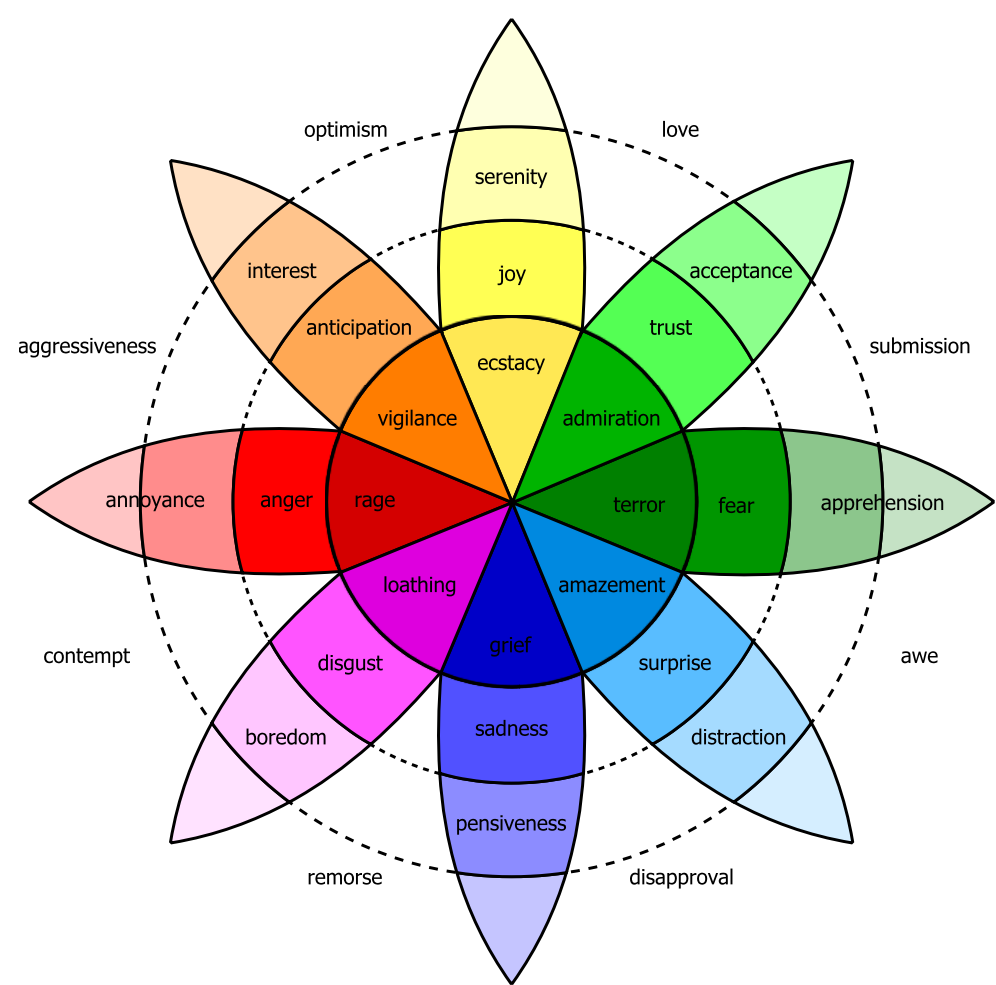

Figure III.2: Plutchik's wheel of emotions

Each sector of the circle represents an intensity level for each basic emotion: the outermost intensity is low, the second is normal and the third intensity is high. At each level, there are specific names according to the intensity of the emotion, for example: serenity at low intensity is similar to joy and ecstasy in a higher intensity of the instance.

Plutchik defines that basic emotions can be combined in pairs to produce complex emotions. These combinations are classified in four groups: Primary Dyads (experienced often), Secondary Dyads (sometimes perceived), Tertiary Dyads (rare) and opposite Dyads (cannot be combined).

Primary Dyads are obtained by combining adjacent emotions, e.g., Joy + Trust $=$ Love. The Secondary Dyads are obtained by combining emotions that are two axes apart, for example, Joy + Fear $=$ Excitement. The Tertiary Dyads are obtained by combining emotions that are three axes apart, for example, Joy + Surprise $=$ Doom. The opposite Dyads are on the same axis but on opposite sides, for example, Joy and Sorrow cannot be combined, or cannot occur simultaneously [17].

The model of "basic emotions" assumes that there are four positive emotions and their counterparts, totaling eight emotions: Anger $\leftrightarrow$ Fear, Joy $\leftrightarrow$ Sadness, Anticipation $\leftrightarrow$ Surprise and Trust $\leftrightarrow$ Disgust. Therefore, it is possible to adapt the Plutchik's model within a structure of 4-axis of emotions [18] as shown in Figure III.3.

The Plutchik's model describes a punctual emotion and represents a 


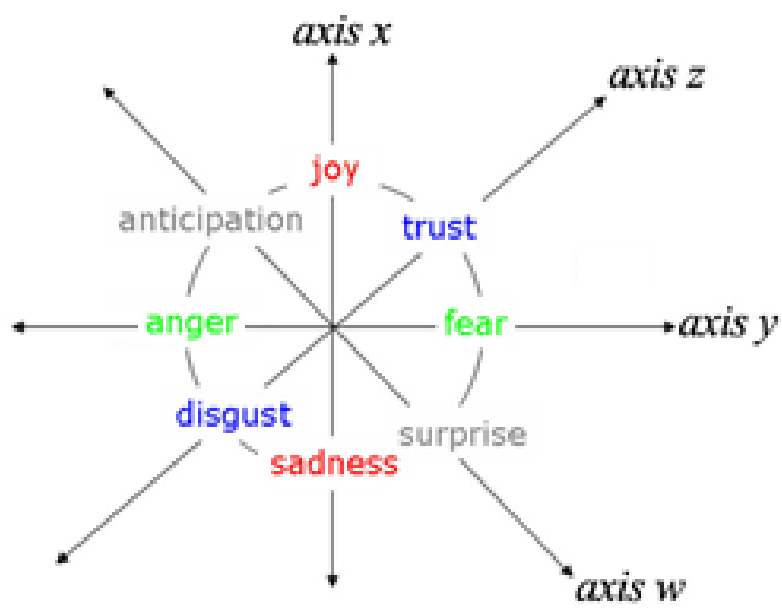

Figure III.3: Simplified 4-axis structure

specific moment in an event. The 4 -axis structure is the base for a $2 \mathrm{D}$ space of genres proposed in this thesis and called emotional preference space. Firstly we define 8 axes to represent genres, which have a correspondence with the 4-axis structure and do not consider negative values (Figure III.4). Each scene has a genre that represents the emotional state of the scene. This genre is the barycentric coordinates of the polygon defined by the main elements of the scene. For example, point a represents a funny terror scene (terror-comedy genre). The set of all possible points defines the emotional preference space (Figure III.5, where a point $s$ is represented by its position vector $x_{s}$ ).

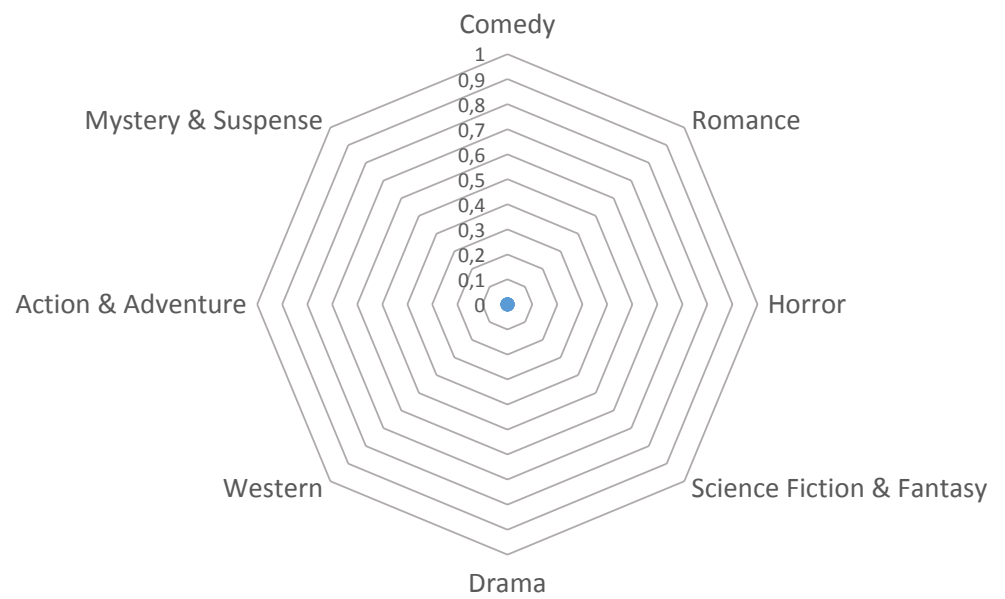

Figure III.4: Example of 8-axis structure to represent genres

\section{III.3 Writing a Story as a Tree of events}

During story writing, the events are described as a tree of events. Each event in the tree must be written using the following structure:

- Event Name: unique name for the event (each event has a unique name); 


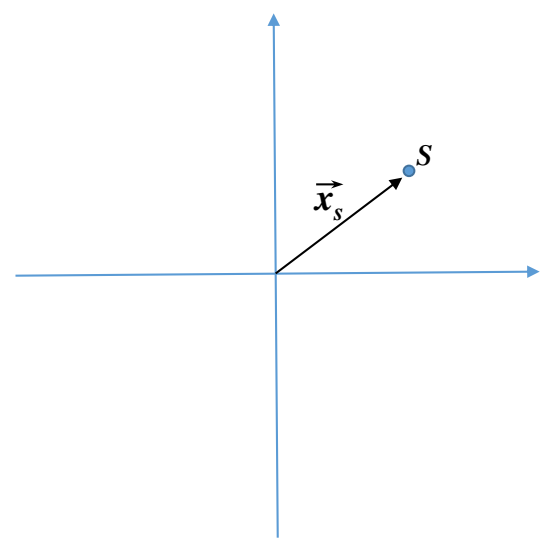

Figure III.5: Point $s$ represented by its position vector $x_{s}$

- Text: describes what happens during the event;

- Dramatic Curves: emotional time series presented in figure III.3:

- Joy/Sadness - axis x.

- Fear/Anger - axis y.

- Surprise/Anticipation - axis w.

- Trust/Disgust - axis z.

The tree of events has different paths, connecting to different future events, until the end of the story. Each branch maps a transition between events. The branches represent actions or suggestions that lead to a new event and must be written using the following structure:

- Action Name: unique name for the action (each action has a unique name);

- Text: describes the action and what happens to lead to the new event;

- Parent Event: Name of the finished event;

- New Event: Name of the new event that action should lead to.

While an event is played, the audience may select the next action that leads to a new event. If no option is chosen or the audience is unable to interact, the actions are selected by the passive interaction model. After the entire story is told, a single branch to each event would have been selected .

The next chapter is responsible for presenting all game theory fundamentals that influenced the "social interaction model" and were used to adapt the stories to a specific audience. 


\section{IV \\ Game Theory}

Game Theory is a branch of mathematics that studies strategic decision making. The problems are modeled in order to analyze strategies for dealing with cooperation or conflicts between rational individuals formally called "players". The strategies are classified as "Pareto Efficient" and "Nash Equilibrium" by its dominance [58].

A strategy is dominated by another if the player can increase his payoff by choosing the other one. If a strategy is Pareto dominated, there is some other one that makes at least one player increase his payoff without deteriorating payoffs from any other player. This means that some other payoff is weakly preferred by all players and strictly preferred by at least one player. If a payoff is not Pareto dominated by any other, than it is Pareto optimal [59].

The Pareto Efficient (or Pareto Optimal) is a measure of efficiency and occurs when there is no other payoff that makes every player at least as well off and at least one player strictly better off. This means that a Pareto-optimal strategy cannot be improved upon without deteriorating the payoff of at least one player [58].

A Nash equilibrium is a set of strategies, one for each player, such that no player has incentive to unilaterally change his/her action. Players are in equilibrium if a change in strategies by any one of them would lead that player to earn less than if she remained with her current strategy. Generally, a Nash Equilibrium is not Pareto efficient, implying that the players' payoffs can all be increased [58].

\section{IV.1 Coordination games}

In game theory, coordination games are a class of games in which players must select the same strategy or similar strategies so that they can maximize their payoffs. These games are also known as pure coordination games or pareto coordination games [60].

The main idea behind this type of game is that players realize gains only if they share their decisions in a coordinated manner. There are many classic 
examples of coordinated sets, for example, consider a two-player game and two-strategies represented by the following matrix on table IV.1:

\begin{tabular}{r|l|l|}
\multicolumn{1}{c}{} & \multicolumn{1}{c}{ Left } & \multicolumn{1}{c}{ Right } \\
Left & A, a & C, c \\
\cline { 2 - 3 } Right & B, b & D, d \\
\cline { 2 - 3 } & &
\end{tabular}

Table IV.1: Two Player Coordination Game Example

The rows represent strategies for the player one and the columns are strategies for the player two. The payoffs should follow the inequalities $A>B$ and $D>C$ for player 1 and, $a>c$ and $d>b$ for player 2. This payoff distribution induces the players to cooperate with each other by choosing the strategy profiles (Left, Left) and (Right, Right). Both strategies are pure Nash equilibrium because $A \succ B$ (A strictly dominates B), $D \succ C, a \succ c$ and $d \succ b$.

\section{(a) Example of Coordination games}

\section{Road Side Game}

In this game, the objective is to avoid the collision of two cars that are in opposite directions. Two drivers are driving on a narrow road and in poor condition. Both must swerve to avoid head-on collision and need to perform the same maneuver to pass (deviate to the left or right) [61]. Since they are in opposite directions, the cars collide selecting different maneuvers. The payoff matrix is presented on table IV.2. A successful passing is represented by a payoff of 10 , and a collision by a payoff of 0 .

\begin{tabular}{r|c|c|}
\multicolumn{1}{c}{} & \multicolumn{1}{c}{ Left } & \multicolumn{1}{c}{ Right } \\
\cline { 2 - 3 } Left & 10,10 & 0,0 \\
\cline { 2 - 3 } Right & 0,0 & 10,10 \\
\cline { 2 - 3 } & &
\end{tabular}

Table IV.2: Choosing sides game

In this case there are two pure Nash equilibria because both players may deviate to the left or to the right. Both cases are Pareto-efficient strategies.

\section{Party x Home Game}

Another coordination game is the "Party x Home" game. In this game, there are two players who want to enjoy each other and must pick one in two possible options: stay at home and watch TV or go to a party. They must decide for the same option or will split and have no fun [61]. Also, going to the party may be more fun than staying at home. The payoff matrix is presented on table IV.3. 


\begin{tabular}{c|c|c|}
\multicolumn{1}{c}{} & \multicolumn{1}{c}{ Party } & \multicolumn{1}{c}{ Home } \\
\cline { 2 - 3 } Party & 10,10 & 0,0 \\
\cline { 2 - 3 } Home & 0,0 & 5,5 \\
\cline { 2 - 3 } & &
\end{tabular}

Table IV.3: Party x Home Game

The option (Party, Party) is pareto dominant of the option (Home, Home) and both are pareto dominant in comparison to the other ones (Party, Home) or (Home, Party) [61].

\section{Battle of Sexes}

A variant of "Home x Party Game" is the "Battle of Sexes" Game. In this game, both players are a couple (husband and wife) and would like to enjoy the same activity but have different preferences. The player one (husband) likes Football and the player two (wife) likes opera. It is better to decide to follow the other player than staying at home, even if it is not your favorite activity [61]. Table IV.4 presents the payoff matrix to this game.

\begin{tabular}{r|c|c|}
\multicolumn{1}{c}{} & \multicolumn{1}{c}{ Football } & Opera \\
\cline { 2 - 3 } Football & 10,5 & 0,0 \\
\cline { 2 - 3 } Opera & 0,0 & 5,10 \\
\cline { 2 - 3 } & &
\end{tabular}

Table IV.4: Battle of Sexes game

Both options (Football, Football) and (Opera, Opera) are pure strategy Nash equilibria and pareto optimal [61].

\section{Stag Hunt Game}

The last game in this section is the Stag Hunt game. In this game, both players are hunters and may choose to hunt a hare or a stag. The hare is an easy and abundant prey but has little meat. A Stag has more meat but requires concentration and teamwork to catch it. If the hunters decide for hunting a stag, they should split and trust each other. During the hunt if one hunter gives up and captures a hare, the other one will stay hungry. If both hunters capture a hare, they will have a median meal, but if both capture a stag, the food would be abundant [61]. This is a good example of social welfare and cooperation. Both hunters would be satisfied by catching a hare but if they cooperate then they would maximize their payoffs by catching a stag. The payoff matrix is presented on table IV.5.

This game presents two pure strategy Nash equilibria (Stag, Stag) and (Hare, Hare) but (Hare, Hare) is preferred because of the risk. Also, both are Pareto-efficient [61]. The Stag Hunt game is an example of "Social Contract". The hunters must keep a mutual social agreement in order to catch a stag. If 


\begin{tabular}{c|c|c|}
\multicolumn{1}{c}{} & \multicolumn{1}{c}{ Stag } & Hare \\
\cline { 2 - 3 } Stag & 10,10 & 1,5 \\
\cline { 2 - 3 } Hare & 5,1 & 2,2 \\
\cline { 2 - 3 } & &
\end{tabular}

Table IV.5: Stag hunt game

the social contract is broken, then a hunter decides for catching a hare and leaves the other one hungry.

\section{IV.2 Social Contract}

A social contract is defined as a non-written agreement that exists between the individuals of a community or group. This agreement guides the behavior and establishes conventions, individual rights and responsibilities. Social contract is considered essential to any organized group behavior and, in democratic societies, is enshrined in the national constitution [62].

To join a society, individuals are asked to accept the social contract even if the rules are not entirely clear. People should be encouraged to put the group's interests ahead of their individual interests and each decision must be made by mutual consent. The imbalance of social norms weakens the collective and influence individuals to make selfish decisions.

In an anarchic state there is no social contract. In this society, people are at war "all against all", making the life "solitary, poor, nasty, brutish, and short" [62].

Every relationship between individuals creates a social contract between them. If one of the individuals violates a rule of this agreement, their relationship weakens. The rupture of the social contract is the same as relationship breakup [62].

\section{IV.3 Social Welfare}

The Social Welfare is a function that evaluates well-being and equity in a group of individuals [63].

For example, the audience formed to attend a show is a small society which, as mentioned above, has preferences and relationships between some or all individuals. The level of audience satisfaction can be denominated social welfare. The individual welfare is determined by the individual's utility function [63]. If the story is meeting an individual's expectations, then it can be said he/she is on high welfare. If the story does not meet an individual expectations, then he/she is on low welfare.

Given a game $G=(N, S, u)$, where $N$ represent the players with strategy sets $S_{i}$ and utilities $u_{i}: S \rightarrow \Re S=S_{1} \times \ldots \times S_{n}$, the welfare function is defined 
by $W: S \rightarrow \Re$.

The social welfare function can be calculated based on two possible criteria:

- Sum of players' utilities (utilitarian objective): $w(a)=\sum_{i=1}^{N} u_{i}(a)$,

- Minimum utility function (fairness or egalitarian objective): $w(a)=$ $\min _{i} u_{i}(a)$.

The social optimum maximizes $w(a)$ over all possible action profiles, $a \in A$.

In an interactive storytelling context, the social welfare is directly proportional to the audience. Higher social welfare levels correspond to the success of a story for a greater number of satisfied individuals.

It is also necessary to determine the break-even point for the social welfare function [64]. The break-even point is the one at which any change in the story worsens the value of social welfare because, despite being pleasing to some people, it will also be displeasing to others in the same audience.

Following these ideas, if an acceptable welfare level is not reached, it means that much of the audience is not satisfied with the story.

Individuals who are not satisfied can give up the story and abandon it before the end. Also, they may influence others because of their relationship, increasing the number of dropouts and negative reviews.

As an audience can be composed of individuals who have very different preferences, it is important that the storyteller identify a middle ground to please as many as possible. Knowing some personality traits of each individual helps to get the story closer to the audience.

\section{IV.4 Price of Anarchy and Price of Stability}

The Price of Anarchy is a measure of efficiency to determine how a system degrades due to selfish behavior of the players [65].

Given a subset $E \subseteq S$ that represents a set of strategies in Nash equilibrium, the Price of Anarchy is defined as the ratio between the "worst equilibrium' and the optimal 'centralized' solution:

$$
P_{O A}=\frac{\max _{s \in S} W(s)}{\min _{s \in E} W(s)}
$$

The Price of Stability (PoS) measures how stable the strategy is [65] and is defined as the ratio between the 'best equilibrium' and the optimal 'centralized' solution: 


$$
P o S=\frac{\max _{s \in S} W(s)}{\max _{s \in E} W(s)}
$$

It is expected that the loss in efficiency is between 'PoS' and 'PoA' as $1 \leq P_{O} S \leq P_{O} A$.

\section{IV.5 Cooperative Games}

Cooperative games are a branch of game theory that models cooperation or collaboration between players. The basic framework of a cooperative game was presented by John von Neumann and Oskar Morgenstern in 1944 and is called characteristic function. The characteristic function provides a payoff to each coalition. A coalition is a set of agents that interact and may represent a set of persons, common objectives or artificial agents [12]. As the payoff is given to a coalition, and not to an individual agent, each player must decide with other players it is better to cooperate. In order to form a coalition, it is necessary to resolve the selection problem and the sharing problem.

The selection problem aims to solve which coalitions must be formed. After that, when the coalition formed receives a payoff, the sharing problem finds the best way to distribute it to the different members of the coalition.

\section{(a) Definition}

Given a set $N$ of $n$ agents, a coalition $C$ is a non-empty subset of $N$ where $C \in 2^{N}$ (power set of $N$ ). The set $N$ is also known as grand coalition [12]. The set of all coalitions is $2^{N}$ and its cardinality is $2^{n}$. A coalition structure $S=C_{1}, \ldots, C_{m}$ is a partition of $N$ and each set $C_{i}$ is a coalition with $\bigcup_{i=1}^{m} C_{i}=N$ and $i \neq j \Rightarrow C_{i} \cap C_{j}=\emptyset$. The size of a set of all $C s$ is of the order $O\left(n^{n}\right)$ and $\omega\left(n^{\frac{n}{2}}\right)$. For $C \subseteq N, v(C)$ is a characteristic function (or valuation function) $v: 2^{N} \rightarrow \Re$ that maps the utility of the coalition $C$. The value of an empty coalition is 0 (i.e. $v(\emptyset)=0$ ).

A cooperative game $(N, v)$ assumes that all agents in $N$ want to cooperate and calculates a payoff distribution $x \in \Re^{n}$ that provides the best values to individual agents. Sometimes all agents prefer to work together and get $v(N)$, but they have different points of view about how they should share the returns of work. This means that some agents may prefer to join another coalition in order of receive better returns.

An example of a cooperative game is the "majority game". In this game, assume that the number of agents $n$ is odd and agents must decide between two alternatives using a majority vote. Each agent has a strict preference for 
only one of the alternatives [12]. The characteristic function assumes that the "winning coalition" has the value 1 and the other ones have the value 0 .

$$
v(C)= \begin{cases}1 & \text { when }|C|>\frac{n}{2} \\ 0 & \text { otherwise }\end{cases}
$$

\section{Types of Valuation Functions}

The valuation functions $v$ define how the agent contributes to the coalition [12]. The marginal contribution represents the contribution of an agent $i \in N$ for a coalition $C \subseteq N \backslash\{i\}$ is $m c_{i}(C)=v(C \cup\{i\})-v(C)$. The many types of valuation functions are presented bellow.

- Additive: $\forall C_{1}, C_{2} \subseteq N \mid C_{1} \cap C_{2}=\emptyset, v\left(C_{1} \cap C_{2}\right)=v\left(C_{1}\right)+v\left(C_{2}\right)$. If a cooperative game is additive, the worth of each coalition is the same whether its members cooperate or not. (i.e. $v(C)=\sum_{i \in C} v(i)$ )

- Monotone: $\forall C_{1} \subseteq C_{2} \subseteq N, v\left(C_{1}\right) \leq v\left(C_{2}\right)$. In monotonic games, larger coalitions have better payoffs.

- Superadditive: $\forall C_{1}, C_{2} \subseteq N \mid C_{1} \cap C_{2}=\emptyset, v\left(C_{1} \cap C_{2}\right) \geq v\left(C_{1}\right)+v\left(C_{2}\right)$. In these games, social welfare is maximized by merging coalitions. Consequently, the agents have incentives to form the grand coalition. In some cases, superadditivity implies monotonicity.

- Subadditive: $\forall C_{1}, C_{2} \subseteq N \mid C_{1} \cap C_{2}=\emptyset, v\left(C_{1} \cap C_{2}\right) \leq v\left(C_{1}\right)+v\left(C_{2}\right)$. Agents are best off when they are on their own. Cooperation is not desirable.

- Convex games: $\forall C \subseteq T \wedge i \notin T, v(C \cup\{i\})-v(C) \leq v(T \cup\{i\})-v(T)$. A valuation function is convex when the marginal contribution of each player increases with the size of the coalition he joins (i.e. Convex valuation functions are superadditive).

- Unconstrained: The valuation function can be superadditive for some coalitions, and subadditive for others.

The valuation function provides a value to a set of agents, not to individual agents. The payoff distribution $x=\left\{x_{1}, \ldots, x_{n}\right\}$ describes how the worth of a coalition is shared between the agents, where $x_{i}$ is the payoff of agent $i$. The sum of payoffs obtained by the members of a coalition is denoted by $x(C)=\sum_{i \in C} x(i)$. 


\section{Solution Concepts}

The solutions to the sharing problem are called solution concepts and are based on different interpretations of fairness [12]. These concepts define the best way to distribute the coalition payoff $v(C)$ among agents.

- Feasible Solution: It is not possible to distribute more utility than is available. A payoff $x$ is feasible when $\sum_{i \in N} x_{i} \leq v(N)$.

- Anonymity: A solution is independent of the names of the agents.

- Efficiency: $x(N)=v(N)$. The payoff distribution is an allocation of the whole worth of the grand coalition to all the players.

- Individual rationality: An agent $i$ will join a coalition only if $x_{i} \geq$ $v(\{i\})$.

- Group rationality: $\forall C \subseteq N, x(C) \geq v(C)$. The sum of the individual payoffs must be at least the value of the coalition.

- Pareto optimal payoff distribution: A payoff distribution $x$ is Pareto optimal iff $\nexists y \in \Re^{n}|\exists i \in N|\left\{y_{i}>x_{i} \wedge \forall j \neq i, y_{j} \geq x_{j}\right\}$.

- Reasonable from above: $x_{i} \leq m c_{i}^{\max }$. An agent $i$ should get at most its best contribution.

- Reasonable from below: $x_{i} \geq m c_{i}^{\max }$. An agent $i$ should get at least its minimum acceptable reward.

A payoff distribution that is efficient and individually rational for all agents is called "imputation". Every imputation is a solution candidate for a payoff distribution, and can also be used to object a payoff distribution [12].

The last definition is the notion of "excess". The excess related to a coalition $C$ given a payoff distribution $x$ is the difference between the coalition utility and the distribution payoffs $e(C, x)=v(C)-x(C)$.

If $e(C, x)>0$ then some part of the value of the coalition is lost. When $C$ is not actually formed, some agent $i \in C$ can take the excess value as a potential increase of its payoff if it joins $C$.

A stable solution is one in which no participant wants to change coalitions or to ask for a different share of the payoff. Some stability concepts are based on the excess of coalitions and are presented below. 


\section{(b) The Core}

The core is a set of imputations in which no coalition has a value greater than the sum of its members' payoffs [12]. Therefore, no coalition has incentive to leave the grand coalition and receive a larger payoff.

Let $(N, v)$ be a cooperative game, payoff distribution $x \in \Re^{n}$ is in the core iff $x$ is an imputation that is group rational.

$$
\operatorname{Core}(N, v)=\left\{x \in \Re^{n} \mid \sum_{i \in N} x_{i}=v(N) \wedge \forall C \subseteq N, x(C) \geq v(C)\right\}
$$

A payoff distribution is in the core if no group of agents has any interest in rejecting it and there is no gain by forming a different coalition.

The core can be also defined in terms of excess by the set of payoff distributions $x \in \Re^{n}$, such that $\forall C \subseteq N, e(C, x) \leq 0$. In this case, there is no coalition that has a positive excess and each coalition's demand can be granted [12].

\section{Non-empty Core}

When each agent of a coalition $\mathrm{C}$ receives no less than the maximum that he can obtain by him/herself (in other words the solution is reasonable from above), the game has a non-empty core [66]. In this case, the game is truly cooperative and players do not have an incentive leave the grand coalition and form a single member coalition. Games with non-empty cores are called balanced.

The Bondareva-Shapley theorem was formulated independently by Olga Bondareva and Lloyd Shapley in the 1960s and describes a condition for the non-emptiness of the core of a cooperative game [66].

Let $(N, v)$ be a cooperative game, where $N$ is the set of players and the value function $v: 2^{N} \rightarrow \Re$ is defined by the set of all subsets of $N$. The $\operatorname{Core}(N, v)$ is non-empty iff $\sum_{C \in 2^{N} \backslash\{\emptyset\}} \alpha(C) v(C) \leq v(N)$ for every function $\alpha: 2^{N} \backslash\{\emptyset\} \rightarrow[0,1]$ where $\sum_{C \in 2^{N}: i \in C} \alpha(C)=1, \forall_{i} \in N$.

\section{(c) The Nucleolus}

The nucleolus is based on the notion of excess and has been introduced by Schmeidler in 1969. When a coalition has a positive excess, some utility is not provided to the coalition's members, and the members complain about it. The goal of the nucleolus is to reduce the amount of complaint by ordering lexicographically the minimal imputation [12]. The ordering is called 
lexicographic because it mimics alphabetical ordering used to arrange words in a dictionary.

Let $(x, y) \in \Re^{m}, x \geq_{\text {lex }} y, x$ is greater or equal to $y$ in the lexicographical ordering when $\left\{\begin{array}{l}x=y \\ \exists t, 1 \leq t \leq m \text { such that } \forall_{i} 1 \leq i<t, x_{i}=y_{i} \wedge x_{t}>y_{t}\end{array}\right.$. Let also $e(x)^{\max }$ be the maximum excess and Imp be the set of all imputations, the nucleolus $N u(N, v)$ is the set

$$
N u(N, v)=\left\{x \in \operatorname{Imp} \mid \forall y \in \operatorname{Imp}, e(y)^{\max } \geq_{\text {lex }} e(x)^{\max }\right\}
$$

The nucleolus has the following properties:

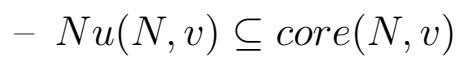

- If $\operatorname{Imp} \neq \emptyset$, then the nucleolus $N u(n, v)$ is non-empty.

- The nucleolus has as most one element.

\section{(d) The Kernel}

The Kernel is another stability concept introduced by Davis and Maschler in 1965. The definition of the kernel is also based on the excess of a coalition. While for the nucleolus, a positive excess was interpreted as an amount of complaint by forming a coalition with positive excess, in the kernel a positive excess is interpreted as benefit that may increase agents' payoff by redistributing the excess between them [12].

Let a Coalition Structure $S=C_{1}, \ldots, C_{k}$, and a positive excess of a coalition $C \notin S$. An agent $i \in C$ can notice the positive excess as a measure of his strength, in other words, if he leaves its current coalition $S$ and joins the coalition $C$, then may have power to generate some surplus $e(C, x)$.

The kernel is based on the idea that two agents can compare their strength by comparing their maximum excess of a coalition.

In a game $(N, v)$, the maximum surplus $S_{k, l}(x)$ of agent $k$ over agent $l$ related to a payoff distribution $x$ is defined by

$$
S_{k, l}(x)=\max _{C \subseteq N \mid k \in C, l \notin C} e(C, x)
$$

Given two agents $\mathrm{k}$ and $\mathrm{l}$, the maximum surplus $s_{k, l}$ of agent $k$ over agent $l$ related to $x$ is the maximum excess for a coalition that includes $k$ but excludes $l$. If two agents in a coalition have the same maximum surplus, they are in equilibrium. When all agents are in equilibrium, the payoff distribution $x$ is in the Kernel. 
Let $(\mathrm{N}, \mathrm{v}, \mathrm{S})$ be a game with coalition structure. The kernel is the set of imputations $x$, a kernel is defined as follows.

$$
K(N, v, S)=\left\{x \in \operatorname{Imp} \mid \forall C \in S,(k, l) \in C^{2}, k \neq l \rightarrow S_{k l}(x) \geq S_{l k}(x) \vee x_{k}=v(\{k\})\right\}
$$

The kernel and the nucleolus are related so and it is possible to define that $N u(N, v, S) \subseteq K(N, v, S)$.

\section{(e) The Shapley Value}

When a coalition is formed, players cooperate to maximize their individual payoffs. Since some players may contribute more to the coalition than others, the final distribution must be fair enough otherwise there is no incentive to collaborate. The Shapley Value calculates how important is each player to the overall cooperation, and what is a reasonable expected payoff [66]. Given a set $N$ of $n$ players and a characteristic function $v$ that describes the total expected sum of payoffs of a coalition where $v: 2^{N} \rightarrow \Re$ with $v(\emptyset)=0$.

The Shapley value calculates the distribution of gains to the players that collaborates in a grand coalition $N$. The amount that a player $i$ gets given a coalitional game $(v, N)$ is denoted by the formula below:

$$
S h_{i}(N, v)=\sum_{C \subseteq N \backslash\{i\}} \frac{|C| !(n-|C|-1) !}{n !}(v(C \cup\{i\})-v(C))
$$

where $n$ is the total number of players and the sum extends over all subsets $C$ of $N$ not containing player $i$. The Shapley value formula is inspired by the fact that when a coalition is formed, each player joins it, one at a time and demands a contribution $(v(C \cup\{i\})-v(C))$ as a fair compensation [12].

\section{(f) Voting Games}

Voting games are a class of coalitional games that models voting in an assembly. This can represent an election between candidates where the winning coalitions are the coalitions of size at least equal to the half the number of voters [12].

A game $(N, v)$ is a voting game when the valuation function have only two possible valid values: 1 for the winning coalitions and 0 for the others [67]. Also, $v$ must satisfy unanimity (i.e. $v(N)=1$ ) and monotonicity (i.e. $S \subseteq T \subseteq N \Rightarrow v(S) \leq v(T))$. 
All agents agree to satisfy unanimity, and then, the coalition wins. Monotonicity defines that the addition of agents in the coalition cannot turn a winning coalition into a losing one. In other words, more supporters should not deteriorate the coalition [12].

In voting games, there are some definitions that must be presented. A coalition $C \subseteq N$ is a minimal winning coalition iff $v(C)=1$ and $\forall i \in$ $C, v(C\{i\})=0$. If a winning coalition is composed by a unique player, it is said that this player is a dictator. More formally, a player $i \in N$ is a dictator iff $\{i\}$ is a winning coalition. A player $i \in N$ is a veto player if $N\{i\}$ is a losing coalition. In other words, $i$ is a veto player iff for all winning coalition $C, i \in C$. Also, a coalition $C \subseteq N$ is a blocking coalition iff $C$ is a losing coalition and $\forall S \subseteq N C, S C$ is a losing coalition [67]. The core to voting games is given by the following formula:

$\operatorname{Core}(N, v)=\left\{x \in \Re^{n} \mid x\right.$ is an imputation $x_{i}=0$ for each non-veto player $\left.i\right\}$

\section{IV.6 Individuals and Empathy}

The relationships between individuals are related to the empathy levels between them. The empathy level in a relationship defines how close the individuals are, and how intense are their experiences and shared emotions.

"Empathy" is the psychological ability to feel what another person would feel if you were experiencing the same situation. It is a way to understand feelings and emotions that another person feels in an objective and rational perspective [53, 68, 19]. "Empathy" is defined by spontaneous attempts to adopt the perspectives of other people and to see things from their point of view. Individuals who share higher empathy levels tend to have similar preferences and do things together $[19,44]$.

According to Adam Smith, "sympathy" is the effect that is produced when we imagine that another person's circumstances are our own circumstances, and find their reaction to the circumstances to be reasonable. Smith refers to this also as "fellow-feeling" and asserts that sympathy is part of human nature, and thus is not an expression of virtue, but is rather a passion that is exhibited by humanity [53].

"Sympathy" occurs when individuals are aware of another person's circumstances and imagine their response or when they receive another person's response and are able to imagine their circumstances. In both cases, "sympathy" manifests itself when an individual imagines that the person experien- 
cing the passion is responding sensibly [53].

The concept of sympathy necessarily involves social standards and what an individual expects from another. Individuals derive pleasure from this sociability when individuals share the level of sympathy. If an individual has a positive response to a positive feeling, it increases the positivity that the individual feels, but, if grief is not mirrored back, it may increase the pain. Also, individuals tend to get upset when others do not sympathize with them $[44,53]$.

Some authors use the term "sympathy" with the same definition of "empathy". According to Sally [68], "empathy" is the ability "to know what it would be like if I were the other person" while "sympathy" is the ability "to know what it would be like to be that other person".

\section{IV.7 Emotional Games}

Emotional Games are an extension of the classical models proposed by Richard Fairchild in 2012 in order to include the human factor in strategic decision. According to Fairchild, humans are not completely self-interested or emotionless, but often exhibit "other-regarding" behavior [44].

In real world, players gain utility from their own material payoffs, but also develop empathetic emotions towards each other. The Emotional Games Theory proposed a behavioral game-theoretic modeling approach that incorporates empathy, social interaction, and psychological affinity [44]. The reciprocal behavior may depend on the social context, social interaction, and psychological closeness of the players [44]. This model proposed that there are two kinds of empathy:

- Conscious Empathy (strategic): Born during the game play

- Unconscious Empathy (innate): Preexisting before game play. (A player simply likes the other for who they are).

The empathy has effects on welfare equilibrium and on how the player perceives the utility function. Next we be present some examples of how empathy can consciously or unconsciously influence the strategic decisions.

\section{(a) Conscious Empathy}

The conscious empathy occurs during the game when players realize that based on psychological and cultural factors could trust each other and cooperate so that both achieve a better result [44]. After the start of the game, individuals who did not know each other begin a certain relationship. This 
relationship may be due to sociocultural or psychological factors. Although they are competing for the best payoff, this initial friendship can influence the cooperation between players. Also, individuals who barely knew each other can strengthen their relationship with interest in obtaining better collective gains. This new relationship is generated by conscious empathy that occurs only during the game. To calculate the new perceived payoffs to influence the conscious empathy, some concepts are necessary [44]. The Empathy Game follows a two-stage game:

- In the First Stage, the players choose their material strategies.

- In the Second Stage, the players choose their empathy levels.

Given the chosen strategies $s_{1}$ and $s_{2}$ for players 1 and 2 and the respective material payoffs $\pi_{1}$ and $\pi_{2}$, the Material Welfare is calculated by the difference of the payoffs and the welfare function:

$$
\begin{aligned}
& m w_{1}=s_{1}-w\left(s_{1}, s_{2}\right) \\
& m w_{2}=s_{2}-w\left(s_{1}, s_{2}\right)
\end{aligned}
$$

$w\left(s_{1}, s_{2}\right)=\pi_{1}+\pi_{2}$. Adding empathy between players to the players' payoffs, the utility functions are described as follows:

$$
\begin{aligned}
& U_{1}=\pi_{1}+{ }_{1} \theta_{2} \cdot \pi_{2}-c_{1} \\
& U_{2}=\pi_{2}+{ }_{2} \theta_{1} \cdot \pi_{1}-c_{2}
\end{aligned}
$$

$\pi_{i}$ is player i's material payoff, ${ }_{i} \theta_{j}$ is player i's effective empathy for player $j$, and $c_{i}$ is player i's (psychological) cost of developing empathy.

According to Fairchild, the effective empathy is affected by each player's actual empathy ${ }_{i} \theta_{j}$ and must be simplified to get an empathy equilibrium. The empathy equilibrium occurs when the empathy of both players by the other is identical. The first step is to identify something in common between players using a closeness index. The closeness index describes the affinity between the players based on psychological, geographic or sociocultural aspects. The effective empathy formula is described as follows:

$$
{ }_{1} \theta_{2}={ }_{2} \theta_{1}=\gamma\left(\phi_{1} \phi_{2}\right)^{1 / 2}
$$

$\gamma$ represents psychological/geographic closeness and ${ }_{i} \theta_{j} \in[0,1)$.

Let the cost of developing empathy be $c_{i}=\beta \phi_{i}^{2}$. Substituting formulas, the utility functions as described as: 


$$
\begin{aligned}
& U_{1}=\pi_{1}+\gamma\left(\phi_{1} \phi_{2}\right)^{1 / 2} \pi_{2}-\beta \phi_{i}^{2} \\
& U_{2}=\pi_{2}+\gamma\left(\phi_{1} \phi_{2}\right)^{1 / 2} \pi_{1}-\beta \phi_{i}^{2}
\end{aligned}
$$

Hence, given that players 1 and 2 have respective material payoffs $\pi_{1}$ and $\pi_{2}$, their optimal empathy levels are found by solving $\frac{\partial U_{1}}{\partial \phi_{1}}=0, \frac{\partial U_{2}}{\partial \phi_{2}}=0$. The pair of reaction functions are:

$$
\begin{aligned}
& \phi_{1}^{*}=\left(\frac{\gamma \pi_{2}^{2 / 3}}{2 \beta} \phi_{2}^{1 / 3}\right) \\
& \phi_{2}^{*}=\left(\frac{\gamma \pi_{1}^{2 / 3}}{2 \beta} \phi_{1}^{1 / 3}\right)
\end{aligned}
$$

In the first equilibrium, $\phi_{1}^{*}=\phi_{2}^{*}=0$, if each player is expecting zero empathy from the other, each player's best response is to choose zero empathy, and this becomes the 'dismal' equilibrium. The original focus of this model is on the case where they coordinate on the 'positive empathy' equilibrium. Therefore, effective empathy is ${ }_{1} \theta_{2}={ }_{2} \theta_{1}=\gamma\left(\phi_{1} \phi_{2}\right)^{1 / 2}=\frac{\gamma}{2 \beta}\left(\pi_{1} \pi_{2}\right)^{1 / 2}$. Substituting formulas, the players' extended equilibrium payoffs are:

$$
\begin{aligned}
& U_{1}=\pi_{1}+\frac{\gamma^{2}}{4 \beta} \pi_{1}^{1 / 2} \pi_{2}^{3 / 2} \\
& U_{2}=\pi_{2}+\frac{\gamma^{2}}{4 \beta} \pi_{2}^{1 / 2} \pi_{1}^{3 / 2}
\end{aligned}
$$

This approach is based on Cournout duopoly equilibrium that calculates the best response of a firm 1 to a firm 2 given a good's price and the amount of production. The objective is to adjust the quantities of production in other to maximize profit given their competitors' decisions. Also, there are some similarities to the Stackelberg leadership model, which describes the reactions of a follower to a leader's decision while they compete on quantity.

Next, some examples demonstrating the influence of the conscious empathy are presented.

\section{Prisoners' Dilemma Example}

Two partners in crime are separated into separate rooms and receive a similar deal. If one player incriminates the other, he may go free or receive a minimal sentence while the other remains in prison. If neither incriminates the other, both are given moderate sentences, but if both incriminates the other, the sentences for both are severe. Each player has a dominant strategy to incriminate the other, and both receives a hard sentence. The best cooperative 
choice is both remain silent [44]. The payoff matrix for this game is presented on table IV.6.

\begin{tabular}{r|c|c|}
\multicolumn{1}{c}{} & \multicolumn{1}{c}{ don't confess } & Confess \\
\cline { 2 - 3 } don't confess & 4,4 & 1,6 \\
\cline { 2 - 3 } Confess & 6,1 & 3,3 \\
\cline { 2 - 3 } & &
\end{tabular}

Table IV.6: Prisoners' Dilemma game

The payoff matrix above represents the original game without considering the empathy between players.

\begin{tabular}{r|c|c|}
\multicolumn{1}{c}{} & \multicolumn{1}{c}{ don't confess } & \multicolumn{1}{c}{ Confess } \\
\cline { 2 - 3 } don't confess & $6.9,6.9$ & $3.6,6.4$ \\
\cline { 2 - 3 } Confess & $6.4,3.6$ & $4.6,4.6$ \\
\cline { 2 - 3 } & &
\end{tabular}

Table IV.7: Prisoners' Dilemma $\beta=0.5, \gamma=0.6$

\begin{tabular}{r|c|c|}
\multicolumn{1}{c}{} & \multicolumn{1}{c}{ don't confess } & \multicolumn{1}{c}{ Confess } \\
\cline { 2 - 3 } don't confess & 12,12 & $8.3,7.2$ \\
\cline { 2 - 3 } Confess & $7.2,8.3$ & $7.5,7.5$ \\
\cline { 2 - 3 } & &
\end{tabular}

Table IV.8: Prisoners' Dilemma $\beta=0.5, \gamma=1$

The impact of empathy is shown on tables IV.7 and IV.8 by adjusting $\gamma$. The variable $\gamma$ represents the psychological/geographic closeness generated by empathy equilibria and changes the perceived payoffs. On table IV.7 the closeness is not enough to change the equilibrium, but the perceived payoffs are quite different. Another example is shown on table table IV.8 and the closeness is high enough to modify the Pareto Optimal and force a cooperation.

\section{Chicken Game Example}

Another classical example in game theory is the Chicken Game. In this game, two rivals need to prove their bravery by driving at each other on a narrow road. The first to swerve loses respect among his peers, but if neither swerves they crash and lose their life. There are two pure strategy equilibria in this game and both equilibria are Pareto optimal. The payoff matrix for this game is presented on table IV.9.

\begin{tabular}{r|c|c|}
\multicolumn{1}{c}{} & \multicolumn{1}{c}{ Swerve } & \multicolumn{1}{c}{ Stay } \\
\cline { 2 - 3 } Swerve & 5,5 & 1,10 \\
\cline { 2 - 3 } Stay & 10,1 & 0,0 \\
\cline { 2 - 3 } & &
\end{tabular}

Table IV.9: Chicken Game

A closeness equal to or greater than 0.85 is enough to change the perceived payoffs in order to force cooperation and both players choose swerve. The updated payoff matrix is shown on table IV.10. 


\begin{tabular}{r|c|c|}
\multicolumn{1}{c}{} & \multicolumn{1}{c}{ Swerve } & \multicolumn{1}{c}{ Stay } \\
\cline { 2 - 3 } Swerve & 14,14 & 12,11 \\
\cline { 2 - 3 } Stay & 11,12 & 0,0 \\
\cline { 2 - 3 } & &
\end{tabular}

Table IV.10: Chicken Game $\beta=0.5, \gamma=0.85$

\section{Another Examples}

In this section, the payoff matrices for The Stag Hunt Game and The Battle of sexes Game are presented. These problems are explained in sections IV.1(a) and IV.1(a), respectively. The influence of the empathy on a Stag Hunt Game, using a $\gamma=0.8$, modifies the perceived payoffs, forcing the cooperative game. In this case, the players will choose to hunt a stag instead of a hare. The original payoff matrix is shown in table IV.5 and the modified one is presented on table IV.11.

\begin{tabular}{cc|c|}
\multicolumn{1}{c}{} & \multicolumn{1}{c}{ Stag } & Hare \\
\cline { 2 - 3 } Stag & 42,42 & $4.6,5.7$ \\
\cline { 2 - 3 } Hare & $5.7,4.6$ & $3.3,3.3$ \\
\cline { 2 - 3 } & &
\end{tabular}

Table IV.11: Stag Hunt Game $\beta=0.5, \gamma=0.8$

In the Battle of Sexes game, a higher closeness will influence the player to choose the better option for the other. The influence of the empathy reverses the perceived payoffs making a player chooses an option to please the other. The original payoff matrix for the Battle of Sexes game is shown on table IV.4 and the modified payoff matrix is presented on table IV.12.

\begin{tabular}{r|c|c|}
\multicolumn{1}{c}{} & \multicolumn{1}{c}{ Football } & Opera \\
\cline { 2 - 3 } Football & 20,25 & 0,0 \\
\cline { 2 - 3 } Opera & 0,0 & 20,25 \\
\cline { 2 - 3 } & &
\end{tabular}

Table IV.12: Battle of Sexes $\beta=0.5, \gamma=0.75$

\section{(b) Unconscious Empathy}

When empathy exists before the game it is called unconscious empathy. This kind of empathy is not formed strategically (consciously) during the game by considering each other's material payoffs. The players may know each other and have a relationship regardless of material payoffs [44]. The unconscious empathy follows a two-stage game:

- In the First Stage, the players form unconscious emotional attachment (empathy) for each other.

- In the Second Stage, they play the material game. 
Since the empathy stage is played unconsciously, the players do not anticipate the effect of this. Initially, the players choose their unconscious empathy levels to maximize the following payoffs:

$$
\begin{aligned}
& U_{1}=\gamma\left(\phi_{1} \phi_{2}\right)^{1 / 2} b_{2}-\beta \phi_{1}^{2} \\
& U_{2}=\gamma\left(\phi_{1} \phi_{2}\right)^{1 / 2} b_{1}-\beta \phi_{2}^{2}
\end{aligned}
$$

$b_{2}\left(b_{1}\right)$ represents player 1's (2's) unconscious (innate) emotional attachment to player 2 (1). In other to simplify the process, it is assumed that $b_{1}=b_{2}=b$. By solving $\frac{\partial U_{1}}{\partial \phi_{1}}=0, \frac{\partial U_{2}}{\partial \phi_{2}}=0$, the equilibrium level of unconscious empathy is derived: ${ }_{1} \theta_{2}^{*}={ }_{2} \theta_{1}^{*}=\gamma\left(\phi_{1}^{*} \phi_{2}^{*}\right)^{1 / 2}=\frac{\gamma}{2 \beta} b$.

Then in the material game, the players choose strategies calculating the following payoffs:

$$
\begin{aligned}
& U_{1}=\pi_{1}+\frac{\gamma}{2 \beta} b \pi_{2} \\
& U_{2}=\pi_{2}+\frac{\gamma}{2 \beta} b \pi_{1}
\end{aligned}
$$

To demonstrate this approach, the present model was applied in two games. Table IV.13 presents the Chicken Game example after an unconscious Empathy of $b=1.00$. In this case, both players prefers to cooperate with each other and choose swerve.

\begin{tabular}{rl|c|} 
& \multicolumn{1}{c}{ Swerve } & \multicolumn{1}{c}{ Stay } \\
\cline { 2 - 3 } Swerve & 12,12 & 15,11 \\
\cline { 2 - 3 } Stay & 11,15 & 0,0 \\
\cline { 2 - 3 } & &
\end{tabular}

Table IV.13: Chicken Game $\beta=0.3, \gamma=0.85, b=1.00$

Table IV.14 presents the Battle of Sexes example after an unconscious Empathy of $b=1.00$. In this case, both players prefers to please the other by choosing the action the other would like most.

\begin{tabular}{r|c|c|}
\multicolumn{1}{c}{} & \multicolumn{1}{c}{ Football } & Opera \\
\cline { 2 - 3 } Football & 20,25 & 0,0 \\
\cline { 2 - 3 } Opera & 0,0 & 20,25 \\
\cline { 2 - 3 } & &
\end{tabular}

Table IV.14: Battle of Sexes $\beta=0.5, \gamma=0.75, b=1.00$

\section{IV.8 Conclusions}

This chapter presented the theoretical foundation for this thesis. The cooperative models and the use of empathy between the players directly 
influenced the proposed models for social interaction and group decisions. These models are presented in the next chapter. 


\section{Social Interaction Models}

In this thesis, social interactions are the process of decision-making in social contexts. This chapter proposes some models of social interaction in order to maximize the individual payoffs by calculating the perceived payoff after the influence of the relationships. The classical individual decision is selfish and greedy, in other words, the player tries to maximize his/her payoffs by choosing what is the best for him/herself. However, the influence of the relationships changes the perceived payoff values. For example, if three friends are competing in a game, the decision to be more aggressive depends on the relationship level and the interest in the subject. Sometimes a player is not interested in winning the game and then cooperates with a friend just to make the other competitor lose. In this case, his/her perceived payoffs in actions that help his/her friend are greater than actions that would make him/her win.

Another example is group decision. When individuals need to decide some action they need to cooperate by selecting what is acceptable for each one and the best for the group ${ }^{1}$. Each individual has a preference but sometimes it is better to decide by another one because the perceived payoff influenced by the group is greater than the best individual payoff. Also, the group decision has some influence over the perceived payoffs due to relationship levels and individuals' personalities. In general, the individuals consider their personal preferences and, after that, consider the others' preferences. In a final decision each individual chooses to stay in the group or to quit if the final perceived payoff is worse then the original individual payoff.

\section{V.1 Concordance Model}

The concordance model proposes a method to calculate the perceived payoff in competitive games after the influence of the relationships. The main idea is to consider how important the subject is to each player, for example, whether they are playing a game just for fun or whether it is a life or

\footnotetext{
${ }^{1}$ John Nash had said, at least in the movie "A Beautiful Mind": . . . because the best result will come... from everyone in the group doing what's best for himself. . and the group.
} 
death objective. Cooperation that is influenced by empathy levels may be ignored depending of how important it is win the game, but they will always influence the players about to choose more aggressive or cooperative actions. In our model, the utility function of player $i$ is an extension of the Fairchild's emotional games equation IV.1 to N-person games and is calculated as follows:

$$
U_{i}=\pi_{i}+C_{i} \sum_{j \neq i}{ }_{i} \theta_{j} . \pi_{j}
$$

$C_{i} \in[0,1]$ is the coefficient of concordance $C_{i}=\left(1-I_{i}\right)$ and $I_{i} \in[0,1]$ is the interest of player $i$ in winning the subject/game in question. The greater the interest of the player, the less will be the concordance with others (possible cooperation). $I_{i}=0$ means that there is no competition $\left(C_{i}=1\right.$, in this case). ${ }_{i} \theta_{j}$ is the coefficient of empathy from player $i$ to player $j$ and $\pi_{i}$ is the original payoff of player $i$.

\section{V.2 Consensus Decision-making Model}

Consensus decision-making is a group decision-making process that seeks an agreement from all participants. The group decision reaches a resolution that may be accepted or supported by all individuals, even if it is not the "preference" of each individual [69]. These decisions are made in agreement by all participants and each individual must accept the group decision or leave. This agreement is discussed during the social interaction and it is called Social Contract (for more information see section IV.2).

The process of deciding on the terms of the agreement and on the decision of the group is called social interaction. During the social interaction, each individual tries to convince the others on his preferences. Some individuals may agree with these suggestions based on the relationship they share, but others may introduce some limits. After some rounds, some individuals give in and accept to approach other preferences [42]. The decision of accepting others' does not eliminate personal preferences but introduce a new aspect to the options. According to the proposed model, some options that are not attractive originally will be chosen because of the induced social reward imposed by the probability function of choosing it. This means that for some individuals, it is better to keep the group together than to take advantage of their preference.

Furthermore, as explained below, individuals high in "openness" do not care so much about their own preferences because they like to experiment new possibilities. They may be convinced by friends or relatives and will tend to support their preferences. 


\section{(a) Individual Definition}

The individual model is used to describe how individuals will behave according to their personality traits. These traits are used to describe how flexible individuals are with new ideas or other suggestions, also, each relationship between individuals or between an individual and a concept is represented by an empathy index.

In Psychology, there are many models to map and define an individual's personality traits. One of the most widely used is called Big Five or Five Factor Model, developed by Ernest Tupes and Raymond Christal in 1961 [28]. This model was forgotten until achieving notoriety in the early 1980s [26]. This model defines a personality through five factors based on a linguistic analysis. It is also known by the acronym O.C.E.A.N. that refers to the five personality traits: Openness to experience; $\mathcal{O} \in[0,1]$; Conscientiousness (Scrupulosity); $\mathcal{C} \in[0,1] ;$ Extraversion; $\mathcal{E} \in[0,1] ;$ Agreeableness (Sociability); $\mathcal{A} \in[0,1]$ and Neuroticism (emotional instability); $\mathcal{N} \in[0,1]$.

The personality of an individual is commonly analyzed and defined through answers to a questionnaire that must be completed and verified by factor analysis. Responses are converted to values that define one of the factors on a scale from 0 to 1 . Also, there are new experimental methods to analyze the personality traits of an individual $[70,71,72]$. There are many works on how to extract the personality traits from Facebook by analyzing likes, shares and comments by an individual. Big Five Experiment ${ }^{2}$, Five $^{3}$ and Apply Magic Sauce $^{4}$ are some examples of applications that generate Big Five analyzes from Facebook User Profiles.

Actually, the consensus decision-making model uses only two individual traits to its formulation: openness to experience and agreeableness. Future works may extend the model to consider the other traits. Each personality trait is described as follows:

\section{Openness to Experience}

Openness reflects how much an individual likes and seeks for new experiences. Individuals high in openness are motivated to seek new experiences and to engage in self-examination. In a different way, closed individuals are more

\footnotetext{
${ }^{2}$ from Online Privacy Foundation

https://www.onlineprivacyfoundation.org/research/personality-facebook/the-big-5-experiment/

${ }^{3}$ from FiveLabs

http://labs.five.com

${ }^{4}$ University of Cambridge Psychometrics Centre

http://applymagicsauce.com/test.html
} 
comfortable with familiar and traditional experiences. They generally do not depart from their comfort zone [20].

\section{Conscientiousness (Scrupulosity)}

Conscientiousness reflects how careful and organized an individual is. Individuals high on conscientiousness are generally hard working and reliable. When taken to the extreme, they can demonstrate "workaholic", compulsive or perfectionist behaviors. Individuals low on conscientiousness are unable to motivate themselves to perform a task that they would like to accomplish. They tend to be more relaxed, less oriented to fulfill or achieve goals and less driven by success. [20]

\section{Extraversion}

Extraversion reflects how an individual is oriented to the external world and gets satisfaction from interacting with other people. Individuals high on extraversion tend to enjoy human interactions, are assertive and energized when around other people. Introverts tend to feel worn by socialization and spent more time alone. Because of this behavior, extroverts are generally good at social interactions due to the large amount of experience, while introverts tend to be socially awkward [20].

\section{Agreeableness}

Agreeableness reflects how much an individual likes and tries to please others. Individuals high on agreeableness are perceived as kind, warm and cooperative. They tend to demonstrate higher empathy levels and believe that most people are decent, honest and reliable. On the other hand, individuals low on agreeableness are generally less concerned with others' well-being and demonstrate less empathy. They tend to be manipulative in their social relationships and more likely to compete than to cooperate [20].

\section{Neuroticism (Emotional Instability)}

Neuroticism is the tendency to experience negative emotions. Individuals high on neuroticism generally experience feelings such as anxiety, anger, jealousy, guilt or depression. They have difficulty dealing with stressful events and overreact in ordinary situations. Generally, higher scores on neuroticism indicates problems to control impulses and delay rewards [20]. 


\section{Empathy between Individuals}

The empathy index indicates the level in a relationship between individuals. For example, when two people like each other, they may want to do things together, thus it indicates a higher level of empathy. In the other hand, people who want avoid each other have a low level of empathy in this relationship. Generally, individuals in a relationship with high empathy choose the same options or a middle ground.

The empathy definition is similar to the "sympathy" definition proposed by Adam Smith [53] (for more information see section IV.6).

\section{(b) Algorithm Definition}

In order to model the individual behavior during social interaction, we proposed an algorithm based on a spring-mass system. Consider that all preferences are modeled in the real coordinate space $\left(\Re^{2}\right)$ and each individual is represented by a point positioned on the emotional preference space (see Figure III.5 in section III.2). Each point (individual) is connected to $n$ springs (where $n$ is the number of individuals). This means that each point has a spring connected to its original position and other $n-1$ springs connected to the other points. Then, we have a total of $\frac{n \times(n+1)}{2}$ springs. The objective function aims to approach each point, considering the constraints of the springs. Each spring is modeled based on the individual personality traits and relationship levels between them. Forces (representing personality traits and empathy) are applied to the springs, causing variations in the lengths of the springs. $F_{i i}$ always reacts trying to restore the initial position of the individual $i$. Therefore, the social interaction will move the initial points to an equilibrium configuration that represents the preferences of the group of individuals. Figure V.1 represents a model with 2 individuals competing for his/her preferences.

There are two formulations to the consensus decision-making model: a quadratic formulation and a Gaussian formulation. The quadratic formulation was investigated first and describes a quadratic utility function to represent the spring forces. This approach describes a smooth relation to the distances given the personality traits. The quadratic formulation is simple and more unstable than the Gaussian formulation. The objective function is described below.

$$
\begin{aligned}
& \min \sum_{i \in A} F_{i i}+\sum_{j \in A, i \neq j} F_{i j} \\
& F_{i i}=\left(1-o_{i}\right) D_{i i}^{2} \\
& F_{i j}=a_{i j}\left(D_{i j}-L_{i j}\right)^{2}
\end{aligned}
$$



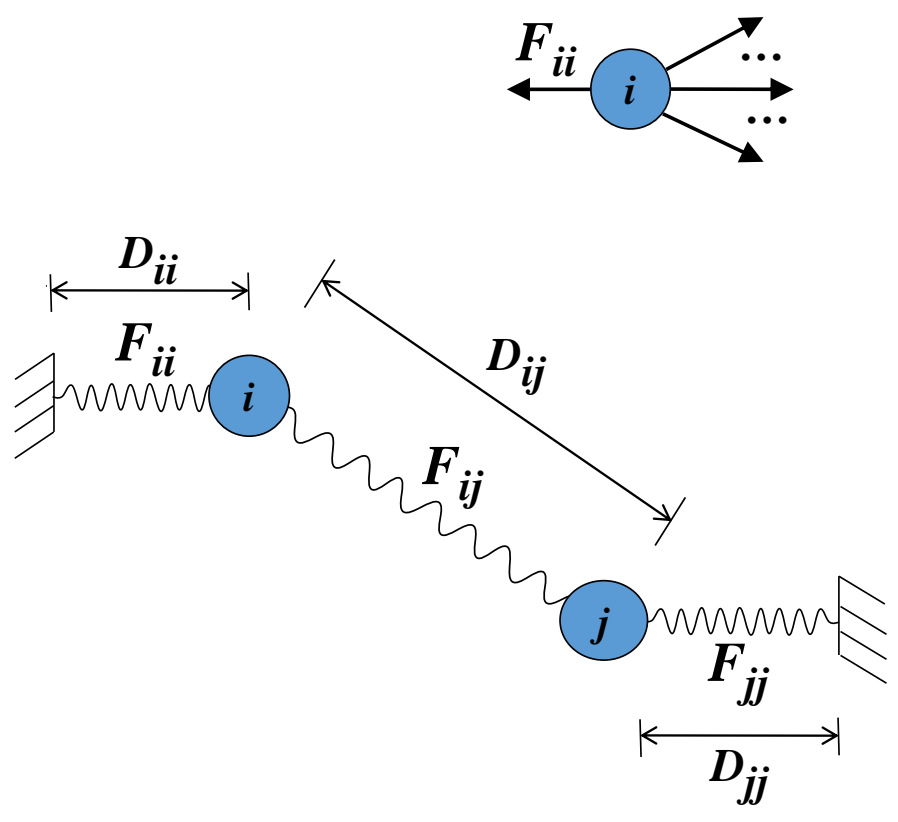

Figure V.1: Spring-mass example with 2 individuals

subject to

$$
\begin{aligned}
L_{i j} & =\left(1-e_{i j}\right) D_{i j}^{0} & & \forall i, j \in A, i \neq j \\
D_{i i} & =\left\|x_{i}-x_{i}^{0}\right\| & & \forall i \in A \\
D_{i j} & =\left\|x_{i}-x_{j}\right\| & & \forall i, j \in A, i \neq j \\
D_{i j}^{0} & =\left\|x_{i}^{0}-x_{j}^{0}\right\| & & \forall i, j \in A, i \neq j \\
o_{i} & \in[0,1] & & \forall i \in A \\
a_{i j} & \in[0,1] & & \forall i, j \in A, i \neq j \\
e_{i j} & \in[-1,1] & & \forall i, j \in A, i \neq j
\end{aligned}
$$

$A$ is a set of individuals, $o_{i}$ is the "openness" level of each individual $i, a_{i j}$ is the "agreeableness" for each pair of individuals $i$ and $j, e_{i j}$ is the empathy level between each pair of individuals, $x_{i}^{0}$ is the original position in space $\Re^{2}$ of individual $i$ and $x_{i}$ the current position in space $\Re^{2}$ of individual $i$. This model assumes that "agreeableness" may also be influenced by the relationship between $i$ and $j$ and it is possible to describe an individual's resistance by the others' preferences.

Also, let $D_{i j}^{0}$ be the original distance between individuals $i$ and $j, D_{i j}$ be the current distance between individuals $i$ and $j$, and $D_{i i}$ be the current distance from the original position of individual $i$ to his current position, the objective of the following model is to find the final positions $x_{i}$ by minimizing 
the cost calculated by the spring forces $F_{i i}$ of each individual $i$ and cost calculated by the spring forces $F_{i j}$ between individuals $i$ and $j$.

The constraint (V.5) defines $L_{i j}$ that represents how the empathy level $e_{i j}$ influences the individual $i$ to approach the individual $j$ from the original distance. Figure V.1 describes the operation of the Spring-mass system with 2 individuals and figure V.2 represents the operation of the Spring-mass system with 4 individuals.

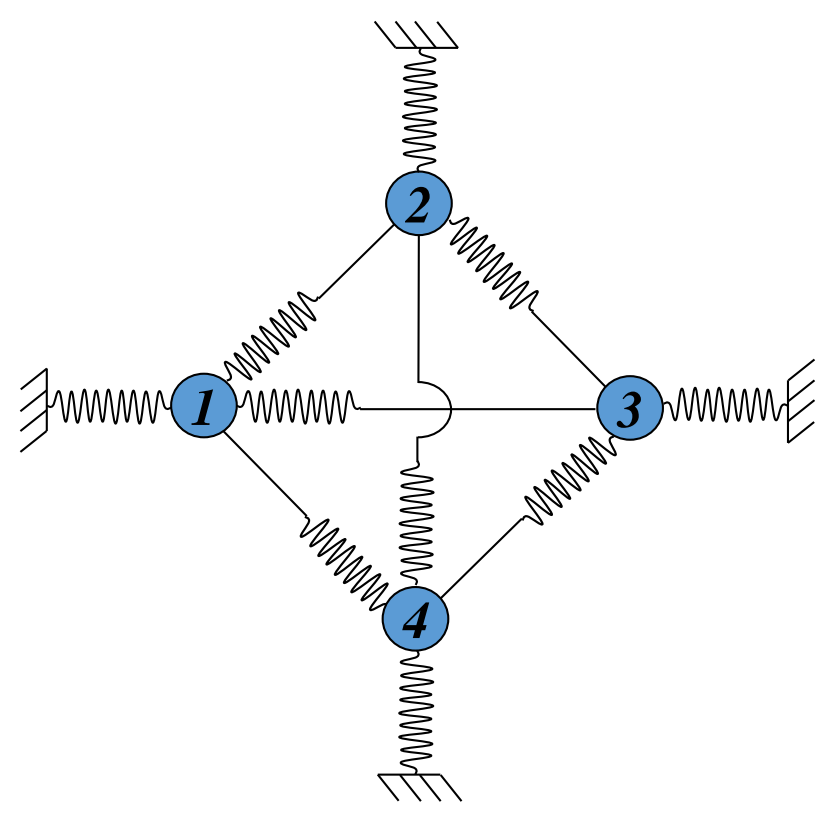

Figure V.2: Spring-mass example with 4 individuals

The Gaussian formulation was defined to represent the relation between the personality traits and the payoff perceived as more accurate. As "openminded" individuals perceive the same payoff to different alternatives and "hard-headed" individuals have a unique preference, the individual payoff is best represented a normal distribution where the "openness" defines the kurtosis. The Gaussian formulation is presented below.

$$
\begin{array}{r}
\min \sum_{i \in A} F_{i i}+\sum_{j \in A, i \neq j} F_{i j} \\
F_{i i}=2\left(1-e^{\frac{-\left(d_{i i}\right)^{2}}{o_{i}^{2}}}\right) \\
F_{i j}=2\left(1-e^{\frac{-\left(d_{i j}-L_{i j}\right)^{2}}{a_{i j}^{2}}}\right)
\end{array}
$$


subject to

$$
\begin{aligned}
L_{i j} & =\left(1-E_{i j}\right) d_{i j}^{0} & & \forall i, j \in A, i \neq j \\
D_{i i} & =\left\|x_{i}-x_{i}^{0}\right\| & & \forall i \in A \\
D_{i j} & =\left\|x_{i}-x_{j}\right\| & & \forall i, j \in A, i \neq j \\
D_{i j}^{0} & =\left\|x_{i}^{0}-x_{j}^{0}\right\| & & \forall i, j \in A, i \neq j \\
o_{i} & \in[0,1] & & \forall i \in A \\
a_{i j} & \in[0,1] & & \forall i, j \in A, i \neq j \\
e_{i j} & \in[-1,1] & & \forall i, j \in A, i \neq j
\end{aligned}
$$

$A$ is a set of individuals, $o_{i}$ is the "openness" level of each individual $i, a_{i j}$ is the "agreeableness" for each pair of individuals $i$ and $j, e_{i j}$ is the empathy level between each pair of individuals, $x_{i}^{0}$ is the original position in space $\Re^{2}$ of individual $i$ and $x_{i}$ the current position in space $\Re^{2}$ of individual $i$. This model assumes that "agreeableness" may also be influenced by the relationship between $i$ and $j$ and it is possible to describe an individual resistance by others' preferences.

Also, let $D_{i j}^{0}$ be the original distance between individuals $i$ and $j, D_{i j}$ be the current distance between individuals $i$ and $j$, and $D_{i i}$ be the current distance from original position of individual $i$ to his current position, the objective of the following model is to find the final positions $x_{i}$ by minimizing the cost calculated by spring forces $F_{i i}$ of each individual $i$ and the cost calculated by spring forces $F_{i j}$ between individuals $i$ and $j$.

The constraint (V.15) defines $L_{i j}$ that represents how the empathy level $e_{i j}$ influences the individual $i$ to approach the individual $j$ from the original distance. The limit of constraint (V.14) as $a_{i j}$ approaches 0 is 2. Figure V.2 represents the operation of the Spring-mass system with 3 individuals.

Figures V.3, V.4, V.5 and V.6 represent the comparison between the costs and distances calculated by the quadratic and Gaussian formulations. The next section presents a meta-heuristic that is used to solve both formulations.

\section{V.3 Solving the Consensus Decision-making Model}

Since this model is not linear, it is not possible to use a linear solver to obtain the optimal solution. Therefore, we use a meta-heuristic approach based on simulated annealing to obtain a good approximate solution.

Simulated annealing is a meta-heuristic for optimization problems based on thermodynamics. Given a large solution space, it solves the optimization 


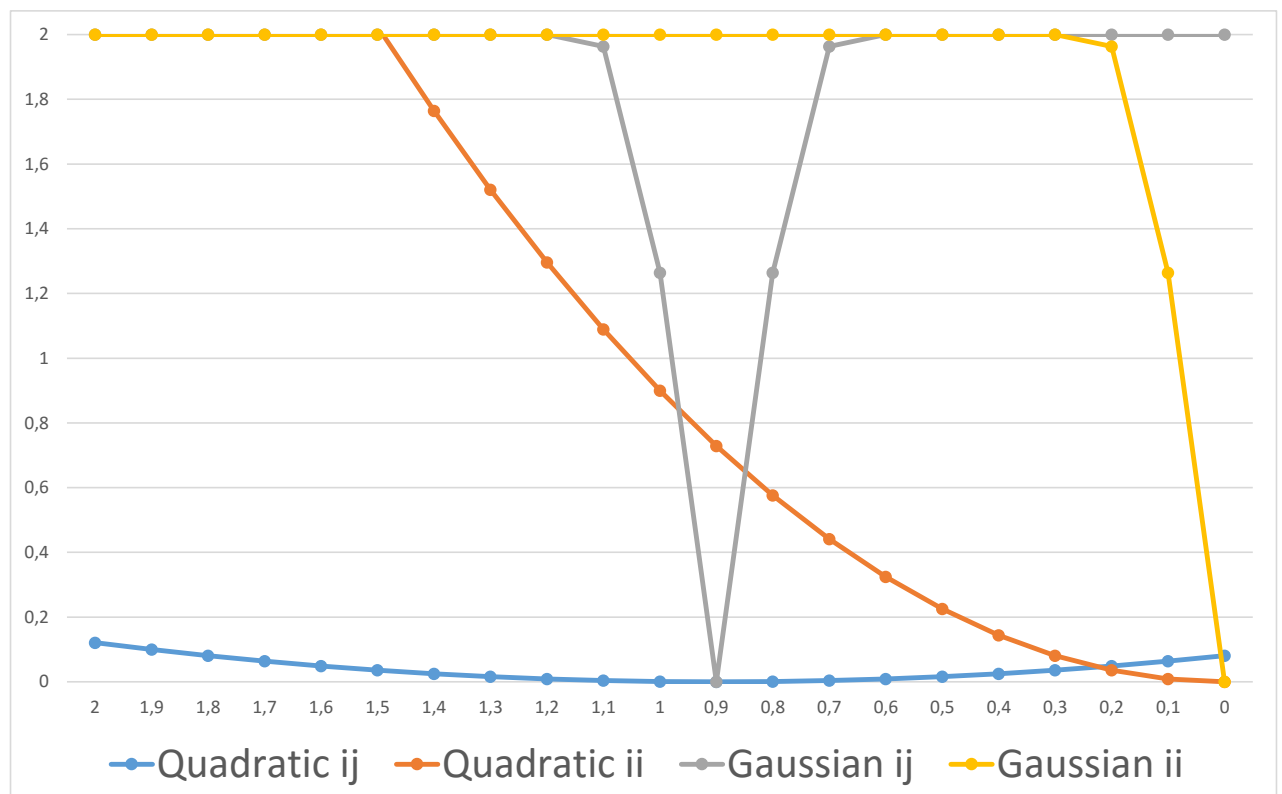

Figure V.3: Relation between cost and distance given different empathy and openness values - Quadratic x Gaussian formulations: $\mathrm{e}=0.1$ and $\mathrm{o}=0.1$

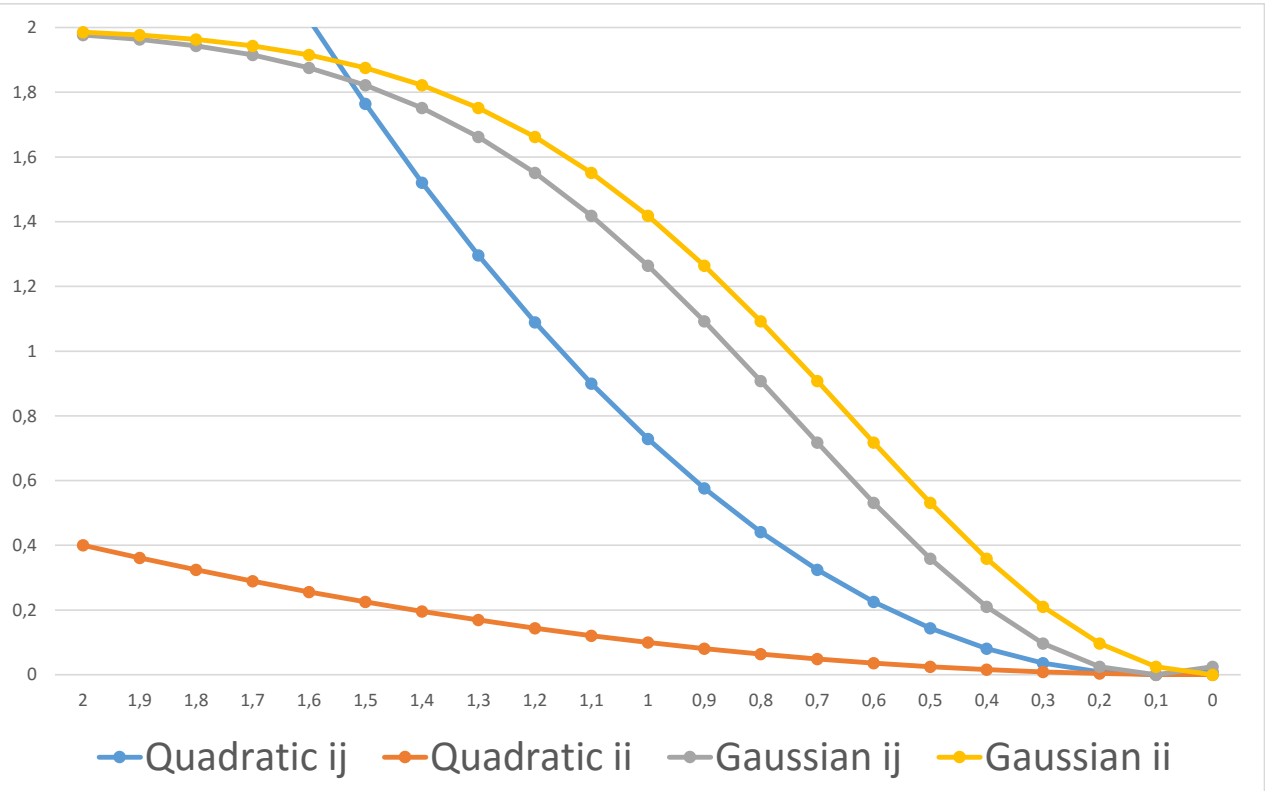

Figure V.4: Relation between cost and distance given different empathy and openness values - Quadratic x Gaussian formulations: $\mathrm{e}=0.9$ and $\mathrm{o}=0.9$

problem by finding a good solution near the global optimum [73]. At each iteration of the algorithm, it changes the current solution within a neighborhood and considers the new solution as the current one if there is any improvement on the objective function or, if there is no improvement, it may consider it 


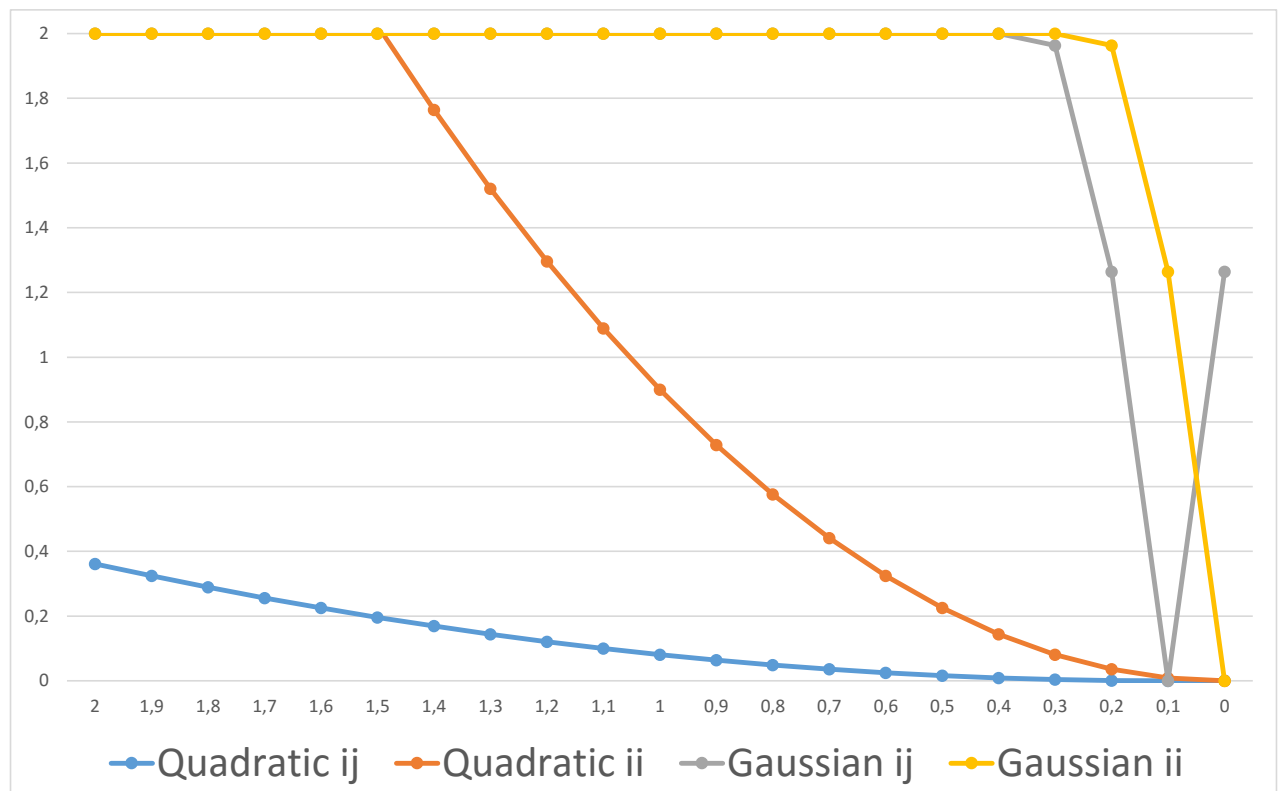

Figure V.5: Relation between cost and distance given different empathy and openness values - Quadratic x Gaussian formulations: $\mathrm{e}=0.9$ and $\mathrm{o}=0.1$

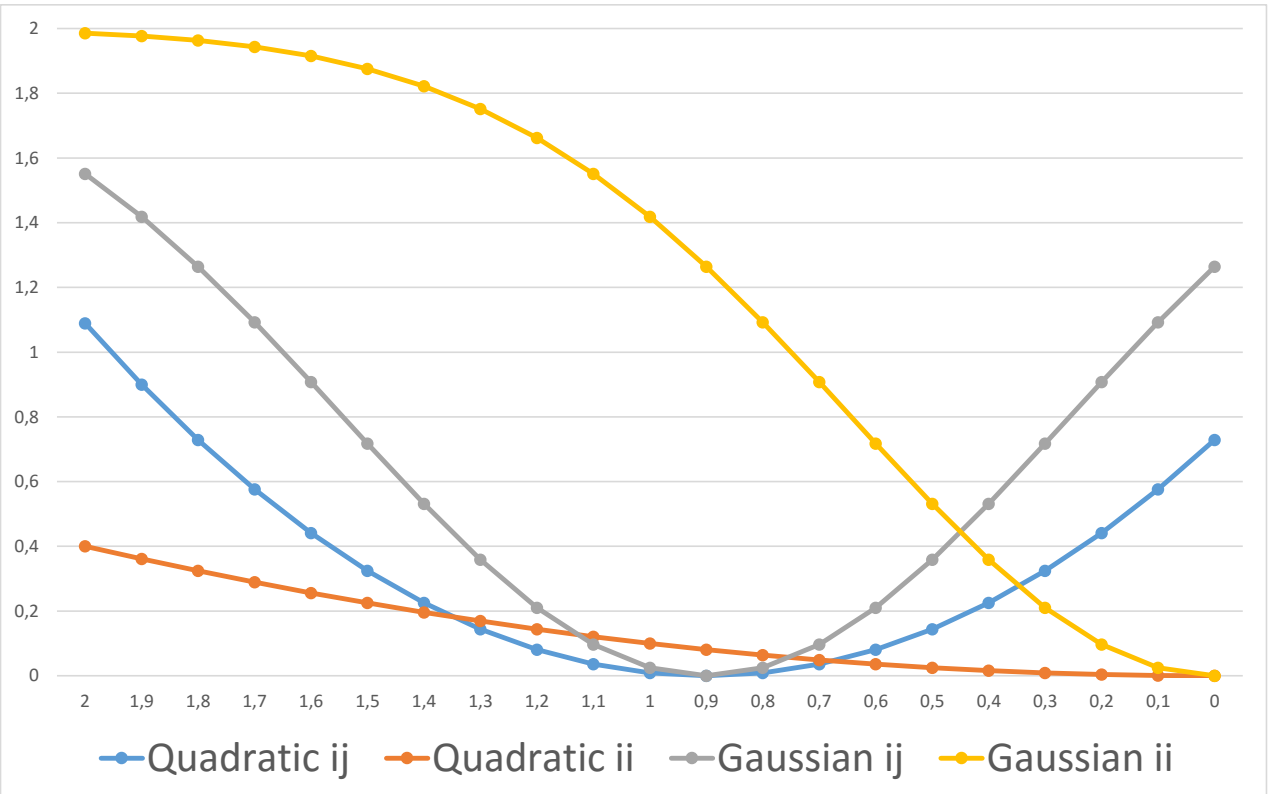

Figure V.6: Relation between cost and distance given different empathy and openness values - Quadratic x Gaussian formulations: $\mathrm{e}=0.1$ and $\mathrm{o}=0.9$

based on a randomized criteria. 


\section{(a) Neighborhood Definition}

The neighborhood used for the consensus decision-making problem is defined by all possible movements of each individual in other to minimize the distances between all individuals according to spring constraints. Let $\vec{a}$ be the current position of individual $a, \vec{b}$ be the referential position based on all relationships between the individuals and $s_{\vec{a}}$ be distance that $a$ will move. It is possible to calculate the step of a movement $\delta_{x}$ for individual $a$ using equations (V.22)-(V.24).

$$
\begin{gathered}
\vec{b}=\left(\sum_{j=1}^{n} \frac{a_{y}^{j} \cdot e_{i j}}{e_{i j}}, \sum_{j=1}^{n} \frac{a_{x}^{j} \cdot e_{i j}}{e_{i j}}\right) \\
\alpha=\left(b_{y}-a_{y}\right) /\left(b_{x}-a_{x}\right) \\
\delta_{x}= \begin{cases}-\sqrt{s_{a}^{2} / \alpha^{2}+1} & a_{x}>b_{x}, \\
\sqrt{s_{a}^{2} / \alpha^{2}+1} & \text { otherwise }\end{cases}
\end{gathered}
$$

The final position after moving the individual $a$ is given by $\vec{a}_{f i n a l}$ as follows:

$$
\vec{a}_{\text {final }}=\left(\delta_{x}+a_{x}, \delta_{x} \cdot \alpha+a_{y}\right)
$$

Three strategies are used to disturb the current solution and walk in the search graph: move a random individual $i$ using the spring force, move an individual $i$ that has the greatest current spring force and move an individual $i$ in the direction of an individual $j$ by selecting random $i$ and $j$ where $i \neq j$.

\section{(b) Simulated Annealing Algorithm}

The simulated annealing method is shown in Algorithm V.1. The algorithm receives as input an initial solution $S_{0}$, limits on the number of iterations $M$, on the number of solution movements per iteration $P$ and on the number of solution improvements per iteration $L$. After each $P$ disturbs, if there is no successful solution it counts a fail. The algorithm stops if the number of failed iterations reaches $F$. During its initialization, the iteration counter starts with 1, the current solution $S$ and the best solution $S^{\prime}$ start equal to $S_{0}$ and the current temperature $T$ is obtained from the function $\operatorname{InitialTemp}()$, which returns a value based on the instance being solved. On each iteration, the current solution is changed within the neighborhood by function Disturb $(S)$ and the improvement is calculated on $\Delta F_{i}$. This solution is then accepted or not as the new current solution and, at the end of each iteration, the temperature is updated given the factor $\alpha$. Each new accepted solution is compared to the best known solution and it may be accepted as the best solution if it minimizes the objective function. 


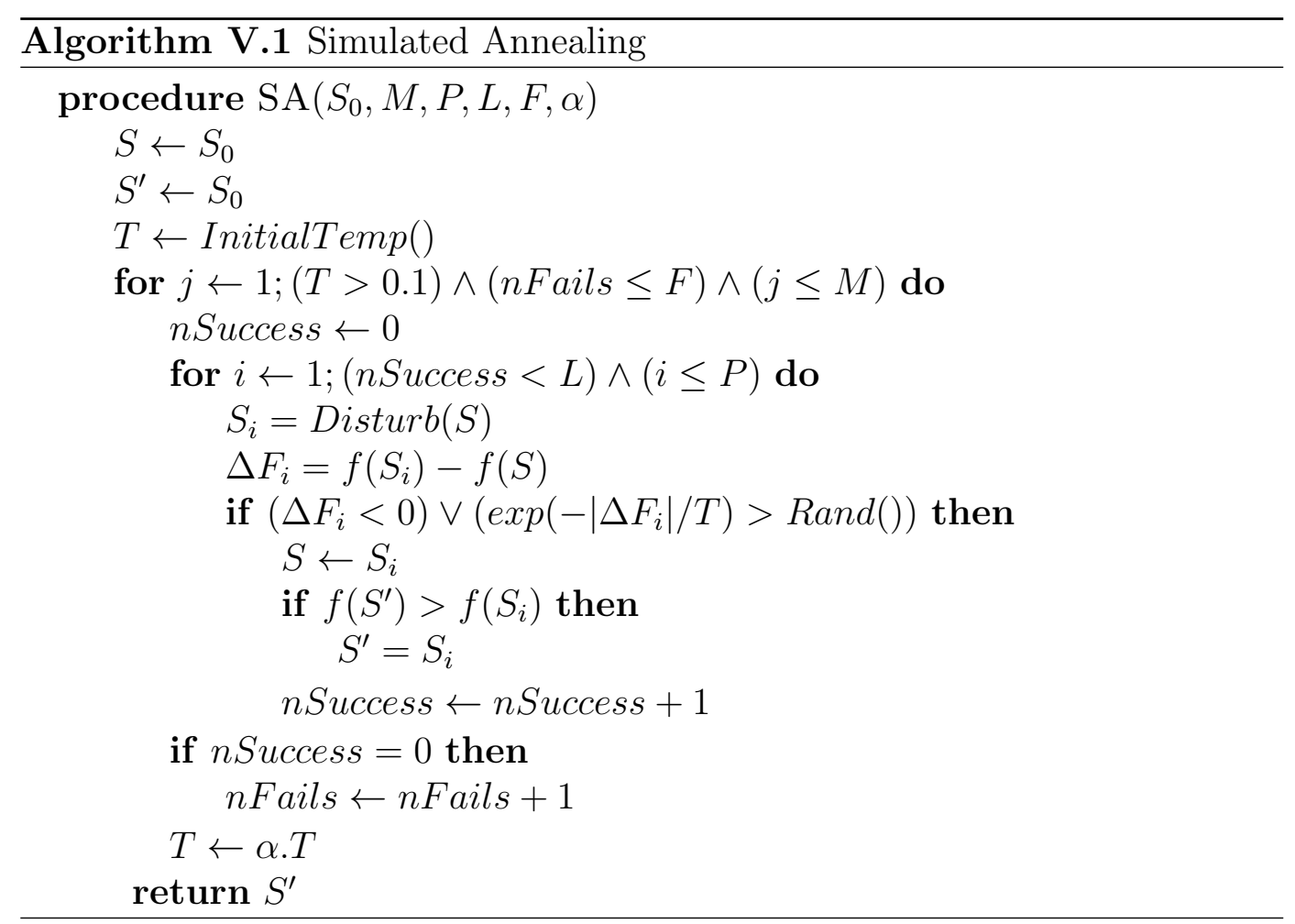

Figure V.7 represents an instance of members of an audience in their original preferences. In figure V.8, the green points represents the new individual preferences after the social interaction.

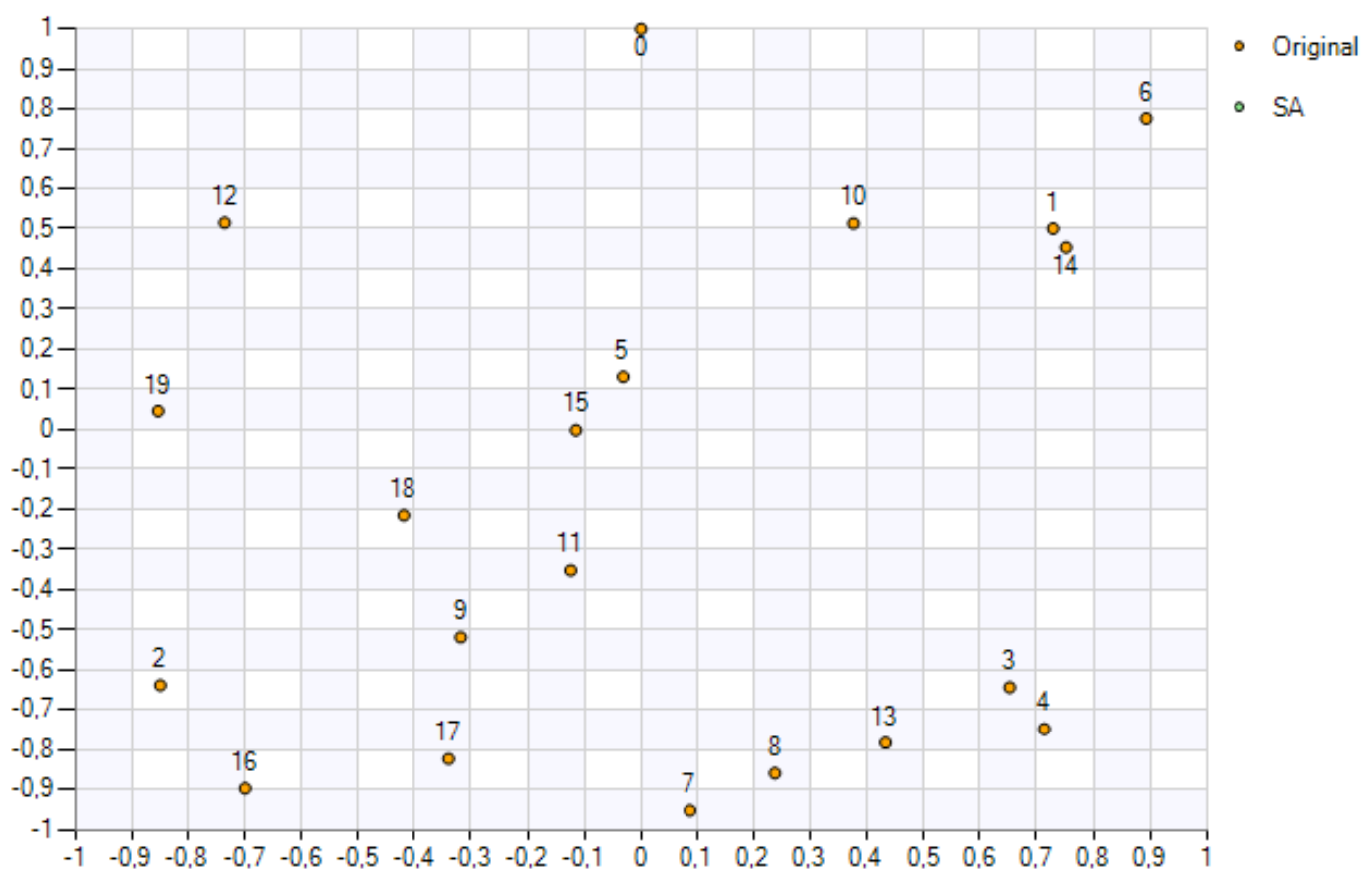

Figure V.7: Example of the original preferences of an Audience

The social interaction models are used to define the competition or cooperation between players and describes the dynamics of a group decision. The group decision reaches a resolution that may be accepted or supported 


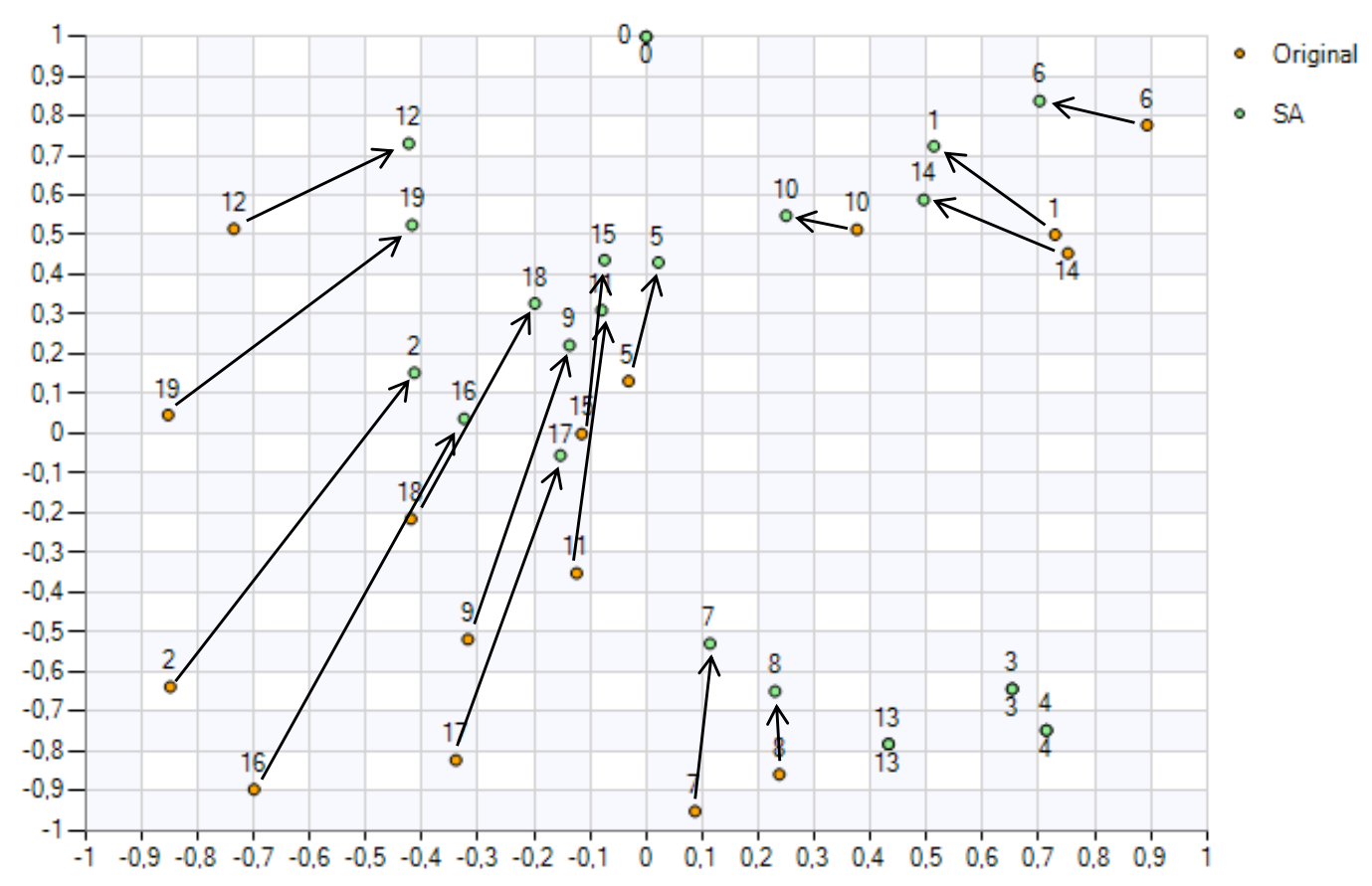

Figure V.8: Example of an Audience after Social Interaction

by all individuals, even if it is not the "preference" of each individual. This middle ground solution is decided by calculating the perceived payoffs due to relationship levels and individual's personalities and in a final decision each individual chooses by stay in group or quit if the final perceived payoff is worse than the individual original payoff.

In relation to the traditional cooperative models described in section IV.5, the proposed models may be used to define the coalitions in a group. Since the set of initial positions of each individuals defines the grand coalition, the Consensus decision-making Model has a non-empty core if there is at least one valid relationship between the individuals. Also, it is possible to define a nucleolus function to describe the incentive to move individuals and the kernel function to describe the incentive to keep them together. A coalition is formed when some individuals are close enough to share the same preferences. Also, the Shapley value may define a payoff distribution given the contribution of each individual to his/her coalition.

The valuation function of the Consensus Decision-making Model is superadditive, since the perceived payoff of each individual considers his/her own payoff and the weighted sum of the payoffs of his/her relationships as described in formula V.1. Similarly to the voting games, an opinion leader may influence the formation of a winning coalition in the same way as a dictator player.

In this thesis, we propose the usage of the social interactive models to calculate the preferences of an audience in storytelling applications. The 
selection of the story events by the indirect influence of the individuals is called passive interaction. In the following chapter, we present a passive storytelling application using social interaction model to define the best event choices given an audience.

\section{V.4 Example Applications}

As the model of social interaction is based on the hypothesis that the perceived value of a subject can be changed in the social influence, it could be applied in other different contexts. In a multiplayer game, the concordance model can assist in the decision to cooperate with some players for the sake of fighting an opponent in common. The idea behind the model is that cooperation only exists as long as there is a common enemy. By the time the players are fighting for the same resource, cooperation is over and the players become selfish.

Furthermore, the consensus decision-making model could be used to determine what is the break even where both players finished a negotiation given their psychological profiles. For example, the model could help to determine the maximum or minimum price that two people could achieve when negotiating a contract or sales price. Also, the model could help to determine how an influential person or opinion leader could influence the group or who is the opinion leader in a group.

Following there are two examples applications that are proposed to use the social interaction model. Both contexts were investigated during this work but need a more detailed and thorough evaluation of the results.

\section{(a) The Office Game}

In a company, a group of individuals share the same room. Each individual has a list of tasks that need to be fulfilled by the deadline. Each individual may decide to work elsewhere but if he/she leaves his/her room, he/she will work precariously in places that are not necessarily intended for the work. If the individual leaves the room, he/she will consequently accumulate his/her tasks and the longer the individual is outside the room less time he/she will have to accomplish the tasks on time.

The room has air conditioning, which should be set at a pleasant temperature to get the job done. If the room is too hot or too cold work begins to become less productive because of the discomfort (i.e., the more comfortable the room, the more productive the individual - this is the payoff). 
Each individual in the room prefers the temperature that suits him/her and the acceptance of suggestions is influenced by his/her personality: Some individuals are "open-minded" and leave a jacket in the room increasing the range of temperatures bearable. Others are more "head-harded" and only accept the temperature that suits them. In order to maximize the efficiency of all workers, the air conditioning must be set to a temperature with which everyone is satisfied.

Given the level of empathy between the individual relationships, the temperature preferences of each one and the individual level of openness, the objective function aims to calculate the temperature that will maximize the social welfare (i.e., the temperature maximizes the sum of all the payoffs). If after having maximized the social welfare there are still people who do not agree with the room temperature, they leave.

\section{(b) Bargain Model}

Considering an interval of preferences that sets the prices of an offer (which can be long or short), a buyer wants to buy as cheaply as possible and the seller wants to sell the most expensive possible. The Bargain Model aims to calculate value with which both agree and close the deal.

For example, if a player launches a bid of 30 dollars and another player launches a sales offer of 35 dollars, they need to negotiate to agree on a price. Given the player profiles, it is possible to calculate how a bid converges to a final trading price of negotiation or if players will not close a deal.

\section{Definition}

Let $O$ (openness) be the aversion to risk of a player. In other words, it defines a stop price to buy or sell the asset. And Let $E$ (empathy) be the influence on others during the negotiation (i.e. major investor or large institution that exerts influence on others).

Is it possible to find the price at which both close the deal or else set that, under current conditions, the gap between the bids remains and there is no trading.

\section{Examples}

1st example - There are two players - a buyer who launches a bid of 30 dollars and another who launches an offer for 35 dollars.

Depending on the profiles, both will have a maximum margin to change their offers (a player may raise a bid or reduce the offer price). In addition, the 
trust deposited in the opponent influences the negotiation and closes prices (empathy).

2nd example - There are several players - in this case the influence of more individuals buying or selling creates an imbalance that tends to pull more easily adversaries since there is a cartel (i.e. an offer greater than the demand or vice versa that offers the same price).

A greater number of opponents offering the same price tends to convince more easily the definition of prices.

This relates to the interest of the player to buy / sell or not. If there is an imbalance in this interest, for example, the player really wants to buy because the price will raise or the seller wants to get rid because the price will fall, the model is highly related to the law of supply and demand. Highest bids or lower sales tend to drag others in the same way that the law of supply and demand. 


\section{VI}

\section{Passive Interactive Storytelling}

In this chapter, we present a simple storytelling application that aims to maximize the audience based on choosing the best option for each individual and for the entire group. Usually, an interactive storytelling application plans a story based on the story context defined by the author and may be influenced by the audience. The audience interacts with the application by selecting one option from a list of suggestions of how the story could be told. Then, these options are used to select future events and adapt the story based on user choices. The application ensures that the story is told if any suggestion is selected.

Interactive storytelling applications are able to create a complete story but cannot evaluate whether the audience is enjoying it without the user feedback. The proposed algorithm tries to create personalized stories passively based on knowledge of the preferences of the audience. This means that the created story would delight the audience even if no explicit suggestion is made by members of the audience.

Also, since each individual in the audience is identified and their preferences are known, it is possible to adapt the story automatically to individual profile but, in order to maximize the audience return, every individual must agree with a middle ground that pleases everyone. The dynamic of choosing the best story for an audience is based on the fact that the individuals will watch the same story, share some intimacy, and want to spend some time together. In a similar way, it is possible to say that they are trying to watch TV and need to choose a program that pleases the entire group. During this interaction, each individual tries to convince the others about his/her preferences. Some individuals may agree with these suggestions based on the relationship they share, but others may introduce some limits. After some rounds, some individuals give up and accept to approach the others' preferences [42]. The decision of accepting the others' preferences does not eliminate personal preferences, but introduces a new aspect to the options.

According to the proposed model some options that originally are not attractive will be chosen, because of the induced social reward imposed by the 
probability function of choosing it. This means that, for some individuals, it is better to keep the group together than to take advantage of their preferences. Furthermore, as explained in section V.2(a), individuals high in "openness" do not care so much about their own preferences because they like to experiment new possibilities. They may be convinced by friends or relatives and will tend to support their preferences.

A story generated based on the spectator profile can get better audience results with less interferences, and it also helps the planning of story sequences while the spectator stays passive. Thus, the storytelling remains interactive, but also passive. The next sections will introduce the audience profile aspects and present the proposed algorithm.

\section{VI.1 Audience}

The audience is a group of people who gather together at a public event, such as a play, movie, concert, TV show or radio broadcast. It is a group of assembled spectators or listeners who attend a performance [74].

The individual is the person who joins the audience and watches the show. Individuals are described by their unique characteristics that define their behavior, their relationships with other individuals and how they deal with other people [26].

These characteristics are easily perceived by the individual attitudes. After a period of observation, it is possible to define a person's personality traits: if he/she is stubborn or accepts suggestions easily, if he/she tries to be pleasant with colleagues or is selfish [27].

Individuals also have relationships based on coexistence, friendship or kinship. This relationship causes the individual to be more open to suggestions and opinions from individuals with whom he/she relates. A relationship also allows the individual to influence others with their opinions and suggestions [47].

The influence of an individual is related to the level of trust that others deposited in your relationship. If a relationship is not strong enough, an individual cannot convince the other and then at least two opinions will exist: the first individual's perspective and perspectives from others who were not convinced [46].

In a Passive Interactive Storytelling application, each individual will be represented by a utility function which maps the payoff according to his/her preferences. The closer from what the individual likes most, the better for him. The preferences representation uses a simplified concept that is related to the 
preferred story genre. As the genre has emotional characteristics, it is possible to relate the genre to a predominant emotion $[75,76]$.

Similar genres and sub-genres may be represented by the same emotion, so the underlying idea is to link an individual preference to a set of genres that convey the same emotions. As the story events have emotional information, it also allows to associate them to a family of genres and consequently the preferred emotions of individuals in the audience. This work uses only the predominant emotion and associates it to the events and individual preferences.

During film screening, individuals in audience get emotionally involved with the story and react according to their preferences. When an individual enjoys what is staged, he/she tends to reflect the same emotions that are proposed by the story. The greater the identification between the individual and the story, the stronger are the emotions experienced [19].

\section{(a) Uncovering Audience Preferences}

The most traditional way to analyze individual personality traits is by using a Big-Five Inventory but, as mentioned in section V.2(a), there are some new proposals using information from social networking profiles. Currently, the largest social network is Facebook ${ }^{1}$, where individuals register their preferences for almost everything (the favorite food of musical taste). Also, Facebook allows a developer to create an application to interact with its users. In order to analyze the audience, a facebook application was developed to offer a BigFive Inventory to individuals, collect the personality traits and save data in SQL database. As shown in figure VI.1, the application presents a form to be completed by the user and calculates the personality traits using his/her answers.

The proposed methodology was applied on a group of 13 students of our graduate program to form a real audience instance. Also, an evaluation of the emotional characteristics of the individuals allowed a positive view of the present techniques during the research. The figure VI.2 represents the personality traits of this real audience instance. Each line color represents a real individual that completed the Big-Five form. The names of the individuals are not disclosed to protect their anonymity.

Lower values on each axis are represented closer to the center of figure VI.2. The axis "Stability" represents the inverse of "Neuroticism" (1Neuroticism) and is commonly used during graphical representations for better understanding. The red areas represent the edges of each axis, the green area represents higher values and the yellow area represents lower values.

\footnotetext{
${ }^{1}$ http://www.facebook.com/
} 


\begin{tabular}{|r||r||l||l||}
\hline Calcular Ajustar Logout & \multicolumn{1}{|l|}{$\begin{array}{l}\text { Openness: } 0.78 \\
\text { Conscientiousness: } 0.556 \\
\text { Extraversion: } 0.525 \\
\text { Agreeableness: } 0.622\end{array}$} \\
Neuroticism: 0.575 \\
\hline I see Myself as Someone Who...
\end{tabular}

Figure VI.1: Big-Five Inventory Facebook Application

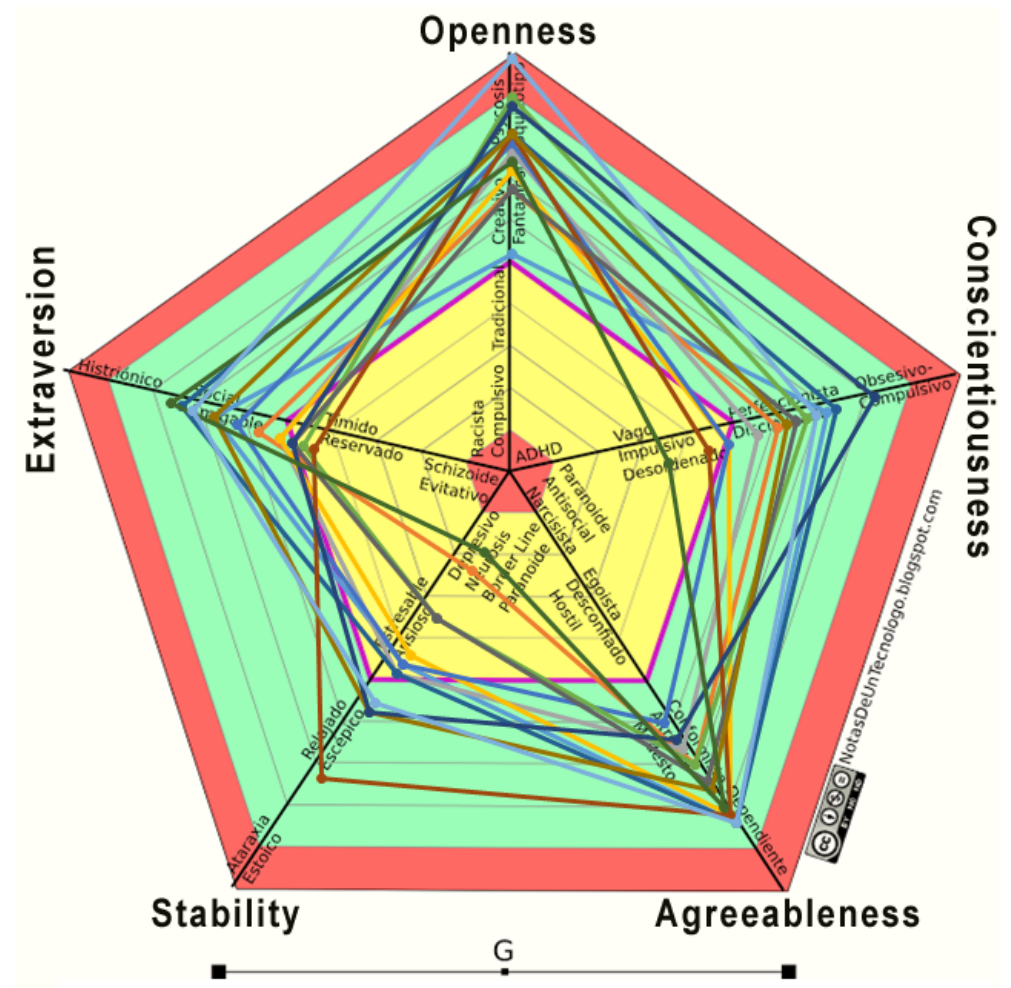

Figure VI.2: Personality Traits collected from Facebook

There are other ways to analyze an individual's personality using his/her Facebook Profile. The information available in user profiles allows to calculate his/her personality by analyzing his/her preferences by music, movies, TV Shows, and social behavior [21, 28, 50, 77]. Considering the personality traits, individuals who score high in "openness" like a greater variety of genres (often contradictory) in comparison to others. Individuals low in "openness" generally prefer the same things and choose the same genres. In this case, there are fewer options to please individuals low in "openness". "Agreeableness" is another 
personality trait which must be considered. Individuals who score high in "agreeableness" try to approach quickly the choices of others and have more patience than others. They sometimes prefer to accept the others' preferences and decisions just to please them all [69].

Also, the individual preferences are used to classify his/her favorite musical or movie genres [41]. Nowadays, there are many movie streaming services like Netflix ${ }^{2}$ and Youtube Movies ${ }^{3}$ which are integrated with Facebook and automatically save the information of watched movies in his/her Facebook profile. Figure VI.3 presents a list of movies and TV shows watched via Netflix and available from a Facebook Profile.

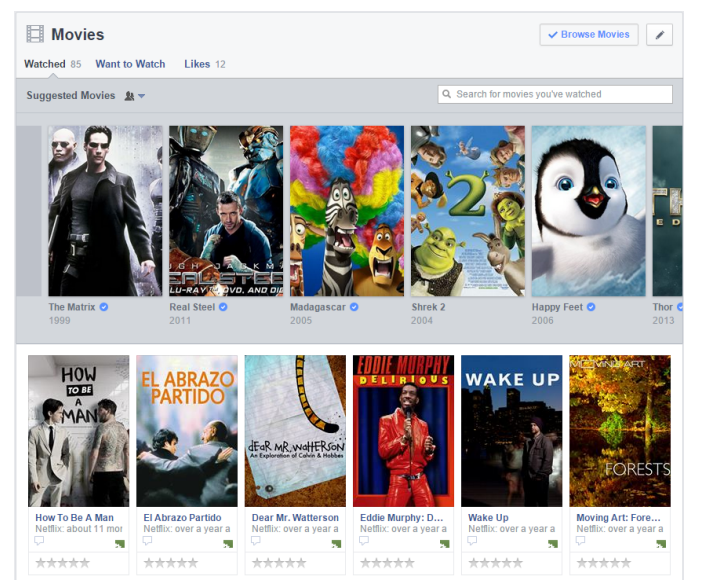

VI.3(a): Movies watched

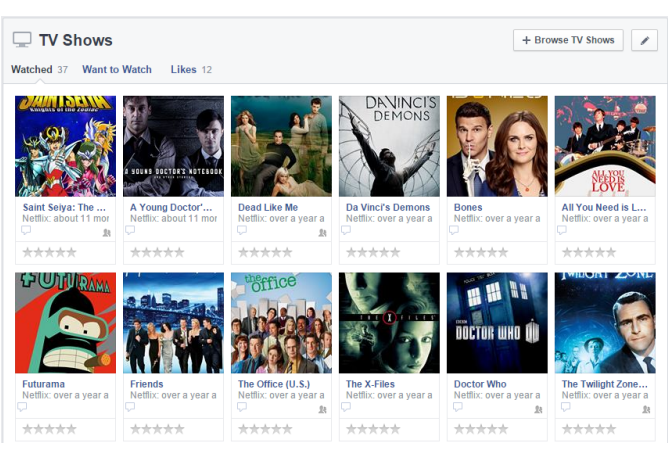

VI.3(b): TV Shows watched

Figure VI.3: Some Movies and TV Shows watched via Netflix - information available from Facebook Profile

After having received the list of watched movies and TV shows, it is necessary to analyze its content and convert each item to the corresponding genre. The genre information is used to define the favorite genres of each individual in the current audience. Websites such as $\mathrm{IMDB}^{4}$ and Rotten Tomatoes $^{5}$ offer a Webservice API to allow developers to query their databases. The present work uses the Rotten Tomatoes database to query the preferred movie and TV show genres given an audience.

Many users still provide this information spontaneously. The Facebook has a form to search and add movies, TV shows, books and music information to the user profile, register user ratings and likes (by using the "like" button). Music streaming services like SoundCloud ${ }^{6}$, Last.Fm ${ }^{7}$ and Spotify ${ }^{8}$ work in

\footnotetext{
${ }^{2}$ http://www.netflix.com/

${ }^{3}$ http://www.youtube.com/movies/

${ }^{4}$ Internet Movies Database: http://www.imdb.com/

${ }^{5}$ http://www.rottentomatoes.com/

${ }^{6}$ http://www.soundcloud.com/

${ }^{7}$ http://www.last.fm/

${ }^{8}$ https://www.spotify.com
} 
a similar way to movie streaming services and also save the information of favorite bands. Figure VI.4 shows a list of favorite bands available from a Facebook Profile.

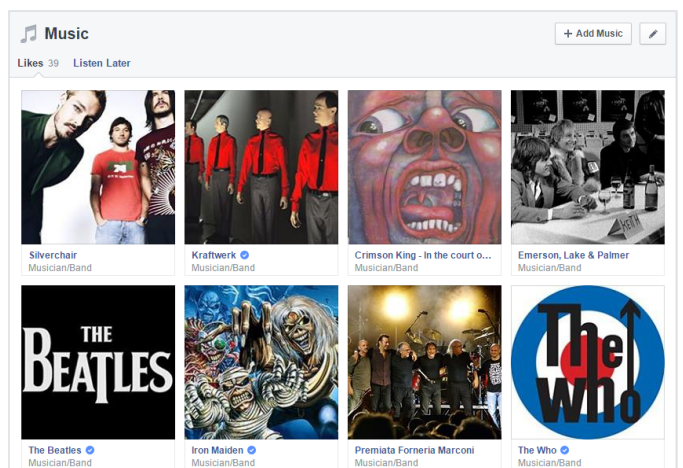

Figure VI.4: Some Favorite Bands - information from Facebook Profile

The empathy between individuals is also available on Facebook. Social Networks have relationship rankings that allow to know who are the closest and less close friends. This information is generated by attending links, shares, and keeping in touch via instant messages [72]. As friends tend to perform many tasks together, the suggestion of a friend can influence the decision of a group Individuals in experience and possibly like a novelty. Individuals with similar characteristics and preferences tend to strengthen their relationships to share experiences, whereas individuals with differing characteristics normally do not exceed a certain level of relationship, keeping a certain distance [48]. Individuals with very different characteristics can maintain a superficial relationship and even avoid each other [48].

Figure VI.5 is an example of use of the relationship level information generated by the Friend Matrix application ${ }^{9}$. The Friend Matrix creates a matrix using pictures from friends profiles and each picture size represents the relationship level the user has with this friend. The matrix represents the closest friends and the bigger pictures are the best friends. Another application that shows the relationship levels is the Wolfram's Personal Analytics ${ }^{10}$, which analyzes the user profile and generates a graph that represent a cluster of facebook friends.

In this thesis, we consider only the personality traits of openness $\left(o_{i}\right)$ and agreeableness $\left(a_{i}\right)$. However, the model can easily incorporate the other 3 traits. These traits were obtained from the forms as mentioned above (Figure V.1), although they could be obtained from some Facebook apps (e.g. Five, Apply Magic Sauce, ....). The empathy $\left(e_{i j}\right.$, also denoted as $\left.{ }_{i} \theta_{j}\right)$ can be obtained from Friend Matrix or Wolfram's Personal Analytics, as mentioned above. Finally,

\footnotetext{
${ }^{9}$ https://www.facebook.com/friendmatrix

${ }^{10} \mathrm{http}: / /$ www.wolframalpha.com/facebook/?adref=personalanalytics.png
} 


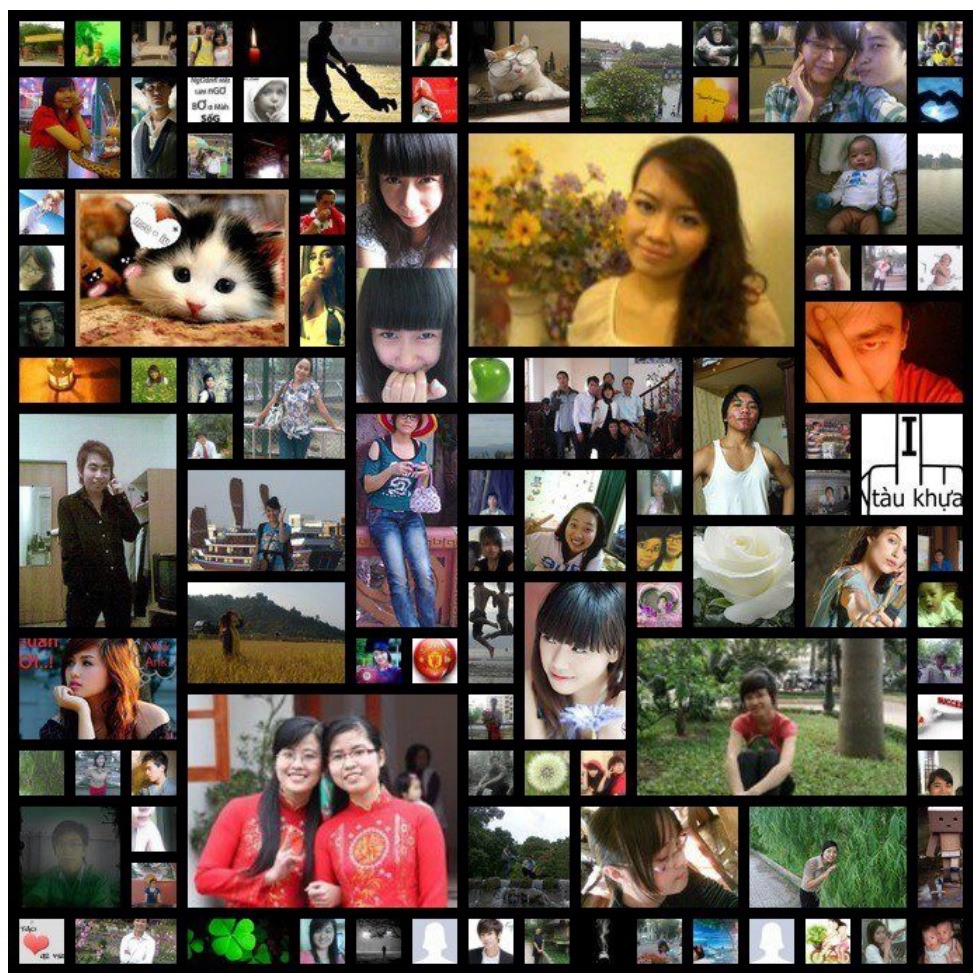

Figure VI.5: Example of Friend Matrix Application

the preferences of the individuals can be obtained by collecting preference data from Netflix, YouTube, and Rotten Tomatoes. The preferences are plotted on the emotional preference space (Figure III.4 and Figure III.5) and the barycentric coordinates are calculated (as the vector $x_{i}$ ).

\section{VI.2 Problem Definition}

The Passive Interactive Storytelling problem aims to generate the best story given an audience. The story is generated based on the story context written by the author and must maximize the audience by choosing the best options for each individual and for the entire group. As it is necessary to understand how the influence of the group acts in the individual choices, the proposed methodology uses the Social Interaction Model to define the preferred options for the audience.

The proposed Passive Interactive Storytelling application follows three steps:

1. Identifies all individuals in the audience, their personality traits, empathy, and preferences;

2. Defines the group preferences using the Social Interaction Model (section $\mathrm{V} .2)$;

3. Uses the adjusted preferences to select the story events 
The story context is written as an events tree as proposed in the section III.1. As a node in the tree represents an event in the story, the best story for the current audience is generated by selecting the best path from the root to a leaf. The proposed algorithm selects the nodes that maximize the expected values given an audience. In the next sections, the algorithm to select the events for the audience is presented.

\section{VI.3 Dealing with a Fixed Audience}

Given a tree of events, each story ending (a leaf of the tree) uniquely determines a sequence of scenes or the story to tell, $\pi$ corresponds to a path from the root of the tree to an ending leaf. The objective function finds the most rewardable path $\pi^{*}$ for a given audience by evaluating the utility function that captures how the audience feels rewarded by the chosen scenes. Formally, the present algorithm is represented by the tuple $\Sigma=(S, A, \Gamma, P, E)$, where:

- $S$ is the finite set of events (scenes) of a story;

- $A$ is the finite set of individuals in an audience;

- $\Gamma^{+}(s)$ is a subset of $S$ containing the child nodes of node $s$;

- $P_{i}\left(s^{\prime} \mid s\right)$ is the conditional probability of $s^{\prime}$ to occur given $s$. For each $s, s^{\prime} \in S$ and $i \in A, P_{i}\left(s^{\prime} \mid s\right)$ is the probability with which individual $i$ chooses state $s^{\prime}$ to follow state $s$. Remark that $\sum_{s^{\prime} \in \Gamma^{+}(s)} P_{i}\left(s^{\prime} \mid s\right)=1$ for each branch $s$ and for each individual $i$, since one branch must be selected on each state;

- $E: S \times A \rightarrow$ is the utility function that determines the expected value of scene $s$ for individual $i$ given his/her own preferences and the influence of his/her relationships.

As sequence of scenes $\pi=\left\{s_{0}, \ldots, s_{k}\right\}$ represents a path from the root to a leaf, the proposed model evaluates the path $\pi$ by computing its expected utility as given by the expression VI.1:

$$
f(\pi)=\sum_{l=1}^{k} \sum_{i \in A}\left(P_{i}\left(s_{l} \mid \gamma\left(s_{l}\right)\right) \cdot E_{i}\left(s_{l}\right)\right)
$$

The function $\gamma: S \rightarrow S$ represents the scene $s$ that precedes $s_{l}$. The utility function $E_{i}\left(s_{l}\right)$, described on equation VI.2, determines the expected value of state $s$ for individual $i$ given his/her own preferences and the influence of his/her relationships. In the present context, it is assumed that the coefficient of concordance $C_{i}=1$ as there is no competition for a final prize. 


$$
E_{i}(s)=d_{i}(s)+C_{i} \sum_{\substack{j \neq i \\ i, j \in A}} \theta_{j} d_{j}(s)
$$

The distance function $d_{i}(s)$ represents how different the scene $s$ is from the individual $i$ preferences and is expressed in equation VI.3. As the scene $s$ genre and the preferred individual $i$ genre uses the emotional notation presented on section III.2, $x_{s}, x_{i} \in \Re^{4}$ are emotions represented in the Plutchik's wheel of basic emotions (Figure III.3).

$$
d_{i}(s)=\left\|\overrightarrow{x_{s}}-\overrightarrow{x_{i}}\right\|
$$

The present model is concluded by proposing an evaluation of the individual probabilities of choice on each story branch. This is done by assuming this probability is proportional to the expected individual reward of the branches and leads to the expression:

$$
P_{i}\left(s^{\prime} \mid s\right)=\frac{R_{i}\left(s^{\prime}\right)}{\sum_{s^{\prime \prime} \in \Gamma^{+}(s)} R_{i}\left(s^{\prime \prime}\right)}
$$

$R_{i}(s)$ is the expected reward at state $s$ for individual $i$, which is given by:

$$
R_{i}(s)=E_{i}(s)+\max _{s^{\prime} \in \Gamma^{+}(s)}\left(P_{i}\left(s^{\prime} \mid s\right) R_{i}\left(s^{\prime}\right)\right)
$$

Let $U(s)$ be the maximum expected utility that can be obtained starting from state $s$ then, the recursion that determines $U(s)$ can be expressed as follows:

$$
U(s)=\max _{s^{\prime} \in \Gamma^{+}(s)} U\left(s^{\prime}\right)+\sum_{i \in A}\left(E(s) P_{i}(s \mid \gamma(s))\right)
$$

where $\gamma(s)$ is the predecessor of $s$. By computing $U\left(s_{0}\right)$, the root's reward, an optimal sequence $\pi^{*}$, with maximum expected reward, can be retrieved in a straightforward way.

The present model allows to determine the best sequence of scenes for fixed audience. In this case, it is considered that all individuals join the audience before the beginning of the story and continue until the end. The next section deals with the possibility of a dynamic audience. Since there is a possibility of an influential late individual to join the audience or some individuals ot leave it, a model is necessary to deal with the probability of the perceived payoffs change.

\section{VI.4 Dealing with a Dynamic Audience}

The story may begin to be told before all individuals have joined the audience. Some individuals may join or leave the audience and their influences may affect the group decisions. In a dynamic audience, the set of individuals 
who join the audience may change during different points of the story and this could influence the ways in which the story is told. In some cases, a single influential individual who joins the audience later is enough to change the way the entire audience understands the story. In order to deal with a dynamic audience, is necessary to recalculate the probabilities and the perceived payoffs of each individual since the influence of new individuals could change the way the audience chooses the events of the story and lead to a new ending. The audience also changes when an influential individual leaves the audience. In this case, the audience could relax and return to their individual preferences.

As during the presentation of the story there is no time for interaction, the application needs at least to adapt the story to the new audience, since there are new preferences that must be considered and used to modify the story. Given a story represented by the sequence of events $\pi:\{E V 1$, EV 3 , EV6, EV12, E2\}, changes in the audience composition imply to recalculate payoffs for the sub-tree from the current state. Figure VI.6 represents a tree of a story, the states in boldface represent the current sequence calculated previously, EVx states represent the plots and Ex states represent the possible endings of the story. The left image represents the original sequence and the right image the new sequence after an audience change.
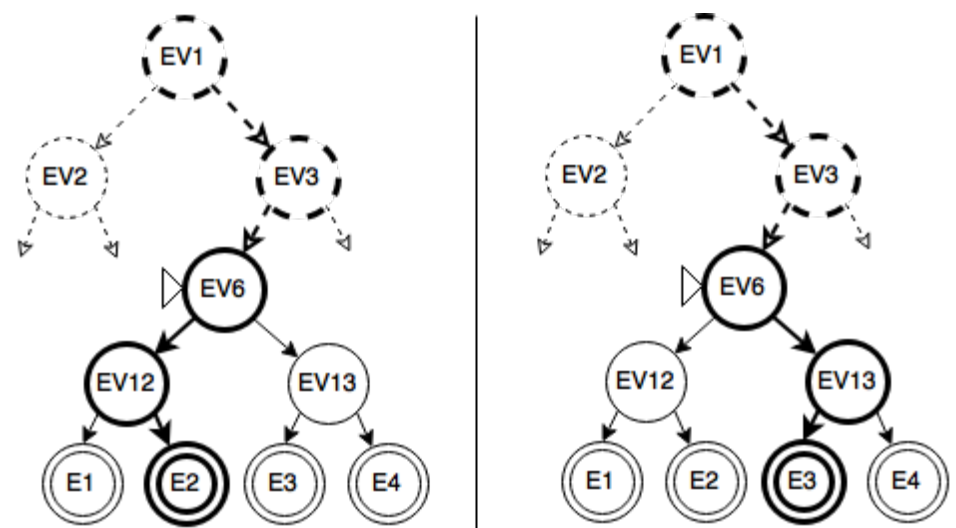

Figure VI.6: Tree of events of a story currently exhibiting event EV6. Events in bold highlight the sequence of a story to be told. The left image represents the original sequence and the right image the new sequence after an audience change.

If there is a change in the composition of the audience it would not be possible to maintain the current sequence, neither to recalculate a sequence using current payoffs. In this case, it is necessary recalculate the entire sub-tree from the current state EV6 and use the new sequence of events $\pi$ to continue the story. Depending on the influence of the new audience composition, the story would end in state E1 instead of E2 or even change the entire sequence to finish the story at ending state E3 or E4. As shown in Figure VI.6, the current 
plot changed from the sequence of events $\pi:\{\mathrm{EV} 1, \mathrm{EV} 3, \mathrm{EV} 6, \mathrm{EV} 12, \mathrm{E} 2\}$ to $\pi:\{\mathrm{EV} 1, \mathrm{EV} 3, \mathrm{EV} 6, \mathrm{EV} 13, \mathrm{E} 3\}$ after the influence of the new components of the audience.

\section{VI.5 Results}

The proposed methodology was initially applied on 13 students of our graduate program to evaluate the emotional characteristics of the individuals. This allowed a positive view of techniques, but as not every user had enough information to generate the preferences, it was necessary to create artificial instances for audiences. We decided to create 16 audience instances with 20 individuals each divided in three groups: 8 entirely mixed audiences with $60 \%$ of individuals supporting a specific emotion, 4 mixed audiences with one opinion leader and 4 random audiences. This starting point allowed a qualitative evaluation of the application of the whole methodology based on a discussion among the participants involved in the experience. Also, each instance was used to generate stories in their original position, after the social interaction using the quadratic model, and after the social interaction using the Gaussian model. Thus, it was possible to compare the results that would be obtained by the audience before and after the application of the social interaction models.

We used two stories during the experiments: The Little Red Cap Story proposed by Araujo [6] and The Princess and The Dragon proposed in [6, 7, 14] to the Logtell Application. In order to use the story of the princess and the dragon, it was necessary to generate its events tree and propose the dramatic curves for each event. The stories and results are detailed below.

\section{(a) Little Red Cap Story}

The story is about a girl called Little Red Cap (or Little Red Riding Hood). Her mother asks the girl to deliver food to her sickly grandmother in the woods and warns her of the danger of leaving the path. A mean wolf observes the girl through the trees and wants to eat her and the food in the basket. Somewhere along the way, the wolf approaches the girl and she naively tells where she is going. He indicates a long way and suggests that the girl pick some flowers for her grandmother. While the girl is on her way, the mean wolf goes to the grandmother's house, gains entry by pretending to be the girl, swallows the grandmother whole and waits for the girl, disguised as the grandma.

When the girl arrives, she notices that her grandmother looks a bit 
strange. At some point, the wolf jumps out of bed and tries to swallow her up too. The girl runs through the woods running from the wolf and asking for help. A hunter comes to the rescue and as the wolf advances on the girl, he kills the wolf with his axe. Then, Little Red Cap is saved by the hunter and with his axe he cuts open the belly of the wolf to save the grandmother. In the end, grandmother emerge unharmed.

The Table VI.1 lists all events that composes the events tree and Table VI.2 illustrates the emotions involved in each of the 20 events present in the story. As some branches lead to the same event, the events tree may be represented by a graph as presented in Figure VI.7. Some events have possibilities of branches such as the moment when the girl meets the wolf in the forest or when the girl escapes. This selection of branches are used to redefine the plots of the story and leads to different endings. The original story is represented by the sequence of events $\pi:\{\mathrm{EV} 1, \mathrm{EV} 2, \mathrm{EV} 3, \mathrm{EV} 4, \mathrm{EV} 5, \mathrm{EV} 7$, EV8, EV9, EV10, EV17, EV11, EV13, EV15 \}.

\begin{tabular}{|l|l|}
\hline EV1 & Mother warns the girl \\
\hline EV2 & Girl leaves her home \\
\hline EV3 & Girl is in the forest \\
\hline EV4 & Girl finds the wolf in the forest \\
\hline EV5 & Wolf cheats the girl \\
\hline EV6 & Wolf attacks the girl \\
\hline EV7 & Wolf goes to Grandma's house \\
\hline EV8 & Wolf swallows Grandma \\
\hline EV9 & Girl arrives at Grandma's house \\
\hline EV10 & Girl speaks with Wolf \\
\hline EV11 & Girl escapes \\
\hline EV12 & Wolf devours Girl \\
\hline EV13 & Girl finds the Hunter \\
\hline EV14 & Wolf gets the girl \\
\hline EV15 & Hunter kills the wolf and saves Grandma \\
\hline EV16 & Wolf kills the Hunter \\
\hline EV17 & Wolf attacks the Girl at Grandma's house \\
\hline EV18 & Wolf eats the Girl after his escape \\
\hline EV19 & Wolf devours the Girl in Grandma's house \\
\hline EV20 & Wolf devours the Girl in the Forest \\
\hline
\end{tabular}

Table VI.1: Little Red-Cap story events

The fairy tale Little Red Cap was transformed in an event tree corresponding to a non-linear variation of the original story by Araujo [6]. New sequences were added to the story allowing it to be adapted and used in the context of interactive storytelling applications. Araujo also proposed the emotions for each event, allowing the story to be planned using the emotional notation. 


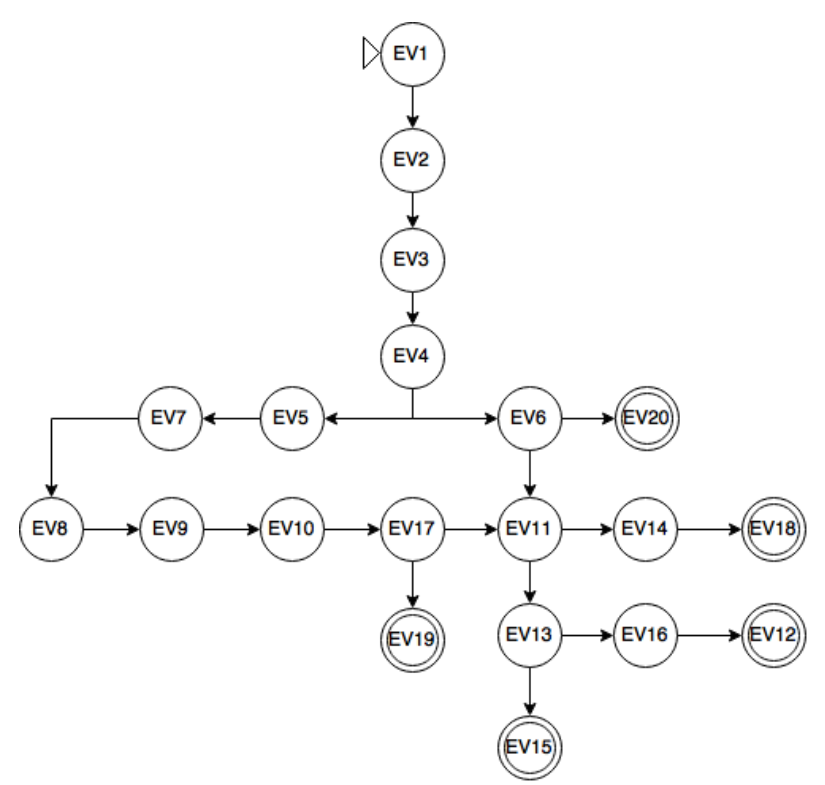

Figure VI.7: Little Red-Cap story as a graph of events

\begin{tabular}{|c|c|c|c|}
\hline EV 1 & Joy + Surprise & EV 11 & Joy + Anticipation \\
\hline $\mathrm{EV} 2$ & Joy + Anticipation & EV 12 & Sadness + Anger \\
\hline EV 3 & Trust + Surprise & EV 13 & Joy + Anticipation \\
\hline $\mathrm{EV} 4$ & Fear + Surprise & EV 14 & Anger + Disgust \\
\hline $\mathrm{EV} 5$ & Fear + Trust & $\mathrm{EV} 15$ & Joy + Anger \\
\hline EV 6 & Anger + Anticipation & $\mathrm{EV} 16$ & Sadness + Surprise \\
\hline EV 7 & Sadness + Anticipation & EV 17 & Anger + Anticipation \\
\hline $\mathrm{EV} 8$ & Anger + Surprise & $\mathrm{EV} 18$ & Sadness + Anger \\
\hline EV 9 & Joy + Fear & EV 19 & Sadness + Anger \\
\hline EV 10 & Trust + Surprise & EV 20 & Sadness + Anger \\
\hline
\end{tabular}

Table VI.2: Dramatic Curves for Little Red-Cap events

The results are presented below. In Tables VI.5, VI.6 and VI.7, the first column represents the method used to generate the story, the second column represents the payoff calculated after it had generated the story and the third column presents its sequence of events $\pi$

Table VI.5 presents the resulting stories for the first group of instances 11. For these instances it is expected that the majority of individuals who support a specific preference is able to convince the others after the social interaction. Despite the sequence of events being consistent with the prevailing emotions, the instances "Amazement", "Ecstasy" and "Rage" had lower results for the Gaussian function than the quadratic function. This occurs because the Gaussian function is more robust and restricts movement in the emotional preference space. Also, it is possible to notice that in some instances the payoff of the quadratic function is lower than the payoff of the original instance (initial preferences of the audience). In contrast, the Gaussian function improved the

\footnotetext{
${ }^{11}$ Total of 8 entirely mixed audiences with $60 \%$ of individuals supporting a specific emotion
} 
results for all instances.

Table VI.6 presents the resulting stories for the second group of instances ${ }^{12}$. For these instances it is expected that the opinion leader be able to convince the others after the social interaction. The most interesting result was obtained for instance "ind Rage". As the final event "EV 15" was modeled using the dramatic curves "Joy + Anger", the Gaussian model suggests that an audience influenced by a "Rage" opinion leader would like it (as anger is equivalent to rage) just as an audience influenced by a "Joy" opinion leader.

Table VI.7 presents the resulting stories for the third group of instances ${ }^{13}$. For these instances we expect better results after social interaction.

\section{(b) The Princess and the Dragon}

The story of the Princess and the Dragon is a variation from the tale of Saint George and the Dragon. In the tale of Saint George, there is a town where a dragon makes its nest near the water supply of a city-state. Then, the citizens of the city have to remove temporarily the dragon from its nest in order to collect water. They attract the dragon to another place by offering a daily human sacrifice chosen by drawing lots. On one occasion, the local princess was selected for the sacrifice and even the local monarch could not save her from this cruel destiny. So, she is offered to the dragon but at some point a traveling Saint George arrives in the town. He offers to fight the dragon and save the princess. Then, he faces and defeats the dragon and saves the princess. In the end, the grateful citizens, influenced by their hero, abandon the ancestral paganism and convert to Christianity. There are many versions of story of Saint George slaying the dragon, but most agree on the following:

- A town was terrorized by a dragon;

- A young princess was offered to or kidnapped by the dragon;

- A brave knight heard about this as he rode into the village;

- The knight slayed the dragon and rescued the princess;

- In some variations the rescuer knight marries the princess.

Table VI.3 lists all events that compose the events tree and Table VI.4 illustrates the emotions involved in each of the 36 events present in the story. The events tree may be represented by a graph as presented in Figure VI.8 to shorten the image as some branches lead to the same event. Some events have possibilities of branches such as the moment when Brian and Hoel are fighting

\footnotetext{
${ }^{12}$ Total of 4 mixed audiences with one opinion leader

${ }^{13}$ Total of 4 random audiences
} 
or when Brian finds Turjan the mage and decides not attack him. There is no original version of this story but we assume that the sequence of events $\pi$ : $\{\mathrm{q} 0$, q1, q2, q4, q6, q25, q19, q28, q30, q32, q33, q34 \} represents the default story.

\begin{tabular}{|c|c|}
\hline$q 0$ & Introduction \\
\hline q1 & Marian at White Palace \\
\hline $\mathrm{q} 2$ & Marian stays at white palace and is Kidnapped \\
\hline q3 & Marian leaves white palace and is dead \\
\hline $\mathrm{q} 4$ & Brian and Hoel fighting \\
\hline q5 & Brian kills Hoel (Hoel is dead) \\
\hline q6 & Brian doesn`t kill Hoel (Hoel Lives) \\
\hline q7 & Brian seeks Turjan (Brian at Green Forest) \\
\hline q8 & Brian seeks Turjan (Brian at Green Forest) \\
\hline q9 & Brian doesn't attack Turjan / Receives force \\
\hline $\mathrm{q} 10$ & Draco kills Brian (Brian is dead, Hoel lives) \\
\hline q11 & Brian attacks Turjan / Receives a curse \\
\hline q12 & Brian attacks Turjan / Receives a curse \\
\hline q13 & Brian attacks Red Castle \\
\hline q14 & Brian kills Draco (Marian lives, Draco is dead) \\
\hline q15 & Brian releases Marian (Marian is free) \\
\hline q16 & Brian Marries Marian (Brian and Marian are married) \\
\hline q17 & Brian proposes Marian \\
\hline q18 & Brian kills Draco (Marian is dead, Draco is dead) \\
\hline q19 & Brian attacks Red Castle \\
\hline q20 & Brian attacks Red Castle \\
\hline $\mathrm{q} 21$ & Draco kills Brian (Hoel lives) \\
\hline $\mathrm{q} 22$ & Hoel kills Draco (Draco is dead) \\
\hline q23 & Hoel releases Marian (Marian is free) \\
\hline q24 & Draco kills Brian (Hoel is dead) \\
\hline q25 & Brian attacks Red Castle \\
\hline q26 & Draco kills Brian (Hoel is dead, Brian is dead) \\
\hline q27 & Draco flies away \\
\hline q28 & Hoel seeks Turjan (Hoel at Green Forest) \\
\hline q29 & Hoel attacks Turjan \\
\hline q30 & Hoel doesn't attack Turjan / Receives force \\
\hline q31 & Hoel receives force \\
\hline q32 & Hoel kills Draco (Marian lives) \\
\hline q33 & Hoel releases Marian (Marian is free) \\
\hline q34 & Hoel Marries Marian (Hoel and Marian are married) \\
\hline q35 & Hoel kills Draco (Marian is dead) \\
\hline q36 & Brian seeks Turjan (Brian at Green Forest) \\
\hline
\end{tabular}

Table VI.3: The Princess and the Dragon story events

As the event " $\mathrm{q} 0$ " represents the introduction of the story, there is no dramatic curve associated to it. During the introduction the following text is displayed: "Once upon a time there was a charming princess, called Marian, lady of the White Palace, and two brave young men, sir Brian and sir Hoel, 


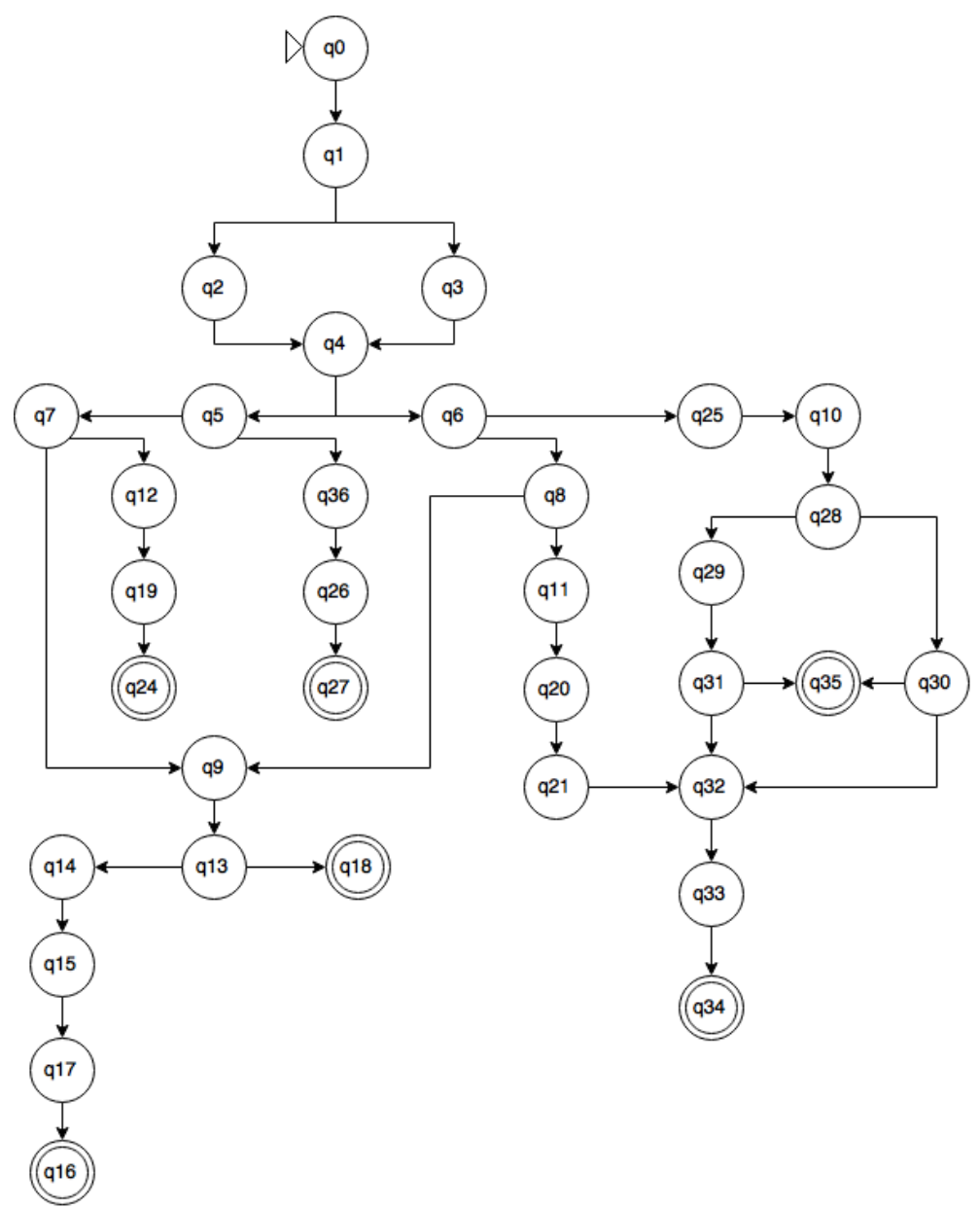

Figure VI.8: The Princess and Dragon Story as a graph of events

\begin{tabular}{|c|c|c|c|}
\hline q0 & - & & \\
\hline q1 & Trust & q19 & Anger + Anticipation \\
\hline q2 & Fear + Surprise & q20 & Anger + Anticipation \\
\hline q3 & Sadness + Disgust & q21 & Sadness + Disgust \\
\hline q4 & Anger + Anticipation & q22 & Joy \\
\hline q5 & Rage + Vigilance & q23 & Ecstasy \\
\hline q6 & Disgust + Anger & q24 & Grief \\
\hline q7 & Anticipation + Joy & q25 & Anger + Anticipation \\
\hline q8 & Anticipation + Joy & q26 & Terror \\
\hline q9 & Joy & q27 & Terror \\
\hline q10 & Sadness & q28 & Anticipation + Joy \\
\hline q11 & Trust + Fear & q29 & Anger + Anticipation \\
\hline q12 & Trust + Fear & q30 & Joy \\
\hline q13 & Anger + Anticipation & q31 & Joy \\
\hline q14 & Joy + Anticipation & q32 & Joy \\
\hline q15 & Ecstasy & q33 & Ecstasy \\
\hline q16 & Ecstasy + Admiration & q34 & Ecstasy + Trust \\
\hline q17 & Ecstasy + Trust & q35 & Grief \\
\hline q18 & Grief + Surprise & q36 & Anticipation \\
\hline
\end{tabular}

Table VI.4: Dramatic Curves for The Princess and the Dragon events 
knights of the Gray Castle. Not far away in the sinister Red Castle, lurched Draco, the evil dragon, ready to seize the princess, despite her guardians, and keep her with super-human strength. But there was also the silent wizard of the Green Forest, Turjan the mage. Whoever approached him with due courtesy could hope for a gift of great fighting power. Uncountable stories can be told in this world of fantasy. Will the princess be abducted by the dragon? Or killed by the monster? Will one of the knights save her or revenge her death, with or without the mage's help? The outcome can be sad, but can also be merry, with the princess and her lover (Brian? Hoel?) getting married in the Church and living happilly ever after."

The results are presented below. In Tables VI.8, VI.9 and VI.10, the first column represents the method used to generate the story, the second column represents the payoff calculated after generating the story and the third column presents its sequence of events $\pi$

Table VI.8 presents the resulting stories for the first group of instances 14. For these instances we expect that the majority of individuals that support a specific preference is able to convince the others after the social interaction. The instance "Admiration" selected the fastest way to love (Ecstasy + Admiration). Brian kills his rival (Hoel) and marries Marian (ending event q16). In general, all instances are consistent with the prevailing emotions. Instances like "Amazement", "Ecstasy" and "Grief" selected their best ending events $\left(\mathrm{q} 18=\right.$ Grief + Surprise $^{15}, \mathrm{q} 34=$ Ecstasy + Trust and $\mathrm{q} 35=$ Grief $)$. Although the payoff of the quadratic function is lower than the payoff of the original instance (initial preferences of the audience), the Gaussian function improved the results for all instances. Although we did not perform an extensive analysis of case studies, the results in tables VI.5 to VI.10 show the superiority of the social interaction model (in the Gaussian case). In fact, the social module produces higher payoff values than the ones found in the case without interactions between individuals (which we call "original" case to emphasize that the individuals stay in their original position in the emotional preference space).

Table VI.9 presents the resulting stories for the second group of instances ${ }^{16}$. For these instances it is expected that the opinion leader is able to convince the others after the social interaction. Again, the instance "ind Rage" selects a happy ending (in this case q34). Analyzing the results of the sequence $\pi:\{\mathrm{q} 0, \mathrm{q} 1, \mathrm{q} 3, \mathrm{q} 4, \mathrm{q} 6, \mathrm{q} 8, \mathrm{q} 11, \mathrm{q} 20, \mathrm{q} 21, \mathrm{q} 22, \mathrm{q} 23, \mathrm{q} 34\}$, it was revealed that several events have the anger emotion (events q4, q6 and q20) that satisfied this audience.

\footnotetext{
${ }^{14}$ Total of 8 entirely mixed audiences with $60 \%$ of individuals supporting a specific emotion

${ }^{15}$ Surprise is in amazement axis

${ }^{16}$ Total of 4 mixed audiences with one opinion leader
} 
Table VI.10 presents the resulting stories for the third group of instances $^{17}$. For these instances we expect better results after social interaction.

\section{Admiration}

\begin{tabular}{|c|c|l|}
\hline Original & 7.31 & $\pi$ : EV 1, EV 2, EV 3, EV 4, EV 5, EV 7, EV 8, EV 9, EV 10, EV 17, EV 19 \\
\hline Quadratic & 7.97 & $\pi:$ EV 1, EV 2, EV 3, EV 4, EV 5, EV 7, EV 8, EV 9, EV 10, EV 17, EV 19 \\
\hline Gaussian & 16.84 & $\begin{array}{l}\text { m: EV 1, EV 2, EV 3, EV 4, EV 5, EV 7, EV 8, EV 9, EV 10, EV 17, EV 11, } \\
\text { EV 13, EV 16, EV 12 }\end{array}$ \\
\hline
\end{tabular}

\section{Amazement}

\begin{tabular}{|c|c|l|}
\hline Original & 1.49 & $\pi:$ EV 1, EV 2, EV 3, EV 4, EV 6, EV 11, EV 13, EV 16, EV 12 \\
\hline Quadratic & 6.56 & $\pi:$ EV 1, EV 2, EV 3, EV 4, EV 6, EV 11, EV 13, EV 16, EV 12 \\
\hline Gaussian & 5.11 & $\begin{array}{l}\pi: \text { EV 1, EV 2, EV 3, EV 4, EV 5, EV 7, EV 8, EV 9, EV 10, EV 17, } \\
\text { EV 11, EV 13, EV 16, EV 12 }\end{array}$ \\
\hline
\end{tabular}

Ecstasy

\begin{tabular}{|c|c|c|}
\hline Original & 6.98 & $\begin{array}{l}\pi: \mathrm{EV} 1, \mathrm{EV} 2, \mathrm{EV} 3, \mathrm{EV} 4, \mathrm{EV} 5, \mathrm{EV} 7, \mathrm{EV} 8, \mathrm{EV} 9, \mathrm{EV} 10, \mathrm{EV} 17, \\
\mathrm{EV} 11, \mathrm{EV} 13, \mathrm{EV} 15\end{array}$ \\
\hline Quadratic & 60.04 & $\pi: \operatorname{EV} 1, \operatorname{EV} 2, \operatorname{EV} 3, \mathrm{EV} 4, \mathrm{EV} 5, \mathrm{EV} 7, \mathrm{EV} 8, \mathrm{EV} 9, \mathrm{EV} 10, \mathrm{EV} 17, \mathrm{EV} 19$ \\
\hline Gaussian & 15.47 & $\begin{array}{l}\pi: \mathrm{EV} 1, \mathrm{EV} 2, \mathrm{EV} 3, \mathrm{EV} 4, \mathrm{EV} 5, \mathrm{EV} 7, \mathrm{EV} 8, \mathrm{EV} 9, \mathrm{EV} 10, \mathrm{EV} 17, \\
\mathrm{EV} 11, \mathrm{EV} 13, \mathrm{EV} 15\end{array}$ \\
\hline
\end{tabular}

\section{Grief}

\begin{tabular}{|c|c|l|}
\hline Original & 1.81 & $\begin{array}{l}\pi: \text { EV 1, EV 2, EV 3, EV 4, EV 5, EV 7, EV 8, EV 9, EV 10, EV 17, } \\
\text { EV 11, EV 13, EV 16, EV 12 }\end{array}$ \\
\hline Quadratic & 0.47 & $\begin{array}{l}\pi: \text { EV 1, EV 2, EV 3, EV 4, EV 5, EV 7, EV 8, EV 9, EV 10, EV 17, } \\
\text { EV 11, EV 13, EV 15 }\end{array}$ \\
\hline Gaussian & 6.16 & $\pi:$ EV 1, EV 2, EV 3, EV 4, EV 6, EV 20 \\
\hline
\end{tabular}

\section{Loathing}

\begin{tabular}{|c|c|l|}
\hline Original & 2.35 & $\pi:$ EV 1, EV 2, EV 3, EV 4, EV 6, EV 20 \\
\hline Quadratic & 10.09 & $\pi:$ EV 1, EV 2, EV 3, EV 4, EV 6, EV 20 \\
\hline Gaussian & 10.69 & $\pi:$ EV 1, EV 2, EV 3, EV 4, EV 6, EV 20 \\
\hline
\end{tabular}

\section{Rage}

\begin{tabular}{|c|c|l|}
\hline Original & 11.42 & $\pi:$ EV 1, EV 2, EV 3, EV 4, EV 6, EV 11, EV 13, EV 16, EV 12 \\
\hline Quadratic & 19.12 & $\pi:$ EV 1, EV 2, EV 3, EV 4, EV 6, EV 11, EV 13, EV 15 \\
\hline Gaussian & 13.38 & $\pi:$ EV 1, EV 2, EV 3, EV 4, EV 6, EV 11, EV 13, EV 15 \\
\hline
\end{tabular}

\section{Terror}

\begin{tabular}{|c|c|c|}
\hline Original & 5.23 & $\begin{array}{l}\pi: \text { EV 1, EV 2, EV 3, EV 4, EV 5, EV 7, EV 8, EV 9, EV 10, EV 17, } \\
\text { EV 11, EV 13, EV 16, EV } 12\end{array}$ \\
\hline Quadratic & 4.96 & $\pi: \operatorname{EV} 1, \mathrm{EV} 2, \mathrm{EV} 3, \mathrm{EV} 4, \mathrm{EV} 6, \mathrm{EV} 20$ \\
\hline Gaussian & 6.46 & $\begin{array}{l}\pi: \mathrm{EV} 1, \mathrm{EV} 2, \mathrm{EV} 3, \mathrm{EV} 4, \mathrm{EV} 5, \mathrm{EV} 7, \mathrm{EV} 8, \mathrm{EV} 9, \mathrm{EV} 10, \mathrm{EV} 17, \\
\mathrm{EV} 11, \mathrm{EV} 13, \mathrm{EV} 16, \mathrm{EV} 12\end{array}$ \\
\hline
\end{tabular}

\section{Vigilance}

\begin{tabular}{|c|c|l|}
\hline Original & 9.07 & $\pi$ : EV 1, EV 2, EV 3, EV 4, EV 6, EV 11, EV 13, EV 15 \\
\hline Quadratic & 7.84 & $\begin{array}{l}\pi: \text { EV 1, EV 2, EV 3, EV 4, EV 5, EV 7, EV 8, EV 9, EV 10, EV 17, } \\
\text { EV 19 }\end{array}$ \\
\hline Gaussian & 20.86 & $\pi:$ EV 1, EV 2, EV 3, EV 4, EV 6, EV 11, EV 13, EV 15 \\
\hline
\end{tabular}

Table VI.5: Little Red Cap selected stories using 8 entirely mixed audiences instances with $60 \%$ of individuals supporting a specific emotion

\footnotetext{
${ }^{17}$ Total of 4 random audiences
} 


\section{ind ecstasy}

\begin{tabular}{|c|c|c|}
\hline Original & 11.04 & $\pi: \operatorname{EV} 1, \operatorname{EV} 2, \operatorname{EV} 3, \mathrm{EV} 4, \mathrm{EV} 5, \mathrm{EV} 7, \mathrm{EV} 8, \mathrm{EV} 9, \mathrm{EV} 10, \mathrm{EV} 17, \mathrm{EV} 19$ \\
\hline Quadratic & 10.25 & $\begin{array}{l}\pi: \mathrm{EV} 1, \mathrm{EV} 2, \mathrm{EV} 3, \mathrm{EV} 4, \mathrm{EV} 5, \mathrm{EV} 7, \mathrm{EV} 8, \mathrm{EV} 9, \mathrm{EV} 10, \mathrm{EV} 17, \\
\mathrm{EV} 11, \mathrm{EV} 13, \mathrm{EV} 16, \mathrm{EV} 12\end{array}$ \\
\hline Gaussian & 10.63 & $\begin{array}{l}\pi \text { : EV 1, EV 2, EV 3, EV 4, EV 5, EV 7, EV 8, EV 9, EV 10, EV 17, } \\
\text { EV 11, EV 13, EV 15 }\end{array}$ \\
\hline
\end{tabular}

\section{ind grief}

\begin{tabular}{|c|c|l|}
\hline Original & 7.06 & $\pi:$ EV 1, EV 2, EV 3, EV 4, EV 5, EV 7, EV 8, EV 9, EV 10, EV 17, EV 19 \\
\hline Quadratic & 1.16 & $\pi:$ EV 1, EV 2, EV 3, EV 4, EV 5, EV 7, EV 8, EV 9, EV 10, EV 17, EV 19 \\
\hline Gaussian & 4.54 & $\begin{array}{l}\pi: \text { EV 1, EV 2, EV 3, EV 4, EV 5, EV 7, EV 8, EV 9, EV 10, EV 17, } \\
\text { EV 11, EV 13, EV 16, EV 12 }\end{array}$ \\
\hline
\end{tabular}

\section{ind rage}

\begin{tabular}{|c|c|l|}
\hline Original & 12.73 & $\pi$ : EV 1, EV 2, EV 3, EV 4, EV 5, EV 7, EV 8, EV 9, EV 10, EV 17, EV 19 \\
\hline Quadratic & 1.64 & $\pi: \mathrm{EV} 1, \mathrm{EV} 2, \mathrm{EV} 3, \mathrm{EV} 4, \mathrm{EV} 6, \mathrm{EV} 20$ \\
\hline Gaussian & 7.49 & $\pi: \mathrm{EV} 1, \mathrm{EV} 2, \mathrm{EV} 3, \mathrm{EV} 4, \mathrm{EV} 6, \mathrm{EV} 11, \mathrm{EV} 13, \mathrm{EV} 15$ \\
\hline
\end{tabular}

\section{ind terror}

\begin{tabular}{|c|c|l|}
\hline Original & 7.63 & $\pi: \mathrm{EV} 1, \mathrm{EV} 2, \mathrm{EV} 3, \mathrm{EV} 4, \mathrm{EV} 6, \mathrm{EV} 20$ \\
\hline Quadratic & 9.04 & $\pi: \mathrm{EV} 1, \mathrm{EV} 2, \mathrm{EV} 3, \mathrm{EV} 4, \mathrm{EV} 5, \mathrm{EV} 7, \mathrm{EV} 8, \mathrm{EV} 9, \mathrm{EV} 10, \mathrm{EV} 17, \mathrm{EV} 19$ \\
\hline Gaussian & 9.15 & $\pi: \mathrm{EV} 1, \mathrm{EV} 2, \mathrm{EV} 3, \mathrm{EV} 4, \mathrm{EV} 5, \mathrm{EV} 7, \mathrm{EV}$ 8, EV 9, EV 10, EV 17, EV 19 \\
\hline
\end{tabular}

Table VI.6: Little Red Cap selected stories using 4 mixed audiences with one opinion leader

\section{Instance1}

\begin{tabular}{|c|c|c|}
\hline Original & 8.93 & $\begin{array}{l}\pi: \mathrm{EV} 1, \mathrm{EV} 2, \mathrm{EV} 3, \mathrm{EV} 4, \mathrm{EV} 5, \mathrm{EV} 7, \mathrm{EV} 8, \mathrm{EV} 9, \mathrm{EV} 10, \mathrm{EV} 17, \mathrm{EV} \\
11, \mathrm{EV} 13, \mathrm{EV} 16, \mathrm{EV} 12\end{array}$ \\
\hline Quadratic & 10.81 & $\begin{array}{l}\pi: \mathrm{EV} 1, \mathrm{EV} 2, \mathrm{EV} 3, \mathrm{EV} 4, \mathrm{EV} 5, \mathrm{EV} 7, \mathrm{EV} 8, \mathrm{EV} 9, \mathrm{EV} 10, \mathrm{EV} 17, \mathrm{EV} \\
11, \mathrm{EV} 13, \mathrm{EV} 16, \mathrm{EV} 12\end{array}$ \\
\hline Gaus & 14.16 & $\mathrm{~V} 2, \mathrm{EV} 3, \mathrm{EV} 4$ \\
\hline
\end{tabular}

\section{Instance 2}

\begin{tabular}{|c|c|l|}
\hline Original & 16.78 & $\begin{array}{l}\pi: \mathrm{EV} 1, \mathrm{EV} 2, \mathrm{EV} 3, \mathrm{EV} 4, \mathrm{EV} 5, \mathrm{EV} 7, \mathrm{EV} \text { 8, EV 9, EV 10, EV 17, EV } \\
11, \mathrm{EV} 13, \mathrm{EV} 16, \mathrm{EV} 12\end{array}$ \\
\hline Quadratic & 29.25 & $\begin{array}{l}\text { m: EV 1, EV 2, EV 3, EV 4, EV 5, EV 7, EV 8, EV 9, EV 10, EV 17, EV } \\
11, \mathrm{EV} 13, \mathrm{EV} 16, \mathrm{EV} 12\end{array}$ \\
\hline Gaussian & 30.67 & $\begin{array}{l}\text { m: EV 1, EV 2, EV 3, EV 4, EV 5, EV 7, EV 8, EV 9, EV 10, EV 17, EV } \\
11, \mathrm{EV} 13, \mathrm{EV} 16, \mathrm{EV} 12\end{array}$ \\
\hline
\end{tabular}

\section{Instance3}

\begin{tabular}{|c|c|l|}
\hline Original & 7.13 & $\pi:$ EV 1, EV 2, EV 3, EV 4, EV 6, EV 11, EV 13, EV 15 \\
\hline Quadratic & 8.43 & $\pi:$ EV 1, EV 2, EV 3, EV 4, EV 6, EV 11, EV 13, EV 15 \\
\hline Gaussian & 10.6 & $\pi:$ EV 1, EV 2, EV 3, EV 4, EV 6, EV 11, EV 13, EV 15 \\
\hline
\end{tabular}

\section{Instance 4}

\begin{tabular}{|c|c|l|}
\hline Original & 7.97 & $\pi$ : EV 1, EV 2, EV 3, EV 4, EV 5, EV 7, EV 8, EV 9, EV 10, EV 17, EV 19 \\
\hline Quadratic & 10.72 & $\pi:$ EV 1, EV 2, EV 3, EV 4, EV 6, EV 20 \\
\hline Gaussian & 13.99 & $\pi:$ EV 1, EV 2, EV 3, EV 4, EV 6, EV 11, EV 13, EV 16, EV 12 \\
\hline
\end{tabular}

Table VI.7: Little Red Cap selected stories using 4 random audiences 


\section{Admiration}

\begin{tabular}{|c|c|l|}
\hline Original & 4.08 & $\pi: \mathrm{q} 0, \mathrm{q} 1, \mathrm{q} 2, \mathrm{q} 4, \mathrm{q} 5, \mathrm{q} 7, \mathrm{q} 9, \mathrm{q} 13, \mathrm{q} 14, \mathrm{q} 15, \mathrm{q} 17, \mathrm{q} 16$ \\
\hline Quadratic & 0.69 & $\pi: \mathrm{q} 0, \mathrm{q} 1, \mathrm{q} 2, \mathrm{q} 4, \mathrm{q} 5, \mathrm{q} 7, \mathrm{q} 9, \mathrm{q} 13, \mathrm{q} 14, \mathrm{q} 15, \mathrm{q} 17, \mathrm{q} 16$ \\
\hline Gaussian & 7.31 & $\pi: \mathrm{q} 0, \mathrm{q} 1, \mathrm{q} 2, \mathrm{q} 4, \mathrm{q} 5, \mathrm{q} 7, \mathrm{q} 9, \mathrm{q} 13, \mathrm{q} 14, \mathrm{q} 15, \mathrm{q} 17, \mathrm{q} 16$ \\
\hline
\end{tabular}

\section{Amazement}

\begin{tabular}{|c|l|l|}
\hline Original & 6.44 & $\pi: \mathrm{q} 0, \mathrm{q} 1, \mathrm{q} 3, \mathrm{q} 4, \mathrm{q} 5, \mathrm{q} 7, \mathrm{q} 9, \mathrm{q} 13, \mathrm{q} 18$ \\
\hline Quadratic & 7.68 & $\pi: \mathrm{q} 0, \mathrm{q} 1, \mathrm{q} 2, \mathrm{q} 4, \mathrm{q} 5, \mathrm{q} 7, \mathrm{q} 9, \mathrm{q} 13, \mathrm{q} 14, \mathrm{q} 15, \mathrm{q} 17, \mathrm{q} 16$ \\
\hline Gaussian & 8.64 & $\pi: \mathrm{q} 0, \mathrm{q} 1, \mathrm{q} 2, \mathrm{q} 4, \mathrm{q} 5, \mathrm{q} 7, \mathrm{q} 9, \mathrm{q} 13, \mathrm{q} 18$ \\
\hline
\end{tabular}

\section{Ecstasy}

\begin{tabular}{|c|l|l|}
\hline Original & 4.63 & $\pi: \mathrm{q} 0, \mathrm{q} 1, \mathrm{q} 3, \mathrm{q} 4, \mathrm{q} 6, \mathrm{q} 25, \mathrm{q} 10, \mathrm{q} 28, \mathrm{q} 30, \mathrm{q} 32, \mathrm{q} 33, \mathrm{q} 34$ \\
\hline Quadratic & 4.41 & $\pi: \mathrm{q} 0, \mathrm{q} 1, \mathrm{q} 2, \mathrm{q} 4, \mathrm{q} 6, \mathrm{q} 25, \mathrm{q} 10, \mathrm{q} 28, \mathrm{q} 30, \mathrm{q} 32, \mathrm{q} 33, \mathrm{q} 34$ \\
\hline Gaussian & 6.48 & $\pi: \mathrm{q} 0, \mathrm{q} 1, \mathrm{q} 2, \mathrm{q} 4, \mathrm{q} 6, \mathrm{q} 25, \mathrm{q} 10, \mathrm{q} 28, \mathrm{q} 29, \mathrm{q} 31, \mathrm{q} 32, \mathrm{q} 33, \mathrm{q} 34$ \\
\hline
\end{tabular}

\section{Grief}

\begin{tabular}{|c|c|l|}
\hline Original & 5.93 & $\pi: \mathrm{q} 0, \mathrm{q} 1, \mathrm{q} 3, \mathrm{q} 4, \mathrm{q} 6, \mathrm{q} 25, \mathrm{q} 10, \mathrm{q} 28, \mathrm{q} 30, \mathrm{q} 35$ \\
\hline Quadratic & 5.96 & $\pi: \mathrm{q} 0, \mathrm{q} 1, \mathrm{q} 2, \mathrm{q} 4, \mathrm{q} 5, \mathrm{q} 7, \mathrm{q} 9, \mathrm{q} 13, \mathrm{q} 18$ \\
\hline Gaussian & 7.07 & $\pi: \mathrm{q} 0, \mathrm{q} 1, \mathrm{q} 2, \mathrm{q} 4, \mathrm{q} 6, \mathrm{q} 25, \mathrm{q} 10, \mathrm{q} 28, \mathrm{q} 30, \mathrm{q} 35$ \\
\hline
\end{tabular}

\section{Loathing}

\begin{tabular}{|c|l|l|}
\hline Original & 2.17 & $\pi: \mathrm{q} 0, \mathrm{q} 1, \mathrm{q} 2, \mathrm{q} 4, \mathrm{q} 5, \mathrm{q} 36, \mathrm{q} 26, \mathrm{q} 27$ \\
\hline Quadratic & 2.29 & $\pi: \mathrm{q} 0, \mathrm{q} 1, \mathrm{q} 2, \mathrm{q} 4, \mathrm{q} 6, \mathrm{q} 25, \mathrm{q} 10, \mathrm{q} 28, \mathrm{q} 29, \mathrm{q} 31, \mathrm{q} 35$ \\
\hline Gaussian & 3.41 & $\pi: \mathrm{q} 0, \mathrm{q} 1, \mathrm{q} 2, \mathrm{q} 4, \mathrm{q} 6, \mathrm{q} 25, \mathrm{q} 10, \mathrm{q} 28, \mathrm{q} 29, \mathrm{q} 31, \mathrm{q} 35$ \\
\hline
\end{tabular}

\section{Rage}

\begin{tabular}{|c|c|l|}
\hline Original & 8.78 & $\pi: \mathrm{q} 0, \mathrm{q} 1, \mathrm{q} 3, \mathrm{q} 4, \mathrm{q} 5, \mathrm{q} 7, \mathrm{q} 9, \mathrm{q} 13, \mathrm{q} 14, \mathrm{q} 15, \mathrm{q} 17, \mathrm{q} 16$ \\
\hline Quadratic & 9.81 & $\pi: \mathrm{q} 0, \mathrm{q} 1, \mathrm{q} 3, \mathrm{q} 4, \mathrm{q} 5, \mathrm{q} 7, \mathrm{q} 9, \mathrm{q} 13, \mathrm{q} 14, \mathrm{q} 15, \mathrm{q} 17, \mathrm{q} 16$ \\
\hline Gaussian & 12.63 & $\pi: \mathrm{q} 0, \mathrm{q} 1, \mathrm{q} 3, \mathrm{q} 4, \mathrm{q} 5, \mathrm{q} 7, \mathrm{q} 9, \mathrm{q} 13, \mathrm{q} 14, \mathrm{q} 15, \mathrm{q} 17, \mathrm{q} 16$ \\
\hline
\end{tabular}

\section{Terror}

\begin{tabular}{|c|c|l|}
\hline Original & 3.53 & $\pi: \mathrm{q} 0, \mathrm{q} 1, \mathrm{q} 2, \mathrm{q} 4, \mathrm{q} 5, \mathrm{q} 7, \mathrm{q} 9, \mathrm{q} 13, \mathrm{q} 14, \mathrm{q} 15, \mathrm{q} 17, \mathrm{q} 16$ \\
\hline Quadratic & 4.13 & $\pi: \mathrm{q} 0, \mathrm{q} 1, \mathrm{q} 2, \mathrm{q} 4, \mathrm{q} 5, \mathrm{q} 7, \mathrm{q} 9, \mathrm{q} 13, \mathrm{q} 18$ \\
\hline Gaussian & 11.16 & $\pi: \mathrm{q} 0, \mathrm{q} 1, \mathrm{q} 2, \mathrm{q} 4, \mathrm{q} 5, \mathrm{q} 36, \mathrm{q} 26, \mathrm{q} 27$ \\
\hline
\end{tabular}

\section{Vigilance}

\begin{tabular}{|c|c|l|}
\hline Original & 5.47 & $\pi: \mathrm{q} 0, \mathrm{q} 1, \mathrm{q} 3, \mathrm{q} 4, \mathrm{q} 5, \mathrm{q} 7, \mathrm{q} 9, \mathrm{q} 13, \mathrm{q} 14, \mathrm{q} 15, \mathrm{q} 17, \mathrm{q} 16$ \\
\hline Quadratic & 0.85 & $\pi: \mathrm{q} 0, \mathrm{q} 1, \mathrm{q} 2, \mathrm{q} 4, \mathrm{q} 6, \mathrm{q} 25, \mathrm{q} 10, \mathrm{q} 28, \mathrm{q} 30, \mathrm{q} 32, \mathrm{q} 33, \mathrm{q} 34$ \\
\hline Gaussian & 12.18 & $\pi: \mathrm{q} 0, \mathrm{q} 1, \mathrm{q} 3, \mathrm{q} 4, \mathrm{q} 5, \mathrm{q} 7, \mathrm{q} 9, \mathrm{q} 13, \mathrm{q} 14, \mathrm{q} 15, \mathrm{q} 17, \mathrm{q} 16$ \\
\hline
\end{tabular}

Table VI.8: The Princess and the Dragon selected stories using 8 entirely mixed audiences instances with $60 \%$ of individuals supporting a specific emotion 


\begin{tabular}{|c|c|l|}
\hline \multicolumn{3}{c|}{ ind ecstasy } \\
\hline Original & 4.24 & $\pi: \mathrm{q} 0, \mathrm{q} 1, \mathrm{q} 2, \mathrm{q} 4, \mathrm{q} 6, \mathrm{q} 25, \mathrm{q} 10, \mathrm{q} 28, \mathrm{q} 30, \mathrm{q} 35$ \\
\hline Quadratic & 9.99 & $\pi: \mathrm{q} 0, \mathrm{q} 1, \mathrm{q} 2, \mathrm{q} 4, \mathrm{q} 6, \mathrm{q} 25, \mathrm{q} 10, \mathrm{q} 28, \mathrm{q} 30, \mathrm{q} 32, \mathrm{q} 33, \mathrm{q} 34$ \\
\hline Gaussian & 12.86 & $\pi: \mathrm{q} 0, \mathrm{q} 1, \mathrm{q} 3, \mathrm{q} 4, \mathrm{q} 6, \mathrm{q} 25, \mathrm{q} 10, \mathrm{q} 28, \mathrm{q} 30, \mathrm{q} 32, \mathrm{q} 33, \mathrm{q} 34$ \\
\hline
\end{tabular}

\section{ind grief}

\begin{tabular}{|c|c|l|}
\hline Original & 4.18 & $\pi: \mathrm{q} 0, \mathrm{q} 1, \mathrm{q} 2, \mathrm{q} 4, \mathrm{q} 6, \mathrm{q} 25, \mathrm{q} 10, \mathrm{q} 28, \mathrm{q} 30, \mathrm{q} 32, \mathrm{q} 33, \mathrm{q} 34$ \\
\hline Quadratic & 7.82 & $\pi: \mathrm{q} 0, \mathrm{q} 1, \mathrm{q} 2, \mathrm{q} 4, \mathrm{q} 6, \mathrm{q} 25, \mathrm{q} 10, \mathrm{q} 28, \mathrm{q} 30, \mathrm{q} 35$ \\
\hline Gaussian & 12.57 & $\pi: \mathrm{q} 0, \mathrm{q} 1, \mathrm{q} 2, \mathrm{q} 4, \mathrm{q} 6, \mathrm{q} 25, \mathrm{q} 10, \mathrm{q} 28, \mathrm{q} 30, \mathrm{q} 35$ \\
\hline
\end{tabular}

ind rage

\begin{tabular}{|c|c|l|}
\hline Original & 5 & $\pi: \mathrm{q} 0, \mathrm{q} 1, \mathrm{q} 2, \mathrm{q} 4, \mathrm{q} 6, \mathrm{q} 25, \mathrm{q} 10, \mathrm{q} 28, \mathrm{q} 29, \mathrm{q} 31, \mathrm{q} 35$ \\
\hline Quadratic & 3.25 & $\pi: \mathrm{q} 0, \mathrm{q} 1, \mathrm{q} 3, \mathrm{q} 4, \mathrm{q} 5, \mathrm{q} 7, \mathrm{q} 12, \mathrm{q} 19, \mathrm{q} 24$ \\
\hline Gaussian & 5.6 & $\pi: \mathrm{q} 0, \mathrm{q} 1, \mathrm{q} 3, \mathrm{q} 4, \mathrm{q} 6, \mathrm{q} 8, \mathrm{q} 11, \mathrm{q} 20, \mathrm{q} 21, \mathrm{q} 22, \mathrm{q} 23, \mathrm{q} 34$ \\
\hline
\end{tabular}

\section{ind terror}

\begin{tabular}{|c|c|l|}
\hline Original & 4.5 & $\pi: \mathrm{q} 0, \mathrm{q} 1, \mathrm{q} 3, \mathrm{q} 4, \mathrm{q} 6, \mathrm{q} 8, \mathrm{q} 11, \mathrm{q} 20, \mathrm{q} 21, \mathrm{q} 22, \mathrm{q} 23, \mathrm{q} 34$ \\
\hline Quadratic & 11.01 & $\pi: \mathrm{q} 0, \mathrm{q} 1, \mathrm{q} 2, \mathrm{q} 4, \mathrm{q} 5, \mathrm{q} 36, \mathrm{q} 26, \mathrm{q} 27$ \\
\hline Gaussian & 16.8 & $\pi: \mathrm{q} 0, \mathrm{q} 1, \mathrm{q} 3, \mathrm{q} 4, \mathrm{q} 5, \mathrm{q} 36, \mathrm{q} 26, \mathrm{q} 27$ \\
\hline
\end{tabular}

Table VI.9: The Princess and the Dragon selected stories using 4 mixed audiences with one opinion leader

\section{Instance1}

\begin{tabular}{|c|c|l|}
\hline Original & 3.08 & $\pi: \mathrm{q} 0, \mathrm{q} 1, \mathrm{q} 2, \mathrm{q} 4, \mathrm{q} 6, \mathrm{q} 25, \mathrm{q} 10, \mathrm{q} 28, \mathrm{q} 30, \mathrm{q} 32, \mathrm{q} 33, \mathrm{q} 34$ \\
\hline Quadratic & 9.26 & $\pi: \mathrm{q} 0, \mathrm{q} 1, \mathrm{q} 3, \mathrm{q} 4, \mathrm{q} 5, \mathrm{q} 7, \mathrm{q} 9, \mathrm{q} 13, \mathrm{q} 14, \mathrm{q} 15, \mathrm{q} 17, \mathrm{q} 16$ \\
\hline Gaussian & 10.31 & $\pi: \mathrm{q} 0, \mathrm{q} 1, \mathrm{q} 2, \mathrm{q} 4, \mathrm{q} 5, \mathrm{q} 7, \mathrm{q} 9, \mathrm{q} 13, \mathrm{q} 14, \mathrm{q} 15, \mathrm{q} 17, \mathrm{q} 16$ \\
\hline
\end{tabular}

\section{Instance2}

\begin{tabular}{|c|c|l|}
\hline Original & 7.69 & $\pi: \mathrm{q} 0, \mathrm{q} 1, \mathrm{q} 2, \mathrm{q} 4, \mathrm{q} 5, \mathrm{q} 7, \mathrm{q} 9, \mathrm{q} 13, \mathrm{q} 14, \mathrm{q} 15, \mathrm{q} 17, \mathrm{q} 16$ \\
\hline Quadratic & 11.43 & $\pi: \mathrm{q} 0, \mathrm{q} 1, \mathrm{q} 2, \mathrm{q} 4, \mathrm{q} 5, \mathrm{q} 7, \mathrm{q} 9, \mathrm{q} 13, \mathrm{q} 14, \mathrm{q} 15, \mathrm{q} 17, \mathrm{q} 16$ \\
\hline Gaussian & 11.93 & $\pi: \mathrm{q} 0, \mathrm{q} 1, \mathrm{q} 2, \mathrm{q} 4, \mathrm{q} 5, \mathrm{q} 7, \mathrm{q} 9, \mathrm{q} 13, \mathrm{q} 14, \mathrm{q} 15, \mathrm{q} 17, \mathrm{q} 16$ \\
\hline
\end{tabular}

\section{Instance3}

\begin{tabular}{|c|l|l|}
\hline Original & 5.07 & $\pi: \mathrm{q} 0, \mathrm{q} 1, \mathrm{q} 2, \mathrm{q} 4, \mathrm{q} 6, \mathrm{q} 25, \mathrm{q} 10, \mathrm{q} 28, \mathrm{q} 29, \mathrm{q} 31, \mathrm{q} 35$ \\
\hline Quadratic & 7.13 & $\pi: \mathrm{q} 0, \mathrm{q} 1, \mathrm{q} 3, \mathrm{q} 4, \mathrm{q} 6, \mathrm{q} 25, \mathrm{q} 10, \mathrm{q} 28, \mathrm{q} 30, \mathrm{q} 32, \mathrm{q} 33, \mathrm{q} 34$ \\
\hline Gaussian & 7.59 & $\pi: \mathrm{q} 0, \mathrm{q} 1, \mathrm{q} 3, \mathrm{q} 4, \mathrm{q} 6, \mathrm{q} 8, \mathrm{q} 11, \mathrm{q} 20, \mathrm{q} 21, \mathrm{q} 22, \mathrm{q} 23, \mathrm{q} 34$ \\
\hline
\end{tabular}

\section{Instance 4}

\begin{tabular}{|c|c|l|}
\hline Original & 6.1 & $\pi: \mathrm{q} 0, \mathrm{q} 1, \mathrm{q} 3, \mathrm{q} 4, \mathrm{q} 6, \mathrm{q} 25, \mathrm{q} 10, \mathrm{q} 28, \mathrm{q} 29, \mathrm{q} 31, \mathrm{q} 35$ \\
\hline Quadratic & 10.13 & $\pi: \mathrm{q} 0, \mathrm{q} 1, \mathrm{q} 3, \mathrm{q} 4, \mathrm{q} 6, \mathrm{q} 25, \mathrm{q} 10, \mathrm{q} 28, \mathrm{q} 29, \mathrm{q} 31, \mathrm{q} 35$ \\
\hline Gaussian & 11.25 & $\pi: \mathrm{q} 0, \mathrm{q} 1, \mathrm{q} 3, \mathrm{q} 4, \mathrm{q} 6, \mathrm{q} 25, \mathrm{q} 10, \mathrm{q} 28, \mathrm{q} 29, \mathrm{q} 31, \mathrm{q} 32, \mathrm{q} 33, \mathrm{q} 34$ \\
\hline
\end{tabular}

Table VI.10: The Princess and the Dragon selected stories using 4 random audiences 


\section{VII \\ Closure}

The present thesis investigate the influence of the social factors in each individual and his/her entire group. The main objective of this research was to propose a model that could cover group decisions in interactive storytelling applications based on the prior knowledge of the audience. In this context, the individuals' information about preferences and relationships is obtained from social networks and submitted to an audience analysis procedure. This procedure determines the scenes (events) that maximize the audience's preferences, taking into account the usual emotional state of the persons and their personality traits.

While writing the story, the author should classify each scene by defining a point in a 2D space of genres, which is called emotional preference space in the present work. These genres were related to the main emotions of the scene, in a 2D space based on the Plutchik's model (see III.2). This emotional information is used by the interactive storytelling application to select scenes that most please the audience and adapts the story automatically without the need for explicit audience interactions.

The audience should not be restricted to explicit interaction mechanisms (such as choosing actions, moving objects, ...) to interfere in the story, as it is usual in most interactive storytelling systems. In the present work, we propose a more ambitious concept, called "passive interactive storytelling", where the system senses the needs and desires of the audience in a natural and continuous way. In relation to the current work on interactive storytelling, this concept is more general than the idea of "passive interaction" by biometric monitoring, as proposed in [9].

In this section we present the final conclusions and some thoughts about future works.

\section{VII.1 Final Considerations}

This thesis is about situations involving interactive storytelling and game theory - two large research areas that have a multitude of applications. 
The proposed models consider two complex situations: N-person games and individuals with emotions and personality traits. Therefore, the present thesis contributes to the areas of behavioral game theory and interactive storytelling.

Although the number of subjects is small, the experimental part of the thesis reveals that the best results come from everyone in the group doing what is best for him/herself and also for the entire group. This is exactly what John Nash said, at least in the movie "A Beautiful Mind". Apart from this expected behavior, the social interaction model proposed by this thesis fulfilled the expectations we had in the beginning of the research work: a storytelling system that can gracefully consider the social interactions of people who have emotions and personality traits.

Some experiments were quite real. The office game proposed on V.4(a) is based on a real life situation we observed in the premises of the ICAD/VisionLab laboratory at PUC-Rio. When sharing the same laboratory, graduate students must agree on the average temperature of the room. The model predicted the exact air conditioning temperature, which then was set according to the present individuals, their preferences and personality traits.

There is no way of capturing the needs and desires of an audience without taking interrelationships into account - in other words, the forces of the social interactions shape the behavior of each individual. We have appreciated this fact by analyzing the results with and without social interactions. In fact, the tables in section VI.5 show better payoff values for the case that we consider social interactions.

Another important conclusion can be made about the role of opinion leaders. In fact, the opinion leaders we have created had a strong influence on the evolving story (section VI.5).

As far as we are aware, this is the first work in the literature that proposes a model for storytelling systems based on the social interactions of audiences, incorporating both emotions and personality traits in an N-person game situation. The future of this model is promising - especially when we think about other applications involving individuals who learn, socialize, and communicate themselves within digital environments.

\section{VII.2 Future Works}

As an important future work, we propose to investigate a model that can deal with a dynamic audience, in order to anticipate changes that inevitably occur in real audiences. The perceived payoffs calculated by the social interaction model depend on the relationship between individuals and impact the group decision. If the group composition changes, because some influential 
member enters or leaves it, this may impact the entire events selection and may change the sequence of events in a story. In section VI.4, we suggest that this dynamic model should deal with the probability of the perceived payoff change.

It is also necessary to carry out more relevant experiments, considering not only larger groups but also stories that truly draws the audience. Furthermore, we propose to incorporate more factors of emotional behavior, group interaction, and storytelling. The goal is to experiment thoroughly on a wide spectrum of stories and audiences.

Moreover, another important issue is to compare the current results with traditional game theory models. The cooperative models may be partially used to determine the coalitions of individuals in an audience who come together to cooperate against other coalitions in a majority voting game. This cooperative model must incorporate the concepts of personality traits proposed in chapter $\mathrm{V}$ in order to define the valuation functions and the perceived payoffs. The reader is referred to the current works on behavioral game theory discussed in the chapter about related works (Chapter II).

In a preliminary investigation, the proposed social interaction models were able to simulate the behavior of individuals in everyday decisions. The results we have obtained suggest that the proposed models can be used for modeling bargain games and detecting the contagion of a social group influenced by an opinion leader. It is important to validate the model by applying in other contexts in order to validate these results and model applications.

As the model of social interaction is based on the hypothesis that the perceived value of a subject can be changed in the social influence, it could be applied in other contexts. In fact, the proposed model can easily be extended to other areas that involve users interacting among themselves within digital environments. 


\section{Bibliography}

[1] FURTADO, A. L.; CASANOVA, M. A.; BARBOSA, S. D.; BREITMAN, K. K.. Analysis and reuse of plots using similarity and analogy. In: Li, Q.; Spaccapietra, S.; Yu, E.; Olivé, A., editors, CONCEPTUAL MODELING - ER 2008, v. 5231 of Lecture Notes in Computer Science, p. 355-368. Springer Berlin Heidelberg, 2008. I

[2] CIARLINI, A. E. M.; BARBOSA, S. D. J.; CASANOVA, M. A.; FURTADO, A. L.. Event relations in plan-based plot composition. Comput. Entertain., 7(4):55:1-55:37, Jan. 2010. I

[3] SZILAGYI, M. N.. Investigation of n-person games by agent-based modeling. Complex Systems, (21):201-243, 2012. I, II

[4] GINTIS, H.. Behavioral game theory and contemporary economic theory. Analyze \& Kritik, 21(1):48-72, 2005. I, II

[5] CAMERER, C. F.. Progress in behavioral game theory. Journal of Economic Perspectives, 11(4):167-188, 1997. I, II

[6] ARAUJO, E. T.; CIARLINI, A. E. M.. Verification of temporal constraints in continuous time on nondeterministic stories. In: PROCEEDINGS OF THE 10TH INTERNATIONAL CONFERENCE ON ENTERTAINMENT COMPUTING, 2011. I.1, II, III.1, VI.5, VI.5(a)

[7] CAMANHO, M.; CIARLINI, A.; FURTADO, A.; FEIJÓ, B.; POZZER, C.. A model for interactive tv storytelling. In: GAMES AND DIGITAL ENTERTAINMENT (SBGAMES), 2009 VIII BRAZILIAN SYMPOSIUM ON, p. 197-206, Oct 2009. I.1, VI.5

[8] CAMANHO, M.. A Model for Stream-based Interactive Storytelling. PhD thesis, Pontifícia Universidade Católica do Rio de Janeiro, Rio de Janeiro, 2014. I.2

[9] GILROY, S.; PORTEOUS, J.. Pinter: interactive storytelling with physiological input. Proceedings of the 2012, p. 333-334, 2012. I.2, VII 
[10] PLUTCHIK, R.. The emotions: Facts, theories, and a new model. New York, Random House, 1962. I.2, II, III.2

[11] PLUTCHIK, R.. A general psychoevolutionary theory of emotions. In: R. Plutchik \& H. Kellerman (Eds.), Emotion: Theory, research, and experience, Theories of emotion, 1980. I.2, II, III.2

[12] CURIEL, I.. Cooperative Game Theory and Applications: Cooperative Games Arising from Combinatorial Optimization Problems. Fundamental Theories of Physics. Springer, 1997. I.2, II, IV.5, IV.5(a), IV.5(a), IV.5(a), IV.5(b), IV.5(c), IV.5(d), IV.5(e), IV.5(f)

[13] ABELHA, P.; GOTTIN, V.; CIARLINI, A.; ARAUJO, E.; FURTADO, A.; FEIJO, B.; SILVA, F.; POZZER, C.. A nondeterministic temporal planning model for generating narratives with continuous change in interactive storytelling. In: AIIDE, 2013. II

[14] KARLSSON, B.; CIARLINI, A. E. M.; FEIJÓ, B.; FURTADO, A. L.. Applying a plan-recognition/plan-generation paradigm to interactive storytelling. In: IN WORKSHOP ON AI PLANNING FOR COMPUTER GAMES AND SYNTHETIC CHARACTERS, 2006. II, III, VI.5

[15] BARBOSA, S. D. J.; FURTADO, A. L.; CASANOVA, M. A.. A decisionmaking process for digital storytelling. 2010 Brazilian Symposium on Games and Digital Entertainment, 0:1-11, 2010. II

[16] GARBER-BARRON, M.; SI, M.. Towards interest and engagement, a framework for adaptive storytelling. AAAI Conference Proceedings, 2012. II, III.1

[17] PLUTCHIK, R.. The nature of emotions. American Scientist, 2001. II, III.2, III.2

[18] RODRIGUES, P.. Um Sistema de Geração de Expressões Faciais Dinâmicas em Animações Faciais 3D com Processamento de Fala. PhD thesis, Pontifícia Universidade Católica do Rio de Janeiro, Rio de Janeiro, 2007. II, III.2

[19] DAVIS, M.. A multidimensional approach to individual differences in empathy. JSAS Catalog of Selected Documents in Psychology, 10, 1980. II, IV.6, VI.1

[20] JOHN, P.; SRIVASTAVA, S.. The big-five trait taxonomy: History, measurement, and theoretical perspectives. In L. A. Pervin \& O. 
P. John (Eds.), Handbook of personality: Theory and research, 2:102138, 1999. II, V.2(a), V.2(a), V.2(a), V.2(a), V.2(a)

[21] KALLIAS, A.. Individual Differences and the Psychology of Film Preferences. PhD thesis, University of London, 2012. II, VI.1(a)

[22] MCCRAE, R.; COSTA, P.. Reinterpreting the myers-briggs type indicator from the perspective of the five-factor model of personality. Journal of Personality, 1989. II

[23] HAMMER, A.; BARGER, N.. Mbti applications: A decade of research on the myers-briggs type indicator, 1996. II

[24] KEIRSEY, D.. Please understand me ii: Temperament, character, intelligence, 1978. II

[25] LAWRENCE, G.; MARTIN, C.. Building people, building programs - a practitioner's guide for introducing the mbti to individuals and organizations. CAPT, 2001. II

[26] RICH, E.. User modeling via stereotypes. Cognitive Science 3, p. 329-354, 1979. II, V.2(a), VI.1

[27] JONES, E.; NISBETT, R.. The actor and the observer: Divergent perceptions of the causes of behavior, 1971. II, VI.1

[28] TUPES, C.; CHRISTAL, R.. Recurrent personality factors based on trait ratings. Technical report, Air Force Systems Command, 1961. II, V.2(a), VI.1(a)

[29] EGGES, A.; KSHIRSAGAR, S.; MAGNENAT-THALMANN, N.. A model for personality and emotion simulation. In: Palade, V.; Howlett, R. J.; Jain, L. C., editors, KES, v. 2773 of Lecture Notes in Computer Science, p. 453-461. Springer, 2003. II

[30] EGGES, A.; KSHIRSAGAR, S.; MAGNENAT-THALMANN, N.. Generic personality and emotion simulation for conversational agents: Research articles. Comput. Animat. Virtual Worlds, 15(1):1-13, Mar. 2004. II

[31] CHANDRA, A.. A computational architecture to model human emotions. In: INTELLIGENT INFORMATION SYSTEMS, 1997. IIS '97. PROCEEDINGS, p. 86-89, Dec 1997. ॥ 
[32] BECKER, C.; KOPP, S.; WACHSMUTH, I.. Simulating the emotion dynamics of a multimodal conversational agent. In: André, E.; Dybkjær, L.; Minker, W.; Heisterkamp, P., editors, AFFECTIVE DIALOGUE SYSTEMS, v. 3068 of Lecture Notes in Computer Science, p. 154165. Springer Berlin Heidelberg, 2004. II

[33] PARK, J.; KIM, W.; LEE, W.; CHUNG, M.. Artificial emotion generation based on personality, mood, and emotion for life-like facial expressions of robots. In: Forbrig, P.; Paternó, F.; Mark Pejtersen, A., editors, HUMAN-COMPUTER INTERACTION, v. 332 of IFIP Advances in Information and Communication Technology, p. 223233. Springer Berlin Heidelberg, 2010. II

[34] KASAP, Z.; BEN MOUSSA, M.; CHAUDHURI, P.; MAGNENATTHALMANN, N.. Making them remember: Emotional virtual characters with memory. Computer Graphics and Applications, IEEE, 29(2):20-29, March 2009. II

[35] KASAP, Z.; MAGNENAT-THALMANN, N.. Intelligent virtual humans with autonomy and personality: State-of-the-art. In: MagnenatThalmann, N.; Jain, L.; Ichalkaranje, N., editors, NEW ADVANCES IN VIRTUAL HUMANS, v. 140 of Studies in Computational Intelligence, p. 43-84. Springer Berlin Heidelberg, 2008. II

[36] MOHAMMAD, S.. From once upon a time to happily ever after: Tracking emotions in novels and fairy tales. In: PROCEEDINGS OF THE 5TH ACL-HLT WORKSHOP ON LANGUAGE TECHNOLOGY FOR CULTURAL HERITAGE, SOCIAL SCIENCES, AND HUMANITIES, LaTeCH'11, p. 105-114, Stroudsburg, PA, USA, 2011. Association for Computational Linguistics. II

[37] HURST, M.; JACKSON, T.; GLENCROSS, M.. Emotion recognition: Theory or practicality. In: AUTOMATION AND COMPUTING (ICAC), 2012 18TH INTERNATIONAL CONFERENCE ON, p. 1-6, Sept 2012. II

[38] GUNES, H.; PANTIC, M.. Automatic, dimensional and continuous emotion recognition. Int. J. Synth. Emot., 1(1):68-99, Jan. 2010. II

[39] ORELLANA-RODRIGUEZ, C.; DIAZ-AVILES, E.; NEJDL, W.. Mining emotions in short films: User comments or crowdsourcing? In: PROCEEDINGS OF THE 22ND INTERNATIONAL CONFERENCE ON 
WORLD WIDE WEB COMPANION, WWW' 13 Companion, p. 69-70, Republic and Canton of Geneva, Switzerland, 2013. International World Wide Web Conferences Steering Committee. II

[40] NAVARATHNA, R.; LUCEY, P.; CARR, P.; CARTER, E.; SRIDHARAN, S.; MATTHEWS, I.. Predicting movie ratings from audience behaviors. In: APPLICATIONS OF COMPUTER VISION (WACV), 2014 IEEE WINTER CONFERENCE ON, p. 1058-1065, March 2014. II

[41] YANG, X.; GUO, Y.; LIU, Y.. Bayesian-inference based recommendation in online social networks. In: INFOCOM, 2011 PROCEEDINGS IEEE, p. 551-555, April 2011. II, VI.1(a)

[42] TORTOSA, M.; STRIZHKO, T.; CAPIZZI, M.; RUZ, M.. Interpersonal effects of emotion in a multi-round trust game. Psicológica, 39:179-198, 2013. II, V.2, VI

[43] CAMERER, C.; SMITH, A.. Cognitive hierarchies and emotions in behavioral game theory. Oxford Handbook of Thinking and Reasoning, K. J. Holyoak \& R. G. Morrison (Eds.), 2012. II

[44] FAIRCHILD, R.. Emotional games. Social Science Research Network, 2012. II, IV.6, IV.7, IV.7(a), IV.7(a), IV.7(b)

[45] SALZMAN, D.; TRIFAN, E.. Emotions, Bayesian Inference, and Financial Decision Making. Arbeitspapiere des Instituts für Volkswirtschaftslehre, Technische Universität Darmstadt. Inst. für Volkswirtschaftslehre, 2005. II

[46] TSAI, J.; BOWRING, E.; MARSELLA, S.; TAMBE, M.. Empirical evaluation of computational emotional contagion models. In: INTELLIGENT VIRTUAL AGENTS, v. 6895 of Lecture Notes in Computer Science, p. 384-397. Springer Berlin Heidelberg, 2011. II, VI.1

[47] TSAI, J.; BOWRING, E.; MARSELLA, S.; TAMBE, M.. Emotional contagion with virtual characters, 2012. II, VI.1

[48] MOLINERO, X.; RIQUELME, F.; SERNA, M.. Power indices of influence games and new centrality measures for agent societies and social networks. In: Ramos, C.; Novais, P.; Nihan, C. E.; Corchado Rodríguez, J. M., editors, AMBIENT INTELLIGENCE SOFTWARE AND APPLICATIONS, v. 291 of Advances in Intelligent Systems and Computing, p. 23-30. Springer International Publishing, 2014. II, VI.1(a) 
[49] TSAI, J.; BOWRING, E.; MARSELLA, S.; WOOD, W.; TAMBE, M.. A study of emotional contagion with virtual characters. In: Nakano, Y.; Neff, M.; Paiva, A.; Walker, M. A., editors, IVA, v. 7502 of Lecture Notes in Computer Science, p. 81-88. Springer, 2012. ॥

[50] KAMAKURA, W. A.; SCHIMMEL, C. W.. Uncovering audience preferences for concert features from single-ticket sales with a factoranalytic random-coefficients model. International Journal of Research in Marketing, 30(2):129-142, 2013. II, VI.1(a)

[51] ROUSSEAU, J.; COLE, G.. The Social Contract. New York: E. P. Dutton \& Co., 1913. II

[52] HUME, D.; SELBY-BIGGE, L.. A Treatise of Human Nature. Número v. 1 em A Treatise of Human Nature. Clarendon Press, 1738. II

[53] SMITH, A.. The Theory of Moral Sentiments. A. Millar, 1759. II, IV.6, V.2(a)

[54] NAGLE, R.; SAFF, E.; SNIDER, A.. Fundamentals of differential equations and boundary value problems. Pearson Addison-Wesley, 2008. II

[55] SILVA, F. A. G.. Emotions in Plots with Non-Deterministic Planning for Interactive Storytelling. PhD thesis, Pontifícia Universidade Católica do Rio de Janeiro, Rio de Janeiro, 2015. III

[56] KISTLER, F.; SOLLFRANK, D.; BEE, N.; ANDRÉ, E.. Full body gestures enhancing a game book for interactive story telling. In: Si, M.; Thue, D.; André, E.; Lester, J. C.; Tanenbaum, J.; Zammitto, V., editors, INTERACTIVE STORYTELLING, v. 7069 of Lecture Notes in Computer Science, p. 207-218. Springer Berlin Heidelberg, 2011. III

[57] ELLSWORTH, P.; SCHERER, K.. Appraisal processes in emotion. In R. J. Davidson, K. R. Scherer, \& H. H. Goldsmith (Eds.), Handbook of affective sciences, p. 572-595, 2003. III.2

[58] MYERSON, R.. Game Theory. Harvard University Press, 1997. IV

[59] GIBBONS, R.. A Primer in Game Theory. A Primer in Game Theory, p. 288, 1992. IV 
[60] GIBBONS, R.. An Introduction to Applicable Game Theory. Journal of Economic Perspectives, 11(1):127-149, 1997. IV.1

[61] COOPER, R.. Coordination Games. Advance praise for coordination games. Cambridge University Press, 1999. IV.1(a), IV.1(a), IV.1(a), IV.1(a), IV.1(a), IV.1(a), IV.1(a)

[62] BINMORE, K. G.. Game Theory and the Social Contract: Playing fair. Número v. 1 em Binmore, Ken: Game theory and the social contract. MIT Press, 1994. IV.2

[63] PATTANAIK, P.; TADENUMA, K.; XU, Y.; YOSHIHARA, N.. Rational Choice and Social Welfare: Theory and Applications. Studies in Choice and Welfare. Springer Berlin Heidelberg, 2008. IV.3

[64] NEOGY, S.. Mathematical Programming and Game Theory for Decision Making. Statistical science and interdisciplinary research. World Scientific, 2008. IV.3

[65] NISAN, N.; ROUGHGARDEN, T.; TARDOS, E.; VAZIRANI, V.. Algorithmic Game Theory. Cambridge University Press, 2007. IV.4

[66] CHALKIADAKIS, G.; ELKIND, E.; WOOLDRIDGE, M.. Cooperative game theory: Basic concepts and computational challenges. IEEE Intelligent Systems, 27(3):86-90, 2012. IV.5(b), IV.5(e)

[67] ZABLITH, F.; ANTONIOU, G.; AQUIN, M.; FLOURIS, G. O. S.; KONDYLAKIS, H.; MOTTA, E.; SABOU, M.. Cooperative games and multiagent systems. The Knowledge Engineering Review, p. 1-31, 2013. IV.5(f)

[68] SALLY, D.. On sympathy and games. Journal of Economic Behavior \& Organization, 44(1):1-30, 2001. IV.6

[69] HARTNETT, T.. Consensus-Oriented Decision-Making: The CODM Model for Facilitating Groups to Widespread Agreement. New Society Publishers, 2013. V.2, VI.1(a)

[70] LEE, E.; AHN, J.; KIM, Y. J.. Personality traits and self-presentation at facebook. Personality and Individual Differences, 69(0):162 - 167, 2014. V.2(a)

[71] AMICHAI-HAMBURGER, Y.; VINITZKY, G.. Social network use and personality. Comput. Hum. Behav., 26(6):1289-1295, Nov. 2010. V.2(a) 
[72] WINTER, S.; NEUBAUM, G.; EIMLER, S. C.; GORDON, V.; THEIL, J.; HERRMANN, J.; MEINERT, J.; KRÄMER, N. C.. Another brick in the facebook wall: How personality traits relate to the content of status updates. Computers in Human Behavior, 34(0):194 - 202, 2014. V.2(a), VI.1(a)

[73] DRÉO, J.. Metaheuristics for Hard Optimization: Methods and Case Studies. Springer, 2006. V.3

[74] NAKUTIS, V.. Electronic audience monitoring : Methods and problems review article. 2(2):20-26, 2008. VI.1

[75] PAYNE, L. L.; SHAW, T.; CALDWELL, L. L.. Movies and mood: An exploration of the critical variables related to mood states. Proceedings of the 1997 Northeastern recreation research symposium., Gen. Tech.:60-63, 1992. VI.1

[76] MADSEN, J.; JENSEN, B.; LARSEN, J.. Predictive modeling of expressed emotions in music using pairwise comparisons. In: Aramaki, M.; Barthet, M.; Kronland-Martinet, R.; Ystad, S., editors, FROM SOUNDS TO MUSIC AND EMOTIONS, v. 7900 of Lecture Notes in Computer Science, p. 253-277. Springer Berlin Heidelberg, 2013. VI.1

[77] CANTADOR, I.; FERNÁNDEZ-TOBÍAS, I.; BELLOGÍN, A.. Relating Personality Types with User Preferences in Multiple Entertainment Domains. EMPIRE 1st Workshop on "Emotions and Personality in Personalized Services", 10. June 2013, Rome, 2013. VI.1(a) 